\title{
EFFECT OF EVAPOTRANSPIRATION RATE ON ALMOND YIELD IN CALIFORNIA
}

\author{
A Thesis \\ presented to \\ the Faculty of California Polytechnic State University, \\ San Luis Obispo \\ In Partial Fulfillment \\ of the Requirements for the Degree \\ Master of Science in Agriculture with specialization in Irrigation
}

by

Dafne Isaac Serrano

October 2018 
(C) 2018

Dafne Isaac Serrano

ALL RIGHTS RESERVED 
COMMITTEE MEMBERSHIP

TITLE: $\quad$ Effect of Evapotranspiration Rate on

Almond Yield in California

AUTHOR: Dafne Isaac Serrano

DATE SUBMITTED: $\quad$ October 2018

COMMITTEE CHAIR: $\quad$ Daniel J Howes, Ph.D., P.E.

Professor of Agriculture and Bio Resource

Engineering

COMMITTEE MEMBER: $\quad$ Franklin Gaudi, Ed.D.

Lecturer of Agriculture and Bio Resource

Engineering

COMMITTEE MEMBER: Christopher S. Appel, Ph.D.

Professor of Natural Resources

Management \& Environmental Sciences 


\section{ABSTRACT \\ Effect of Evapotranspiration Rate on Almond Yield in California \\ Dafne Isaac Serrano}

Since 2011, California has been under drought conditions. These conditions have not only affected water availability for farmers, but also production. California's second most valuable crop, almonds, has been affected by drought conditions. This study used three models (Model 1-3) to describe almond yield variability from year to year and almond yield variability within a year in Kern County, CA. The study evaluated 185 almond farms that were classified in three locations (east side, west side and north west side). The years of the study were 2011 (wet year) and 2013-2015 (drought condition years). Model 1 determined a functional regression between almond yield and annual evapotranspiration during the 4 years of the study. The $\mathrm{R}^{2}$ was $7.9 \%$, meaning low association between both variables and high unexplained variability (92.1\%). Model 2 evaluated year to year variation. A regression function between almond yield and annual evapotranspiration after adjusting for location, precipitation, chilling hours and year was made. The $\mathrm{R}^{2}$ of this model $62.6 \%$, and all the variables used had a $\mathrm{p}<0.05$. The $\mathrm{R}^{2}$ was higher than Model 1; however, there was high unexplained variability (47.4\%). Model 3 evaluated within-year variation. A regression function between almond yield and annual evapotranspiration after adjusting for tree age and location (east, west and northwest side) was made for each year (2011 and 2013 -2015). Coefficient of variation of evapotranspiration and soil available water storage were analyzed as additional variables in Model 3; however, they were not introduced in Model 3 due to the low increase in $\mathrm{R}^{2}$ in each year $(<2 \%)$. The $\mathrm{R}^{2}$ of Model 3 for each year were, $60.4 \%, 49.7 \%, 53.8 \%$ and 
53.2\% for the years 2011, 2013-2015, respectively. Model 3 also had high unexplained almond yield variability in each year (39.6\%-50.3\%). This high unexplained variability leads to introduce additional variables to the functional regression model for further studies. Identifying these additional variables and having a functional regression model with high $\mathrm{R}^{2}$ would lead to understand how low evapotranspiration could potentially lead to a positive response on yield in drought conditions; thus, making farmers improve water use efficiency and hence, lowering production cost. However, the high unexplained variability clearly indicates that evapotranspiration is only one of many factors that influence yield. If improved yield is an important outcome, future studies must examine large- scale almond-producing farms with multiple agricultural system variables.

Keywords: Evapotranspiration, tree age, drought condition year, wet year, coefficient of variation of evapotranspiration, chilling hours and almonds. 


\section{ACKNOWLEDGMENTS}

I would like to thank my mentors at Cal Poly for all the patience and advices they gave me through this process. I would especially like to thank my thesis chair, Dr. Howes, who provided invaluable knowledge and assistance, Dr. Appel for all the help and support, Dr. Gaudi who helped me understand irrigation with all the terms and the different units while making it a fun process; and Dr. Chance for helping me understand statistics and its complexity.

I would like to thank Jose and Tracy for all the shared wisdom and for giving me support and strength during this process. In addition, I want to thank Diana - because she helped me understand English grammar and editing -- Quiero agradecer a mis padres por estar siempre apoyandome durante todo el camino, y a una persona muy especial que me acompaño durante mis momentos mas difíciles y me dijo una de las frases mas bonitas.

Finally, I want to thank God for the opportunity he gave me.

Por si hoy es todo...Gracias totales 


\section{TABLE OF CONTENTS}

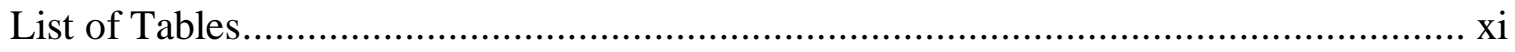

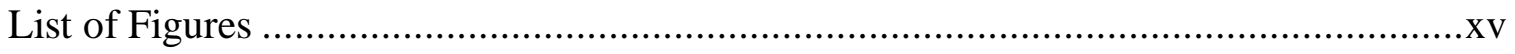

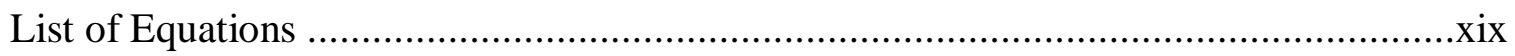

\section{CHAPTER}

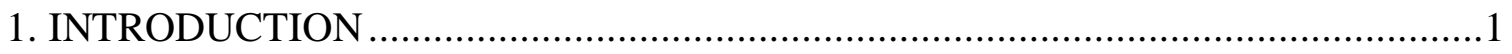

1.1 Statement of Research Question .................................................

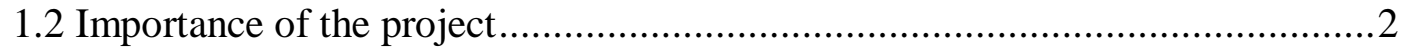

1.3 Issues and Assumptions.....................................................................4

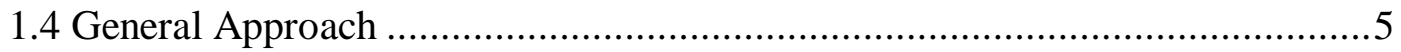

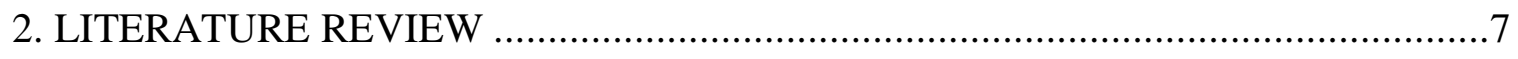

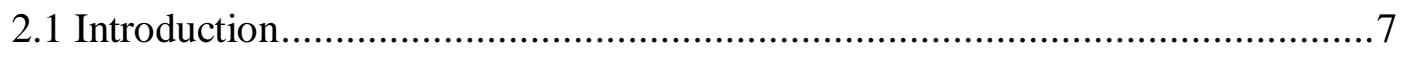

2.1.1 Almond production in California .......................................... 8

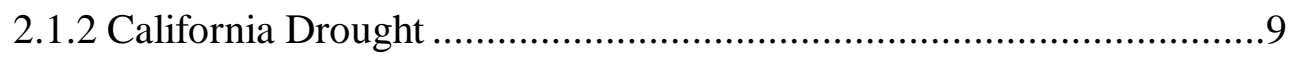

2.2 Evapotranspiration ..................................................................... 11

2.2.1 Introduction ..................................................................... 11

2.2.2 Satellite-Based Energy Balance for Mapping Evapotranspiration with Internalized Calibration (METRIC) ...................................... 13

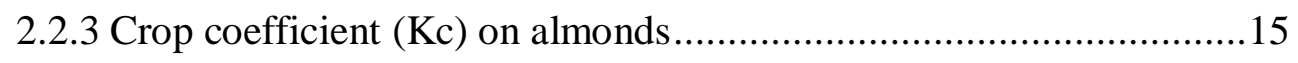

2.2.4 The Physiological Stages of Almond Growth ...............................15

2.2.5 Soil ...................................................................................... 18 


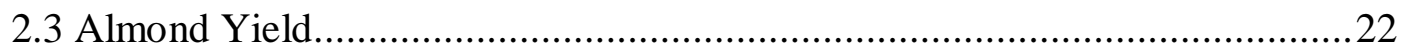

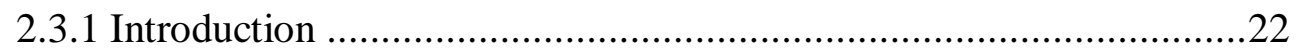

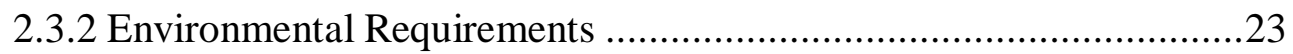

2.3.2.1 Chilling and Heat Requirements........................................23

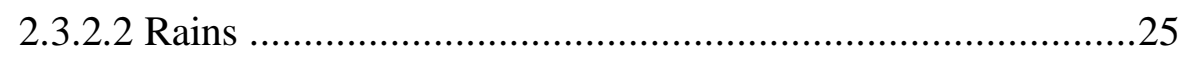

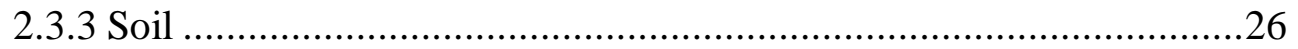

2.3.3.1 Physical Characteristics ....................................................26



2.4 Deficit-Irrigation Strategies for Drought Conditions..................................29

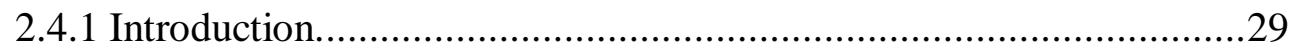

2.4.2 Deficit Irrigation techniques ............................................................

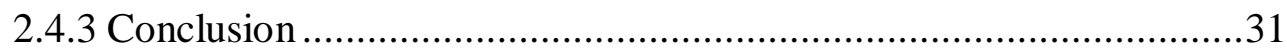

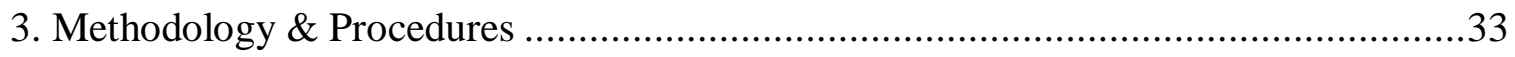

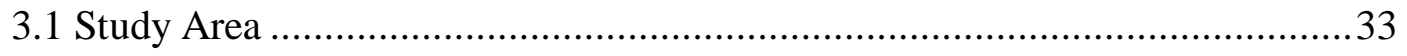

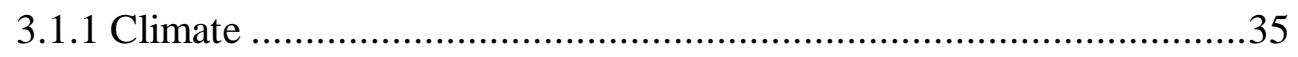

3.1.1.1 Precipitation ........................................................................

3.1.1.2 Chilling Hours …………………....................................... 40

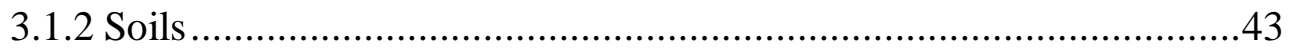

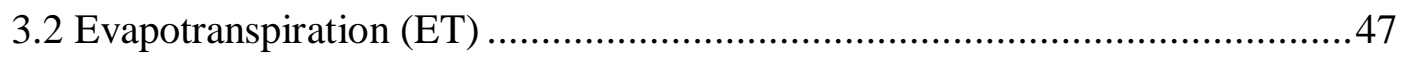

3.3 Coefficient of Variation of Evapotranspiration (CV) …...............................48

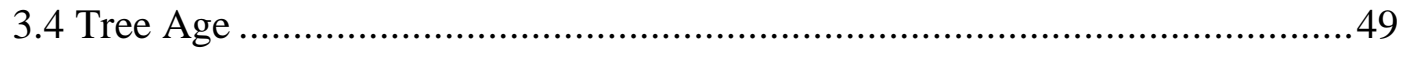

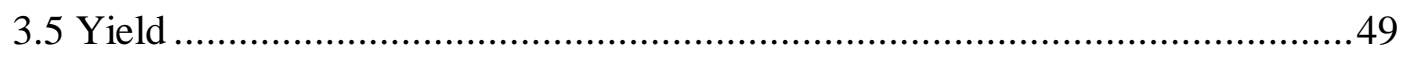

3.6. Data Collection \& Analysis ......................................................................51 


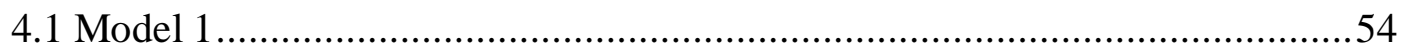

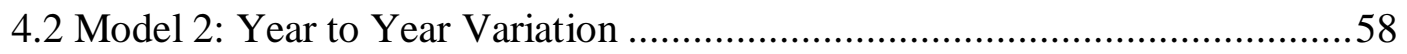

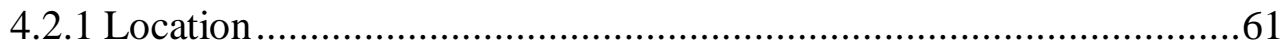

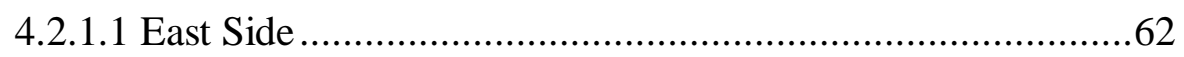

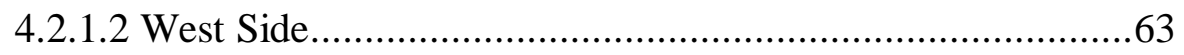

4.2.1.3 North West Side ................................................................64

4.2.2 Chilling hours and Precipitation .......................................................65

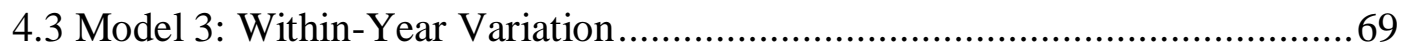



4.3.1.1 Tree age

4.3.1.2 Soil Available Water Storage (AWS) ……………………....74

4.3.1.3 Coefficient of Variation (CV) of Evapotranspiration ............77

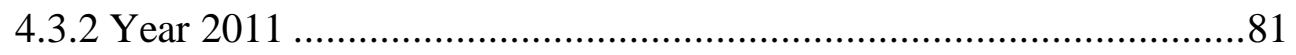

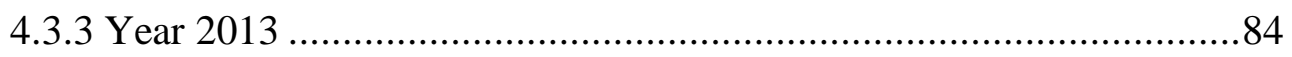

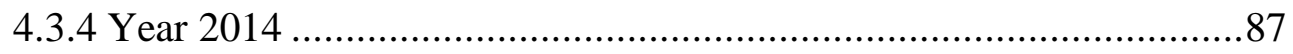

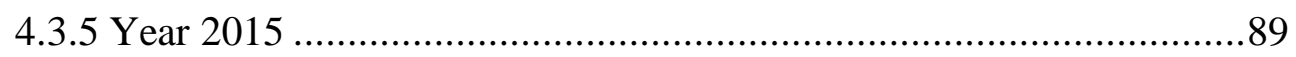

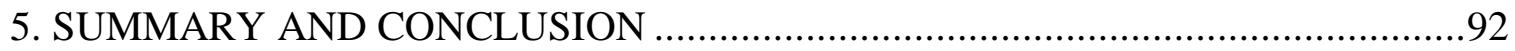

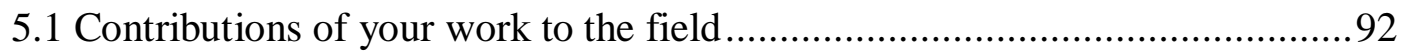

5.2 Limitation/Strengths and weakness of your work..........................................94

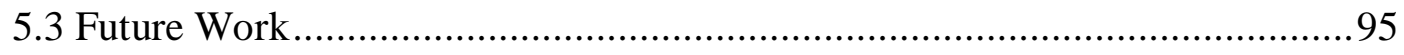

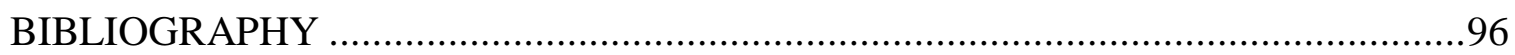




\section{APPENDICES}

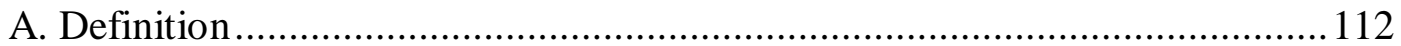

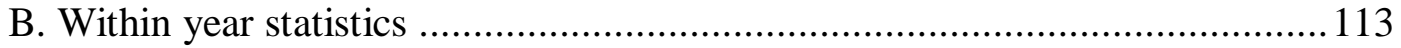

C. Residuals plots for year to year variation ............................................ 117 


\section{LIST OF TABLES}

Table

Page

1. Estimates of the monthly crop coefficients $(\mathrm{Kc})$ determined for almond orchards.

Adapted from Water Scarcity and Sustainable Agriculture in Semiarid

environment. 2018

2. Typical Soil Water Characteristics for Different Soil Types (Adapted from FAO-

56, Allen et al. 1998).

3. Almond production top 10 countries for year 2015. Production includes almond shells. (Adapted from FAO data).

4. Salinity threshold and their reduction in yield for almond. Adapted from Mass and Hoffman (1977) and Fulton et al. (1996).

5. CIMIS station names and identification numbers, and number of fields in each location of the study in the Northwestern portion of Kern County, CA.

6. Fields locations and soil orders in percentage of the total area of each of the three locations in Kern County North Western part, CA.

7. Model 1 summary of fit of Almond yield as a function of annual evapotranspiration in California's Central Valley (Kern County) for the months April-October in 2011 and 2013-2015 ( $\mathrm{n}=185)$.

8. Model 1 parameter estimates of Almond yield (lbs/acre) as a function of annual evapotranspiration (inches) in California's Central Valley (Kern County) for the months April-October in 2011 and 2013-2015 ( $\mathrm{n}=185)$. Alpha level=0.05. 
9. Model 2 summary of fit of Almond yield as a function of annual evapotranspiration after adjusting for year in California's Central Valley (Kern County) for the months April-October in 2011 and 2013-2015 (n=185)... .58

10. Average almond yield (lbs/acre) for the years 2011, 2013-2015 in all the state of California. (Adapted from USDA/NASS, Pacific Regional Office 2018).

11. Average almond yield (lbs/acre) for the years 2011, 2013-2015 in California's Central Valley (Kern County) $(\mathrm{n}=185)$. Alpha level $=0.05$.

12. Model 2 parameter estimates of fit of almond yield (lbs/acre) as a function of annual evapotranspiration (inches) after adjusting for year in California's Central Valley (Kern County) for the months April-October in 2011 and 2013-2015 $(\mathrm{n}=185)$. Alpha level=0.05.

13. Average almond yield (lbs/acre) for the years 2011, 2013-2015 in east side location of Kern County, CA (n=97). Alpha level $=0.05$.

14. Average almond yield (lbs/acre) for the years 2011, 2013-2015 in west side location of Kern County, CA ( $n=78)$. Alpha level $=0.05$.

15. Average almond yield (lbs/acre) for the years 2011, 2013-2015 in north west side location of Kern County, CA $(n=10)$ Alpha level $=0.05$.

16. Summary of fit estimates of Almond yield as a function of annual evapotranspiration after adjusting for year, location, precipitation and chilling hours in California's Central Valley (Kern County) for the months April-October in 2011 and $2013-2015(n=185)$. .65

17. Parameter estimates for Model 2 of almond yield (lbs/acre) as a function of annual evapotranspiration (inches) after adjusting for year, location, precipitation 
(inches) and chilling hours (CU) in California's Central Valley (Kern County) for the months April-October in 2011 and 2013-2015 ( $\mathrm{n}=185)$. Alpha level $=0.05$.

18. Model 3 summary of fit for year 2011 of almond yield as a function of annual evapotranspiration in California's Central Valley after adjusting for tree year and location (Kern County) for the months April-October in $2011(\mathrm{n}=185)$

19. Model 3 parameter estimates for year 2011 of almond yield (lbs/acre) as a function of annual evapotranspiration (inches) in California's Central Valley after adjusting for tree year and location (Kern County) for the months AprilOctober in $2011(\mathrm{n}=185)$. Alpha level $=0.05$.

20. Model 3 summary of fit for year 2013 of almond yield as a function of annual evapotranspiration in California's Central Valley after adjusting for tree year and location (Kern County) for the months April-October in 2013 ( $\mathrm{n}=183$ ).

21. Model 3 parameter estimates for year 2013 of almond yield (lbs/acre) as a function of annual evapotranspiration (inches) in California's Central Valley after adjusting for tree year and location (Kern County) for the months AprilOctober in $2013(\mathrm{n}=183)$ Alpha level $=0.05$. .86

22. Model 3 summary of fit for year 2014 of almond yield as a function of annual evapotranspiration in California's Central Valley after adjusting for tree year and location (Kern County) for the months April-October in $2014(\mathrm{n}=183)$.

23. Model 3 parameter estimates for year 2014 of almond yield (lbs/acre) as a function of annual evapotranspiration (inches) in California's Central Valley after adjusting for tree year and location (Kern County) for the months AprilOctober in $2014(\mathrm{n}=183)$. Alpha level $=0.05$. .88 
24. Model 3 summary of fit for year 2015 of almond yield as a function of annual evapotranspiration in California's Central Valley after adjusting for tree year and location (Kern County) for the months April-October in $2015(n=183)$

25. Model 3 summary of fit for year 2015 of almond yield (lbs/acre) as a function of annual evapotranspiration (inches) in California's Central Valley after adjusting for tree year and location (Kern County) for the months April-October in 2015

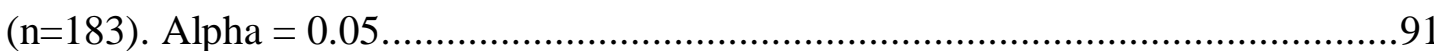




\section{LIST OF FIGURES}

Figure

Page

1. Change in California almond acreage and yield per acre. Period 1919-2013 (Excerpted from Summer et al 2015).

2. California drought monitor map in 2015 (Excerpted from Richman and Leslie 2015) 10

3. The three stages of almond fruit development and the typical length and weight of the fruit at each stage. Adapted from the UC Almond Production Manual, 1996 and Annual growth cycle of almond Adapted from almond s botany production and uses 2017.

4. Dormancy breaking of reproductive buds and flowering in almond referenced to the phenological stages as described by Felipe (1977). Adapted from Lang et al. (1987), Luedeling et al. (2009) and Prudencio and Dicenta (2018).....

5. Almond producing counties in California (production expressed in million pounds). Excerpted from Almond Board of California 2016.

6. Field sites (east, west and northwest side) analyzed in this study and CIMIS station locations used in this study in the Kern County-northwestern part, CA. Kern County division based on the survey made by the United States Department of Agriculture with the Natural Resource's Conservation Service (USDA-NRCS). ...35

7. Field sites (east, west and northwest side) analyzed in this study and CIMIS stations location used in this study. Kern County North Western part, CA.

Division made by the NRSC-USDA survey. .36 
8. Precipitation data in inches for the east side location, data gathered from CIMIS Station Shafter \#5 and Famoso \#138, for the months October-April in 2011 and 2013-2015.

9. Precipitation data in inches for the west side location, data gathered from CIMIS Station Belridge \#146, for the months October-April in 2011 and 2013-2015.

10. Precipitation data in inches for the northwest side location, data gathered from CIMIS Station Blackwells Corner \#54, for the months October-April in 2011 and 2013-2015.

11. Cumulative chilling hours data in $\mathrm{CU}$ for the east side location, data gathered from CIMIS Station Shafter \#5 and Famoso \#138, for the months NovemberFebruary in 2011 and 2013-2015.

12 Cumulative chilling hours data in $\mathrm{CU}$ for the west side location, data gathered from CIMIS Station Belridge \#146, for the months November-February in 2011 and 2013-2015.

13. Cumulative chilling hours data in CU for the northwest side location, data gathered from CIMIS Station Blackwells Corner \#54, for the months November-

February in 2011 and 2013-2015

14. Soil order map for Kern County, CA. Kern County division classified by the USDA-NRCS soil survey. Data excerpted from USDA-NRCS 2018 using ArcGis 10.5.1 (ESRI,2017).

15. Soil order map for Northwestern part of Kern County, CA. Data excepted from USDA-NRCS 2018 using ArcGis 10.5.1 (ESRI,2017). 
16. Field sites analyzed (east, west and northwest side) and CIMIS stations used location. In addition, Available water storage for a depth of $100 \mathrm{~cm}$ data in $\mathrm{cm} / \mathrm{m}$, in Northwestern part of Kern County, CA. Data excepted from USDA-NRCS 2018 using ArcGis 10.5.1 (ESRI,2017). .46

17. Annual ET measured by ITRC-METRIC (inches) in 2011 for Field sites analyzed (east, west and northwest side) and CIMIS stations used. Data extracted from ITRC-METRIC using Arcgis 10.5.1 (ESRI,2017). .51

18. Almond yield as a function of annual evapotranspiration in California's Central Valley (Kern County) for the months April-October in 2011 and 2013-2015 $(\mathrm{n}=185)$

19. Almond yield (lbs/acre) as a function of year and geographic area in California's Central Valley (Kern County) for the years 2011, 2013-2015( $\mathrm{n}=185)$.

20. Almond yield as a function of annual evapotranspiration and year in California's Central Valley (Kern County) for the months April-October in 2011 and 2013$2015(n=185)$.

21. Almond yield as a function of tree age and year in three locations of Kern County, CA for the years 2011 and 2013-2015 ( $\mathrm{n}=185)$.

22. Evapotranspiration as a function of tree age and year in three locations of Kern County, CA for the years 2011 and 2013-2015 $(n=185)$. .73

23. Almond yield as a function of soil available water storage and year in three locations of Kern County, CA for the years 2011 and 2013-2015 ( $\mathrm{n}=185)$. .755

24. Evapotranspiration as a function of soil available water storage and year in three locations of Kern County, CA for the years 2011 and 2013-2015 ( $\mathrm{n}=185)$. .76 
25. Almond yield as a function of coefficient of variation of evapotranspiration and year in three locations of Kern County, CA for the years 2011 and 2013-2015 $(\mathrm{n}=185)$

26. Evapotranspiration as a function of coefficient of variation of evapotranspiration and year in three locations of Kern County, CA for the years 2011 and 2013$2015(n=185)$. 


\section{LIST OF EQUATIONS}

Equation

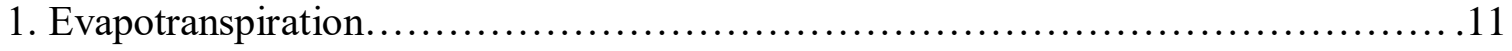

2. Crop coefficient by the dual crop method..........................................12

3. Energy balance equation for METRIC (Allen et al. 2007)......................... 14

4. Coefficient of Variation....................................................... 48

5. Coefficient of Variation, weighted average.........................................49

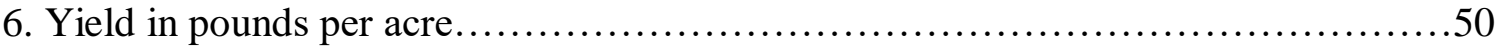




\section{CHAPTER}

\section{INTRODUCTION}

\subsection{Statement of Research Question}

The amount of water a crop requires during its growing season can be determined by calculating evapotranspiration rate. In any agricultural region, evapotranspiration (ET) rate is affected by climate, crop characteristics, crop management and agricultural practices.

Within California's agricultural regions, there is a wide spectrum of microclimates, allowing for the production of a diversity of crops (Allen et al. 1998). One of these micro-climates is the Mediterranean climate, prevalent in the Central Valley, making it an ideal region for almond production. Almond production in California, represents $19 \%$ of total farm on cash receipts, making it one of the most important crops for the state economically.

During the previous two decades, technical advances in agricultural practices-including pruning, fertilization and irrigation scheduling--helped farmers improve water management relative to non-drought years, and enabled them to achieve higher yields (Steduto et al. 2012). Since 2011; however, California has experienced severe drought conditions, greatly affecting water availability for farmers. Thus, almond farmers have had to be highly efficient with water use.

The overall research goal was to determine the effect of climate and agricultural practices on almond yield in California. 


\subsection{Importance of the project}

Crop production is limited by the amount of water a crop receives. Water can be applied by irrigation or occur by rainfall. During the past decade, water demand has increased worldwide due to climate change (Steduto et al. 2012). This increase in water demand has made water supply considerably more expensive. Therefore, farmers have adopted new irrigation scheduling techniques to be efficiently use water resources. This irrigation scheduling is based on calculating crop evapotranspiration (Doll 2014).

Moreover, Doorenbos and Kassam (1979) developed a model based on their discovery of a positive linear relationship between evapotranspiration (ET) and yield. This equation identifies the optimal evapotranspiration rate that would maximize yield with the minimum amount of water applied, resulting in higher water use efficiency and higher income compare to conventional production (Burt and Mutziger 2001).

During the past decade's drought, California's almond industry was frequently blamed, in the mass media, for excessive--and unsustainable —water use (Robin 2015). What such reporting failed to calculate; however, was that the increase in crop yield had in fact overtaken the increase in applied water per unit of land (Goldhamer and Fereres 2017a). In 2014, California's average almond yield was 2150 lbs/acre compared with 980 lbs/acre and 680 lbs/acre in 1980 and 1960, respectively (USDA 2011; Almond Board of California 2015). These results demonstrate that a functional relationship between yield and evapotranspiration can help determine the amount of water used to produce a pound of almonds.

Cal Poly’s Irrigation Training and Research Center (ITRC) (2017) developed a regression model to show a relationship between ET and yield of almonds in California's 
Central Valley for the period 2011-2014. The model; however, did not show any relationship between these two factors. This study also measured plant density and tree age as factors that could potentially affect almond yield; however, these factors did not help explain variability found in yield.

However, Goldhamer and Fereres (2017) found a high correlation $\left(\mathrm{R}^{2}=97.9 \%\right)$ between ET and almond yield in California. They reduced the water applied in order to reduce ET and they found that the crop load of the tree did not change by the amount of water applied. The individual kernel dry weight; however, did in fact change with different irrigation regimes.

Goldhamer and Salinas (2006), did not find a significant difference in almond yield, when reducing the amount of applied water. In addition, the individual kernel dry weight also did not change when the applied water was reduced. Notably, every treatment had a significant difference in both yield and kernel dry weight compared to the control treatment, which had no reduction in water applied.

In the long term, if a low evapotranspiration rate leads to a positive response on yield in drought conditions, then farmers could improve water use efficiency and hence, lower the production cost. A potential long-term outcome of this thesis study was to reduce the amount of water needed to produce a pound of almonds. Implementing this practice will help not only almond growers, but also environmental conservation, by reducing the water use in agriculture. 


\subsection{Issues and Assumptions}

Evapotranspiration rate and yield are affected by different variables, including environmental conditions and agricultural practices. This study was limited to the assessment of the influence of the evapotranspiration (ET) rate, coefficient of variation of ET, tree age, and soil available water storage on almond yield. It was assumed that almond growers provided an accurate planting date to calculate tree age. Also, beyond the scope of this study was the measurement of the amount of water evaporation during the dormant season-November to March. Given that almond trees end their dormant season at the end of March; this study measured evapotranspiration from April to October.

The evaluation of how different agricultural practices, such as fertilizer input, pruning techniques and cover crops affect almond yield or evapotranspiration were also not the focus of this study; likewise, measurement of salt accumulation in each field and the salinity of the irrigation water were not studied

As reference, it was assumed that the data gathered from the California Irrigation Management Information System (CIMIS) weather station would represent the microclimate in each of the fields evaluated. Also, it was assumed that the ET data and soil extracted from Arcgis 10.5.1 (ESRI, 2017) have a high accuracy. It was beyond the study's resources to measure on farm ET by a direct method.

Kernel yield (meat yield or nut yield) data were provided by farmers; it was assumed that each farmer provided accurate kernel yield data after processing total yield. It was beyond the study's resources to conduct a comparison of individual kernel dry weight to yield or evapotranspiration. 


\subsection{General Approach}

This study constituted both applied and analytical research because it determined the type of relationship between almond yield and evapotranspiration after adjusting for tree age, coefficient of variation of ET rate and soil available water storage. This study was carried out in California's Central Valley, specifically in Kern County, with farmers in that area.

The type of data utilized in the study was empirical data. Evapotranspiration rate was gathered with satellite imagery using ITRC-METRIC software, with data collected for the years 2011, 2013-2015. As referenced, kernel yields were provided by farmers. Soil data was gathered from Natural Resources Conservation Service Soil Survey Geographic database (NRCS-SSURGO). Cumulative chilling hours and precipitation parameters were collected by CIMIS stations close to each field. Data were synthetized to find the relationship between ET and almond yield after adjusting for chilling hours, precipitation, coefficient of variation of ET, soil available water storage and tree age.

Three functional regression models were used to synthetize data. These models were developed to describe the variability in almond yield. Model 1 described the relationship between evapotranspiration and almond yield, it did not use any additional variables to adjust evapotranspiration. Model 2 described year-to-year variation in which the parameters location, precipitation and chilling hours were used to adjust the effect of ET on almond yield. Model 3 described within-the-year variation in which the variables tree year, soil available water storage, and coefficient of evapotranspiration were used to adjust the effect of evapotranspiration on almonds yield. 
Finally, the objective of this study was to evaluate almond yield in California, and the effect of the California drought and ET as the main two factors that have had a significant influence on almond production during the years 2011, 2013-2015. 


\section{LITERATURE REVIEW}

\subsection{Introduction}

Almonds are the second most valuable crop in California, with an on farm value of $\$ 4.35$ billion (Sumner et al. 2015). A significant cost associated with California almond production is irrigation. Indeed, irrigation represents $5 \%$ of the total production cost for almonds.

The amount of water required by almonds and other crops can be estimated by evapotranspiration (ET) (Almond Board of California 2016). Evapotranspiration is the process by which evaporation and transpiration remove water from the land surface and the plant, respectively (Allen et al. 1998). The optimal amount of water required by a crop is, however, more than the potential ET rate of the crop (Barrett and Skogerboe 1980). Thus, the yield is a function of the amount of water applied and water use by the crop.

Imagery software is used to measure actual ET in large scale farms. Software such as Surface Energy Balance Algorithm for Land (SEBAL) or Mapping Evapotranspiration at High Resolution with Internalized Calibration (METRIC) are commonly employed for this function (Allen and Trezza 2007). Actual ET is affected by numerous factors such as the physiological stage of the almonds, tree age and soil type. Therefore, it is important to understand the factors that influence water use in almond production.

Actual ET has a linear effect on almond yield (Doorenbos and Kassam 1979; Steduto et al. 2012). However, not only actual ET effects almond yield: some other environmental factors, including chilling and heat requirements, precipitation and soil type influence this as well (Rafael Socias i Company and Gradziel 2017). The 
combination of ET and environmental factors will not only impact total production but also will have an impact on nut quality as well (Doll 2017a).

Since 2011, almond production in California was affected by drought conditions, these conditions not only affect the water availability for almond growers but also affected physiological process in almond trees. One of these processes is ET, which is highly dependent on atmospheric condition and soil conditions. Deficit irrigation (DI) techniques might help mitigate drought conditions without compromising yield; however, further research is needed to observe the long-term effect of DI on almond trees.

\subsubsection{Almond production in California}

In 2014, almonds represented about $25 \%$ of California farm exports and the almond industry generated approximately 104,000 jobs in the state. In 2013 , the number of almond bearing acres in California reached 840,000 acres. Moreover, almond yields have steadily increased over the last century (Sumner et al. 2015). (Figure1)

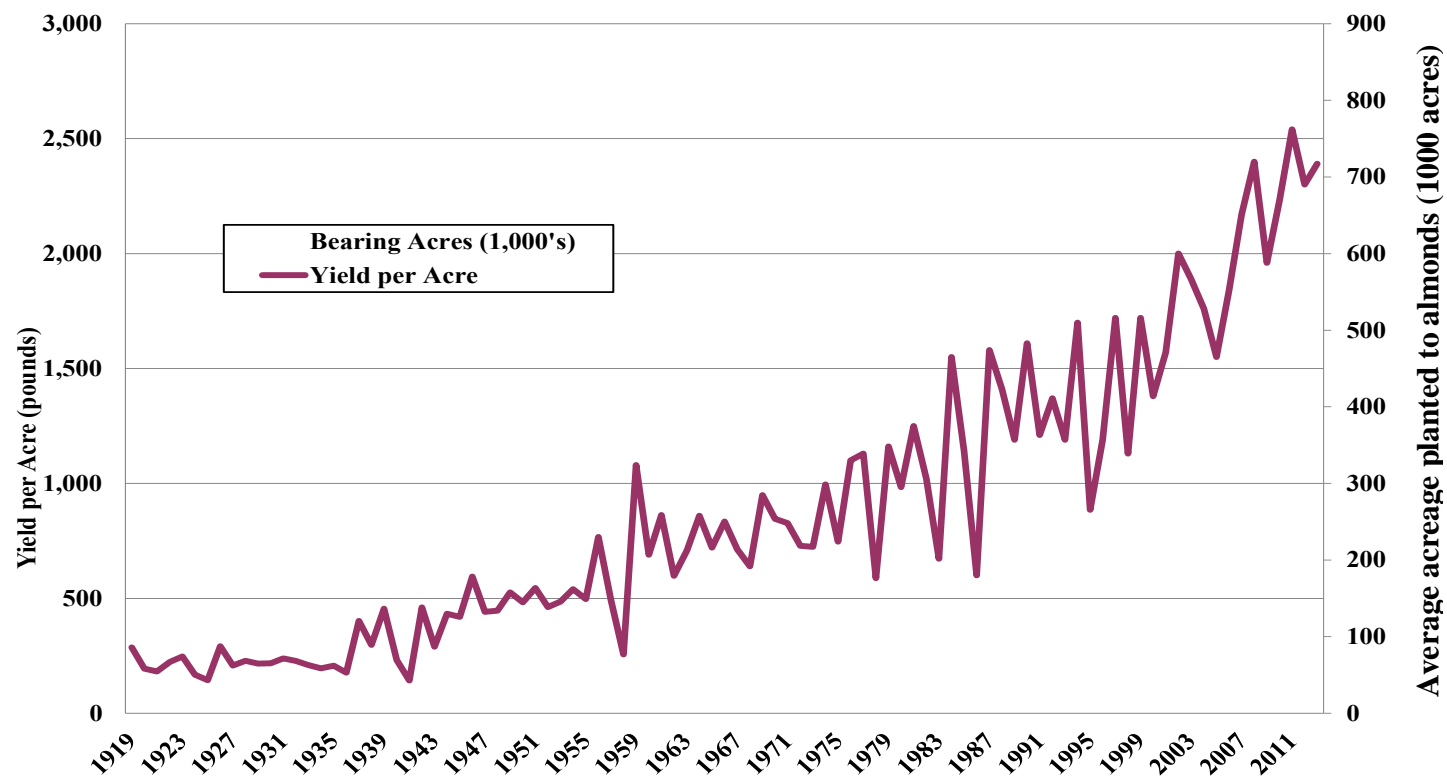

Figure 1. Change in California almond acreage and yield per acre. Period 1919-2013 (Excerpted from Summer et al 2015). 
Between 2008-2018, yields and almond planted acres have increased exponentially but data ended at 2013. Over the last five years, however, yields have been on a slight decline, which may be associated with California's drought.

\subsubsection{California Drought}

Along with a reduction in precipitation, the California drought has caused an increase in average temperature since 2011 (Richman and Leslie 2015). The part of the state most effected is the Central Valley (Figure 2). This is also where the greatest concentration of almond production takes place. In 2014, more than 420,000 acres were idle. The direct impact to agriculture was a loss of $\$ 1.5$ billion. Part of this loss in revenue was associated with drilling wells for groundwater supply, which increased production costs. The total value for groundwater pumping was $\$ 447$ million in 2015 (Cody and Brougher 2015). 


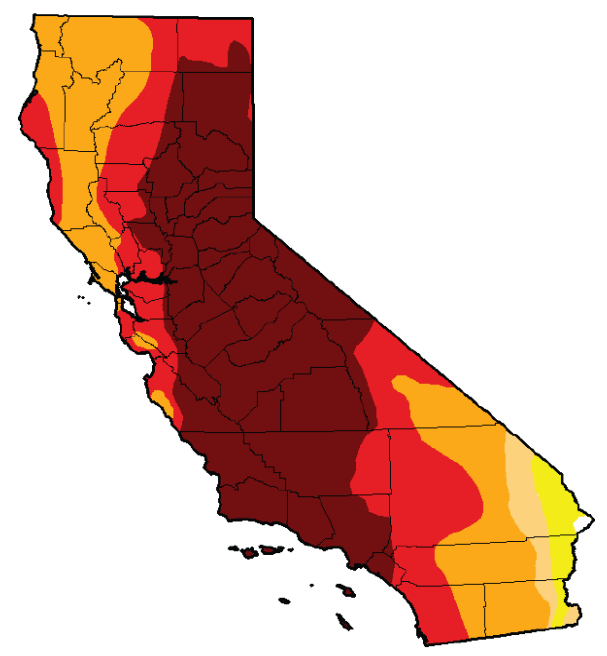

July 28, 2015

Intensity:

DO - Abnormally Dry

D1 - Moderate Drought

D2 - Severe Drought

D3 - Extreme Drought

D4 - Exceptional Drought

Figure 2. California drought monitor map in 2015 (Excerpted from Richman and Leslie 2015)

A wide spectrum of strategies that might help mitigate drought conditions have been studied (Egea et al. 2010; Goldhamer and Fereres 2017b; Goldhamer et al. 2006; García-Tejero et al. 2015; García-Tejero et al. 2018; Espadafor et al. 2018 ). Some of these studies have examined the effect of the reduction of the amount of water applied to almond trees. Others measured the direct impact of water reduction on almond yield, and water use efficiency. Adapting agricultural production to drought conditions would require actual implementation these studies' findings, followed by further research into yield improvement with better water use efficiency. 


\subsection{Evapotranspiration}

\subsubsection{Introduction}

The amount of water a crop requires can be determined by calculating evapotranspiration rate (ET). Evapotranspiration uses weather data and algorithms that describe climatic factors along with crop physiological stage. Most agricultural fields resemble each other to some extent so that the variables used to determine ET, plant density, height, and water availability are generally uniform. This makes the calculation of ET straight forward (Allen and Pereira 2011).

Calculating the ET for a crop requires several components. The first is potential evapotranspiration or evapotranspiration of the reference crop (ETo). The second component is crop coefficient $(\mathrm{Kc})$. Equation [1] estimates ET for a specific crop.

$$
E T c=E T o \times K c
$$

To calculate ETo climate factors are used. Most of the data required are obtained through weather station measurements in calculations using the FAO Penman-Monteith Formula (Allen et al. 2006). As such, the ETo may be different depending on geographic region and current weather conditions.

The crop coefficient (Kc) takes into consideration the physical and physiological differences between crops. For calculating the Kc, there are two methods: The first method is a single relationship between the crop evaluated and the ETo. With this method, it is assumed that the crop is not under any environmental stress. The second 
method splits $\mathrm{Kc}$ into evaporation $(\mathrm{Ke})$, transpiration $(\mathrm{Kcb})$ and crop stress $(\mathrm{Ks})$. The formula of $\mathrm{Kc}$ in the second method is defined as (Allen et al. 1998) Equation [2].

$$
K c=(K s \times K c b)+K e
$$

where:

Ks: is crop stress; this value cannot be higher than 1

Kcb: Basal crop coefficient; this value does not consider stress and soil evaporation Ke: Soil evaporation; this value depends on soil moisture.

For calculating ET, the second method is more accurate than the first, because the evaporation rate changes between irrigations. These changes are due to less soil tension after an irrigation event; therefore, increasing the potential evapotranspiration rate. Before the next irrigation, the evapotranspiration potential decreases because the soil tension is higher. This method is affected by the frequency of irrigation events as well as the type of irrigation system being utilized (Allen et al. 1998).

Calculating the amount of water a crop requires during a growing season is essential to maximizing its yield. Indeed, in some stages of growth, water is the main factor determining yield. For example, crop yield is highly dependent on water use during the reproductive stage of growth (Kato and Yamagishi 2008). Studies have shown that there is a linear relationship between evapotranspiration rate and yield. It should be noted that studies are based on optimal agricultural practices and optimal orchard management to have the highest possible yield (Steduto et al. 2012). 


\subsubsection{Satellite-Based Energy Balance for Mapping Evapotranspiration with Internalized}

\section{Calibration (METRIC)}

Estimating ET and using it as a parameter for irrigation scheduling is common in the Central Valley. Growers usually plan their irrigation schedule after making calculations based on the equation for estimated ET proposed by Allen et al. 2006 (Eq. 2). But instead of an estimated ET, the actual ET can be measured with remote sensing data. Remote sensing data is an indirect type of ET measurement, because it is found by the average of a relationship between parameters (Bastiaanssen and Bos 1999; Rana and Katerji 2000).

One of the firsts methods of ET measurement was Surface Energy Balance Algorithm for Land (SEBAL). This algorithm follows a set of equations to convert spectral radiances into ET. SEBAL uses spatially distributed, near-infrared and thermal infrared data, usually coming from satellite imagery. The most common satellite imagery software used by SEBAL is Landsat (Bastiaanssen 2000). These spatial distributed data are gathered pixel by pixel, producing an accurate measurement of ET of the field.

Mapping Evapotranspiration at High Resolution with Internalized Calibration (METRIC) is another method in which remote sensing with surface energy balance is used to measure actual ET. Mapping Evapotranspiration at High Resolution with Internalized Calibration is based on SEBAL, and uses the same technique for estimating the surface temperature gradient as an index function of radiometric surface temperature (Allen et al. 2007). 
In addition, METRIC auto calibrates and uses alfalfa as its reference crop; and follows the process in which ET is estimated using an energy balance equation. Equation [3].

$$
E T=\text { net radiation }- \text { heat to the soil }- \text { heat to the air }
$$

Allen et al. (2007) compared METRIC with the lysimeters technique to measure ET. Researchers have made studies in which they compared both methods. The difference between ET results rendered by the two techniques was relatively small--less than 4\%--making METRIC an accurate method for ET measurement. On the other hand, while using METRIC software, Chavez and Howell (2007) found errors as high as 15\% for high biomass vegetation and as high as $9 \%$ for lower biomass-higher temperature surface. However, one of the drawbacks of using METRIC in California is that the reference crop used by the CIMIS stations is grass. One of the major disadvantages about METRIC is that the spatial image is taken every 16 days. Thus, the ET measured will be biased depending on when the irrigation event had happened (Howes and Gaudi 2012).

For the METRIC system to be more accurate to California conditions, the Irrigation Training and Research Center (ITRC) made different modifications to METRIC, including changing alfalfa to grass as the reference crop and using LandSat 8 software for higher resolution imagery. In LandSat 8, each pixel can represent an area of 30 meters by 30 meters (Howes and Gaudi 2012). 


\subsubsection{Crop coefficient $(\mathrm{Kc})$ on almonds}

Climate change and California drought have prompted researchers look for a more precise technique to estimate almond water requirements relative to the direct on farm ET method. An important component of the formula for calculating the almond water requirement is the crop coefficient $(\mathrm{Kc})$. For almond crop irrigation scheduling, $\mathrm{Kc}$ reported in the FAO Irrigation and Drainage Paper. No. 56 is commonly used.

Previously the FAO reported that the Kc for almond trees during their flowering stage is 0.9, being the highest Kc for all the growing season (Allen et al. 1998). However, recent studies (Steduto et al. 2012) have shown, that Kc values cannot be applied to current climatic conditions and certain new agricultural practices, including higher tree densities, better nutrient management and shorter irrigation frequency compared to traditional practices. And in fact, Steduto et al (2012) reported a Kc as high as 1.08 and Goldhamer and Fereres (2017) reported a Kc as high as 1.17.

Other factors cause an increase in Kc values as well: Kc values reported in FAO Irrigation and Drainage Paper No. 56 were calculated using surface irrigation. This type of irrigation system utilizes a greater time interval between irrigation events, thereby reducing the evaporation rate. Drip/micro irrigation, which by contrast uses a shorter interval between irrigation events, leads to higher evaporation rate and therefore, a higher Kc value.

\subsubsection{The Physiological Stages of Almond Growth}

Crop coefficient (Kc) depends on a given crop's physiological stage (Allen et al. 1998). Almond is a deciduous tree, meaning it has a dormant stage, in which none or little transpiration occurs. In the northern hemisphere, dormancy occurs from late 
October to mid-February (Doll 2009; Steduto et al. 2012). After dormancy, the flowering and leaf budding stages commence, causing transpiration to begin. Transpiration will occur until fruit maturation. In the northern hemisphere, the transpiration period usually occurs from Mid-March to September-October (Steduto et al. 2012).

Flowering and leaf budding stages determine the maximum potential of fruit production. Because these two physiological processes are happening at the same time, there is a competition for carbohydrates (Steduto et al. 2012). Esparza et al. (2001) found that previous year irrigation and fertilization also had an impact on the maximum potential of almond fruit production.

Kester and Labavitch (1996) classify fruit growth into three stages. Figure 3 shows each growth stage during a production cycle in the northern hemisphere. Each physiologic stage would have a different crop coefficient $(\mathrm{Kc})$. Many studies have determined monthly Kc value (Table 2). 


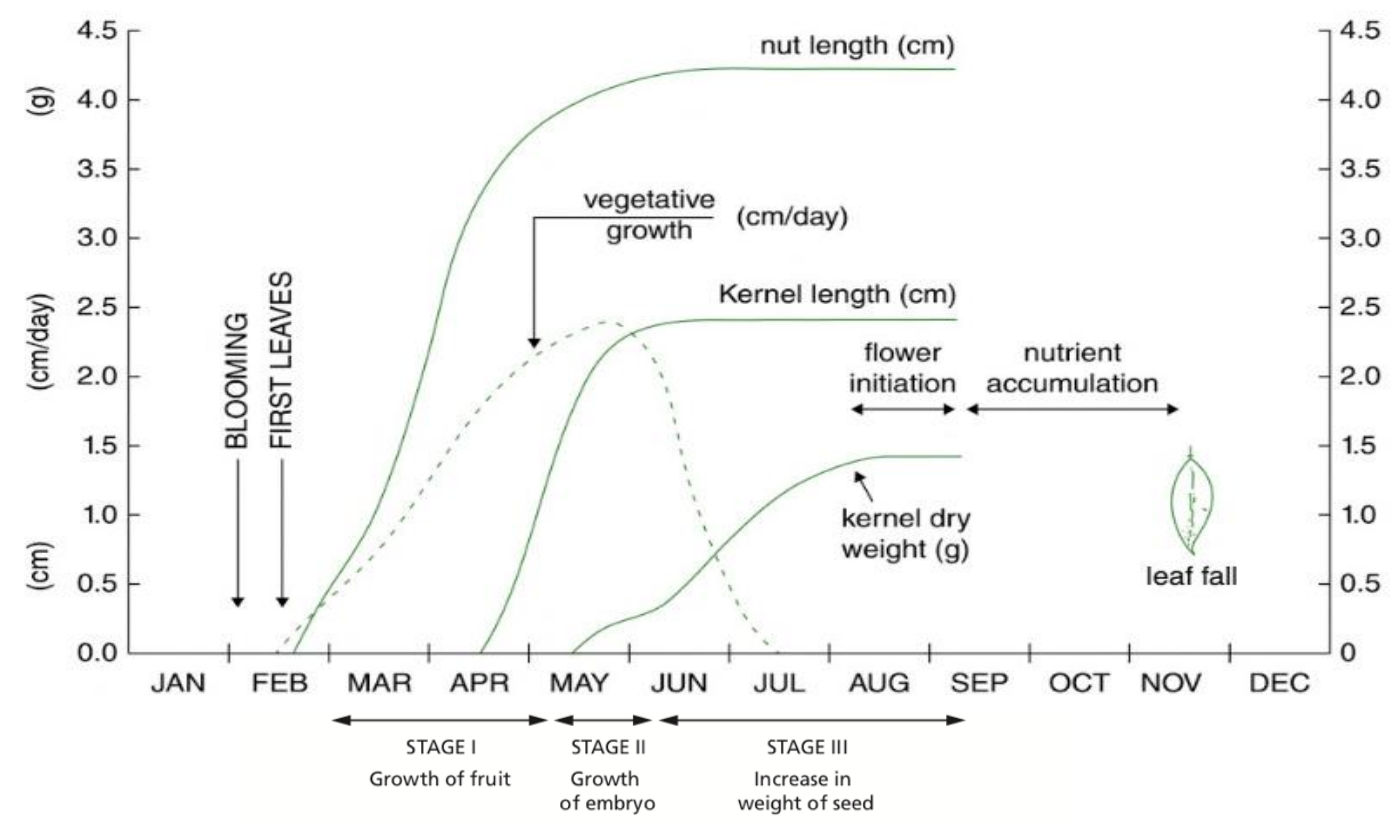

Figure 3. The three stages of almond fruit development and the typical length and weight of the fruit at each stage. Adapted from the UC Almond Production Manual, 1996 and Annual growth cycle of almond Adapted from almond s botany production and uses 2017.

Table 1. Estimates of the monthly crop coefficients $(K c)$ determined for almond orchards. Adapted from Water Scarcity and Sustainable Agriculture in Semiarid environment. 2018.

\begin{tabular}{lllllll}
\hline Month & FAO 56 $^{\mathrm{a}}$ & GOL89 $^{\mathrm{b}}$ & GIR06 $^{\mathrm{c}}$ & SAN12 $^{\mathrm{d}}$ & GT 15 $^{\mathrm{e}}$ & GF16 $^{\mathrm{f}}$ \\
\hline Mar & 0.40 & 0.54 & 0.40 & 0.88 & - & 0.20 \\
Apr & 0.57 & 0.63 & 0.65 & 1.01 & 0.55 & 0.75 \\
May & 0.84 & 0.76 & 0.80 & 1.02 & 0.90 & 0.95 \\
Jun & 0.90 & 0.85 & 0.92 & 1.09 & 1.05 & 1.10 \\
Jul & 0.90 & 0.96 & 0.96 & 1.14 & 1.15 & 1.15 \\
Aug & 0.90 & 0.94 & 1.05 & 1.08 & 1.05 & 1.17 \\
Sep & 0.90 & 0.92 & 0.82 & 1.08 & 0.80 & 1.12 \\
Oct & 0.75 & 0.83 & 0.60 & 0.96 & 0.70 & 0.87 \\
Nov & 0.65 & 0.70 & 0.40 & 0.85 & - & -
\end{tabular}

a Allen et al. (1998): Values for orchards without ground cover crop using the reported lengths of crop development stages for California and Mediterranean regions.

${ }^{\mathrm{b}}$ Goldhamer (1996): Values for mature trees without cover crop, in the San Joaquin Valley (1700lbs/ac $2250 \mathrm{lbs} / \mathrm{ac})$

${ }^{\mathrm{c}}$ Girona (2006): Values derived for mature trees with yield of $\sim 1600 \mathrm{lbs} / \mathrm{ac}$, irrigated with microsprinklers and with ground cover crop during the summer season. Method of ETc calculation: soil-water balance. ${ }^{\mathrm{d}}$ Sanden et al. (2012): Values for mature, high-yielding ( $4000 \mathrm{lbs} / \mathrm{ac}$ ) almond trees irrigated with microsprinklers without ground cover crop. Method of ETc calculation: eddy covariance technique. ${ }^{\text {e}}$ García-Tejero et al. (2015): Values derived for drip-irrigated 4-year-old trees without ground cover crop. Method of ETc calculation: soil-water balance using drainage lysimeters. 
${ }^{\mathrm{f}}$ Goldhamer and Fereres (2017): Values derived for mature, high-yielding ( $\left.3500 \mathrm{lbs} / \mathrm{ac}\right)$ trees irrigated with microsprinklers without ground cover crop. These values are not exactly $\mathrm{Kc}$, but irrigation coefficients (ICs) calculated as the ratio of water applied to ETo.

Stage 1 of fruit growth concerns development and formation involving the growth

of the hull and shell. Stage 1 starts after just after dormancy; hence the almond tree does not yet have sufficient leaves to begin essential physiological processes--principally photosynthesis. Crop coefficient $(\mathrm{Kc})$ values during stage 1 are low $(<0.8)$ (Doll 2017a).

Stage 2 begins after the full growth of the hull and shell, and continues through the full development of the kernel, when the shell starts to harden. It is important to consider this stage as one of the most sensitive growth stages. If water demand is not satisfied during this period, it can cause splitting of the shell (Kester and Labavitch 1996). This stage normally lasts for a month; in the northern hemisphere, usually from May to June (Figure 3). Crop coefficient (Kc) values in stage 2 are from 0.8-1.0, dependent upon different climate and management conditions (Table2).

Stage 3 is the last stage of fruit growth and is complete when the full formation of the fruit has finished. During this time, the kernel begins to store carbohydrates and starts gaining weight. The kernel separates from the hull and shell. In the northern hemisphere, this stage generally starts in early June and lasts until the end of the season (October). Kc values are the highest in during this final growth stage (Doll 2017a) (Table 2).

\section{$\underline{2.2 .5 \text { Soil }}$}

Soil has the capacity to retain water that will be available for plants (Allen et al. 1998). Soil moisture content in the upper layer determines evaporation from the soil. Many crops have most of their roots in the upper soil layers. Thus, most of the transpiration and water extraction is done in the upper layers (Campos et al. 2016). 
Plant physiological processes are not effected by soil moisture when the soil moisture content is close to field capacity (Laio et al. 2001). If the soil moisture content decreases to a critical point, evaporation from the surface layer and transpiration will be effected (Campos et al. 2016): Calculating evaporation from the soil is based on soil moisture content and soil properties. If there is a reduction in soil moisture, the amount of evaporation will decrease.

Evaporation is estimated by the amount of energy available in the surface layer of the soil (Allen and Pereira 2009). The maximum amount of water that can evaporate depends on soil physical and chemical characteristics and soil-water characteristics (Allen et al. 1998). These include soil hydraulic properties, tillage, soil temperature, and wetting characteristics (Allen et al. 2005). For calculation purposes, evaporation from soil is divided in two stages: an energy limiting stage and a falling rate stage. To calculate evaporation, a surface layer depth of 0.10 meters and a minimum soil moisture content of 0.5 of the wilting point (Table 2) is used (Allen et al. 2005).

The two stages of evaporation described by Allen et al. (1998) are considering saturated conditions. During Stage 1, evaporation is limited by the energy availability in the soil surface, this is dependent on ambient temperature prior irrigation or precipitation. The heat store in soil prior to the wetting event may contribute to the available energy (Allen 2011). Stage 1 ends when hydraulic properties of the upper soil become the limiting factor to evaporation at a constant rate (Allen et al. 2005).

Stage 2 begins once the readily evaporable water has evaporated; the amount ranges from $5-12 \mathrm{~mm}$ depending on the soil texture. During stage 2 the evaporation of soil surface moisture decreases as the water stored within the soil decreases (Allen et al. 
2005). Stage two also depends on hydraulic properties of the soil because evaporation is conditioned by the flux of water in the upper layer of the soil (Allen 2011). The equation proposed by Allen et al. (1998) states that total evaporation is limited to water held to the soil beyond 50 percent of the wilting point.

Plant transpiration is effected by atmospheric demand, soil water potential and hydraulic conductivity (Kool et al. 2014). Soil moisture available for transpiration is defined by the fraction of transpirable soil water (FTSW) (Fuentealba et al. 2016). The FTSW has different thresholds depending on the soil type (Sadras and Milroy 1996). Sadras and Milroy (1996) found the FTSW threshold point for coarse soils was higher (0.72) compared to fine soils (0.43). Allen et al. (1998) described that the fraction of available water holding capacity depleted before evapotranspiration is reduced as Readily Available Water (RAW). The RAW differs from crop to crop in the same soil. It is important to consider that soil characteristics also effect the RAW. For example, RAW for sandy soils is lower if compared to clayed soils of the same depth (Table 2). 
Table 2. Typical Soil Water Characteristics for Different Soil Types (Adapted from FAO-56, Allen et al. 1998).

\begin{tabular}{|c|c|c|c|c|c|}
\hline \multirow{3}{*}{$\begin{array}{l}\text { Soil Type } \\
\text { (USDA soil } \\
\text { texture } \\
\text { classification) }\end{array}$} & \multicolumn{3}{|c|}{ Soil water characteristics } & \multirow{2}{*}{\multicolumn{2}{|c|}{$\begin{array}{l}\text { Evaporation parameters } \\
\text { Amount of water that can be } \\
\text { depleted by evaporation }\end{array}$}} \\
\hline & & & & & \\
\hline & $\begin{array}{l}\theta_{\mathrm{FC}} \\
\mathrm{m}^{3} / \mathrm{m}^{3}\end{array}$ & $\begin{array}{l}\theta_{\mathrm{WP}} \\
\mathrm{m}^{3} / \mathrm{m}^{3}\end{array}$ & $\begin{array}{l}\theta_{\mathrm{FC}}-\theta_{\mathrm{WP}} \\
\mathrm{m}^{3} / \mathrm{m}^{3}\end{array}$ & $\begin{array}{l}\text { Stage } 1 \\
\mathrm{~mm}\end{array}$ & $\begin{array}{l}\text { Stage } 1 \text { and } 2 \\
\mathrm{~mm}\end{array}$ \\
\hline Sand & $0.07-0.17$ & $0.02-0.07$ & $0.05-0.11$ & $2-7$ & $6-12$ \\
\hline Loamy sand & $0.11-0.19$ & $0.03-0.10$ & $0.06-0.12$ & $4-8$ & $9-14$ \\
\hline Sandy loam & $0.18-0.28$ & $0.06-0.16$ & $0.11-0.15$ & $6-10$ & $15-20$ \\
\hline Loamy sand & $0.20-0.30$ & $0.07-0.17$ & $0.13-0.18$ & $8-10$ & $16-22$ \\
\hline Silt loam & $0.22-0.36$ & $0.09-0.21$ & $0.13-0.19$ & $8-11$ & $18-25$ \\
\hline Silt & $0.28-036$ & $0.12-0.22$ & $0.16-0.20$ & $8-11$ & $22-26$ \\
\hline Silt clay loam & $0.30-0.37$ & $0.17-0.24$ & $0.13-0.18$ & $8-11$ & $22-27$ \\
\hline Silty clay & $0.30-0.42$ & $0.17-0.29$ & $0.13-0.19$ & $8-12$ & $22-28$ \\
\hline Clay & $0.32-0.40$ & $0.20-0.24$ & $0.12-0.20$ & $8-12$ & $22-29$ \\
\hline
\end{tabular}

Note: $\theta=$ volumetric weight; $\mathrm{FC}=$ field capacity; WP wilting point. 


\subsection{Almond Yield}

\subsubsection{Introduction}

Almond production is mostly concentrated in two countries: The United States and Spain together account for around $68 \%$ of the global production of almonds. The USA contributes $62 \%$ of total global production with an average yield of 4960 pounds per acre and Spain contributes 6\% with an average yield of 1940 pounds per acre (Table 3) (FAO 2015). California produces a full $100 \%$ of total US almond production (USDAERS 2016). The high yields obtained in the US are largely a result of favorable environmental conditions and intensive agricultural practices, which include high water and fertilization inputs (Gradziel and Socias i Company 2017).

California production is focused in the San Joaquin Valley. The main production counties are: Fresno, Kern, Madera, Merced and Stanislaus. These counties have an average production above 50000 US tones per year (Almond Board of California 2016) . Drought conditions have made irrigation costs increase in the San Joaquin Valley. Thus, there is a trend in almond production towards producing in the Sacramento Valley because of lower ET and lower irrigation costs (Gradziel 2017). 
Table 3. Almond production top 10 countries for year 2015. Production includes almond shells. (Adapted from FAO data).

\begin{tabular}{lrrr}
\hline Country & $\begin{array}{c}\text { Production } \\
\text { (US ton) }\end{array}$ & $\begin{array}{c}\text { Area } \\
\text { (Acres) }\end{array}$ & $\begin{array}{c}\text { Yield } \\
\text { (pounds/acre) }\end{array}$ \\
\hline USA & $2,207,644.53$ & $890,000.55$ & $4,961.00$ \\
Spain & $223,040.50$ & $229,807.65$ & $1,941.11$ \\
Iran & $162,991.01$ & $229,807.65$ & $1,418.50$ \\
Morocco & $124,209.51$ & $395,412.48$ & 628.25 \\
Syrian Arab Republic & $97,930.41$ & $270,372.41$ & 724.41 \\
Turkey & $93,696.43$ & $73,318.52$ & $2,555.87$ \\
Italy & $82,214.76$ & $143,597.66$ & $1,145.07$ \\
Australia & $80,360.68$ & $76,886.72$ & $2,090.37$ \\
Algeria & $72,857.25$ & $99,837.83$ & $1,459.51$ \\
Tunisia & $67,240.97$ & $452,128.02$ & 297.44 \\
\hline Worldwide & $3,543,161.54$ & $4,446,698.95$ & $1,593.61$ \\
\hline
\end{tabular}

\subsubsection{Environmental Requirements}

Almonds are usually produced in Mediterranean climates. The California Central Valley's climatic conditions epitomizes those characterizing this type of climate: rainy winters, with mild frost duration, and hot dry summers (Kester and Ross 1996). These conditions are essential, given that temperature during the winter will affect the duration of dormancy and the blooming date of almonds (Egea et al. 2003). And rain will affect yield if it occurs during pollination or harvesting stages of almonds (Alonso 2017).

\subsubsection{Chilling and Heat Requirements}

The beginning of the blooming stage depends on two main factors: low temperature during endodormancy, and high temperature during ecodormancy. Accordingly, chilling requirements affect the length of endodormancy and heat requirements affect the length of ecodormancy (Figure 4). (Lang et al. 1987; Luedeling et al. 2009). 
Because low temperature is the main factor affecting endodormancy, to break endodormancy, almond trees need exposure to a certain amount of chilling hours (Campoy and Egea 2011). If these chilling hour requirements are not met, yield may be negatively impacted (Luedeling 2012). For calculating exposure to chilling hours, chill accumulation models are utilized; those most often used are: the number of hours below $45^{\circ} \mathrm{F}$, the number of hours between $32-45^{\circ} \mathrm{F}$, and Utah model (Byrne and Bacon 1992). These models estimate cumulative chilling requirements in chilling units (CU).

Egea et al. (2003) found a wide range of chilling requirements for almonds, from $266 \mathrm{CU}$ to $996 \mathrm{CU}$. On the other hand, Alonso et al. (2005) found chilling the requirement for almonds falls between 400-600 CU. Both of these studies were made in Spain. Studies made in Chile found that the chilling requirements ranged from 200-400 CU (Ramírez and Reginato 2010). Once the chill accumulation is met, endodormancy is broken.

Once endodormancy is fulfilled via chilling requirements, ecodormancy begins (Lang et al. 1987). In order to break ecodormancy, almond trees need exposure to higher temperatures, this is known as heat requirements. For measuring heat requirements the Growing Degree Hour (GDH) model is used (Anderson and Kesner 1986). By definition, the GDH is a sequential accumulation of the temperature by hour above the base temperature. Egas et al. (2003) found a range from 5900-7438 GDH are required to fulfill ecodormancy, while Alonso et al. (2005) found more variability (5500-9300). Ecodormancy is considered completed when $50 \%$ of the flowers are blooming. 


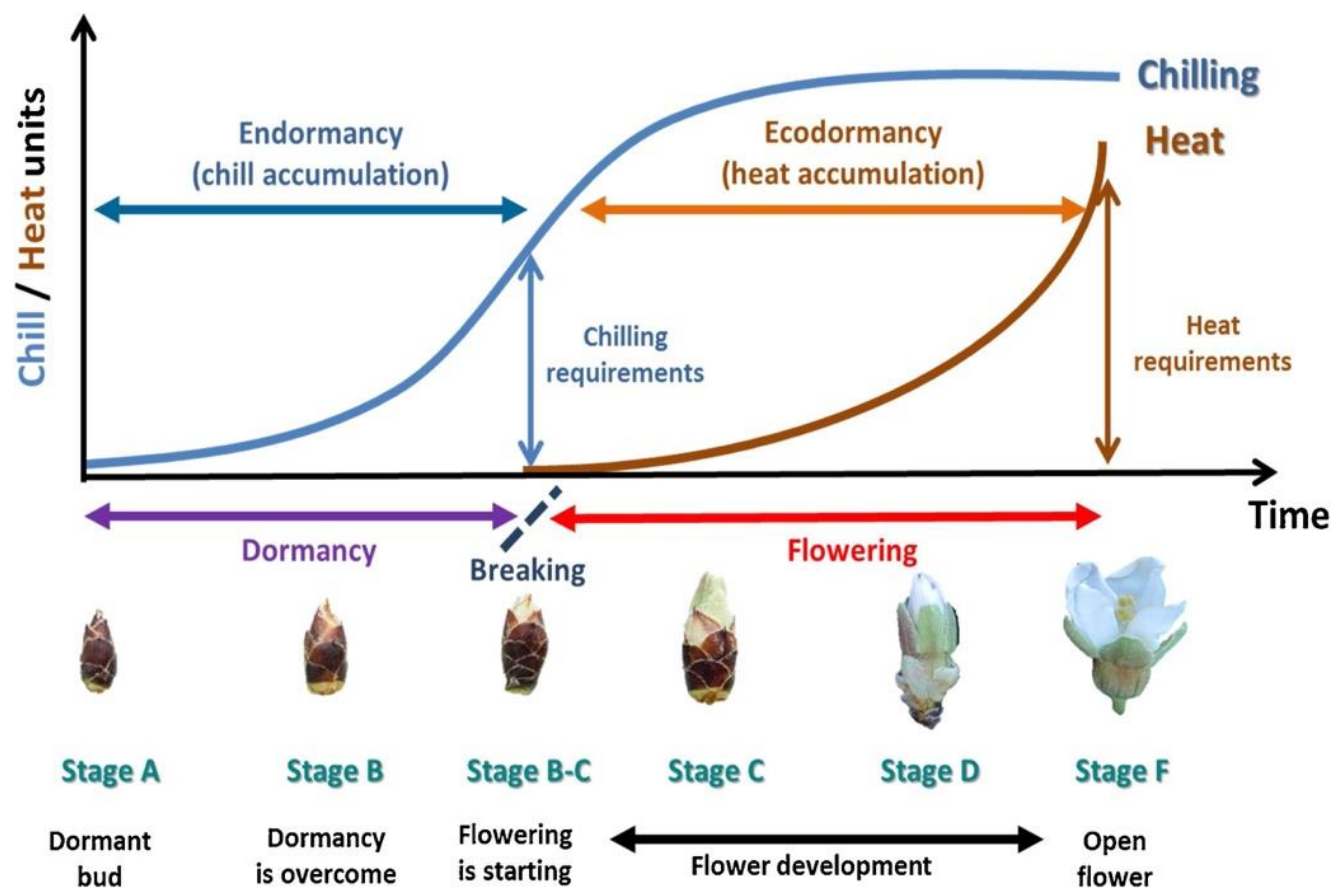

Figure 4. Dormancy breaking of reproductive buds and flowering in almond referenced to the phenological stages as described by Felipe (1977). Adapted from Lang et al. (1987), Luedeling et al. (2009) and Prudencio and Dicenta (2018).

\subsubsection{Rains}

Rains are an essential factor in non-irrigated almond orchards. Rain will have an impact on yield if it occurs during the blooming stage (Dorfman and Heien 1988). During this stage, rain will suppress anther dehiscence and insect cross pollination reducing blossom. Alston et al. (1997) found a negative correlation between rainfall in February and yield. Furthermore, a high incidence of fungal disease often occurs if rains occurs in the blooming season, promoting fungal diseases including: Monilinia Laxa, Botrytus cinereal and Sclerotinia scletotiorum (Palacio-Bielsa et al. 2017).

Excessive rains prior to the spring will saturate the soil. Doll (2017a) found that yellow trees syndrome is a symptom of high soil moisture due to saturated soil (Doll 2017b). Saturated soil reduces the amount of oxygen in the soil killing fine roots. Also, saturated soils promote the development of fungal diseases. Almond trees are most 
sensitive of the indehiscent fruit to Phytophthora (fungal disease) (Gradziel and Kester 1996).

For almonds, harvesting season usually occurs during late summer or early fall. If rains occurs in the start of the harvesting season, harvest efficiency is reduced (Alonso 2017). Harvest-season rains can also activate the vegetative growth of the tree, increasing potential damage to the trunk caused by the vibrations of the shaking machine which is most commonly used to harvest the fruit (Connell et al. 1996). Indeed, irrigation — which has the same effect as rains - is reduced three weeks prior to the start of the harvesting season to prevent tree injury due to mechanical vibration.

\subsubsection{Soil}

\subsubsection{Physical Characteristics}

Almond trees have better yield when they are grown in loam-textured, deep and uniform soil compared to compacted clayed soils (Fulton et al. 1996). These ideal conditions allow almond roots reach a length of as much as 3 meters (Alonso 2017). Fulton et al. (1996) found differences in yield by changing the soil structure using different tillage methods to promote root growth. In claypan soils, using a moldboard tillage method, he found a yield of $1433 \mathrm{lbs} / \mathrm{acre}$, compared to $1009 \mathrm{lbs} / \mathrm{acre}$ without using any tillage method. These two resulting yields can be compared with the conventional ripper tillage method, where the yield was $1120 \mathrm{lbs} / \mathrm{acre}$.

In almonds, about $75 \%$ of all the roots are found in the first three feet of the soil layer. Roots can spread as wide as 15 meters (Catlin 1996). Directly impacting root growth are soil physical characteristics, in particular: soil texture, soil depth and degree of saturation (Alonso 2017). 
Ravina and Magier (1984) found that clayed soil--with its characteristic slow drainage and limited aeration-- negatively impacts yield. On the other hand, sandy soils have larger pores compared to clay, which facilitate aeration and water movement through the soil, promoting root growth.

The drawback with sandy soils is the available water holding capacity and the cation exchange capacity: both of these characteristics are relatively low compared to clayed soils (Arquero 2013). Therefore, irrigation intervals have to be shorter to avoid water stress. Low cation exchange capacity makes frequent fertilization necessary with sandy soil, with low input to avoid fertilizer leaching.

\subsubsection{Salinity}

Almonds have low salt tolerance (Ottman and Byrne 1988). Evidence shows that salt accumulation in the soil causes symptoms of water stress--even if the soil moisture content is adequate (Fulton et al. 1996). Further data published by Mass and Hoffman (1977) is still used to determine percentage of yield reduction due to salinity in water and in soil on almond production (Table 4).

Table 4. Salinity threshold and their reduction in yield for almond. Adapted from Mass and Hoffman (1977) and Fulton et al. (1996).

\begin{tabular}{lccc}
\hline & \multicolumn{3}{c}{ Percent of full yield potential } \\
\hline Salinity $(\mathrm{dS} / \mathrm{m})$ & 100 & $99-40$ & $<40$ \\
\hline Average root zone & $<1.5$ & $1.5-4.8$ & $>4.8$ \\
Irrigation Water & $<1.1$ & $1.1-3.2$ & $>3.2$ \\
\hline
\end{tabular}

Salinity also significantly effects water uptake and almond yield (Zrig et al. 2016). Franco et al. (2000) compared different salinities in irrigation water: a lower salinity water $(0.8 \mathrm{dS} / \mathrm{m})$, to higher salinity water $(4.26 \mathrm{dS} / \mathrm{m})$. A decrease of $46.5 \%$ in yield was found when high saline water was used. 
In related findings, Phogat et al. (2018) reported that almond water uptake decreased by $10 \%$ when salinity of the irrigation water was $1.9 \mathrm{dS} / \mathrm{m}$, compared to $0.78 \mathrm{dS} / \mathrm{m}$. This study's soil salinity had an average range of $2.4-3.7 \mathrm{dS} / \mathrm{m}$. This range is above the salinity threshold that Mass and Hoffman (1977) described (Phogat et al. 2018) for adequate yield (Table 4).

In summary, the aforementioned salinity studies have shown that salinity affects not only water uptake (Phogat et al. 2018), but also yield (Franco et al. 2000). Phogat et al. (2018) found that even if salinity levels in the soil were constant, water uptake was affected. Under these high salinity conditions, a reduction of evapotranspiration is expected. 


\subsection{Deficit-Irrigation Strategies for Drought Conditions.}

\subsubsection{Introduction.}

With climate change and water scarcity conditions, new practices have been promoted in agricultural areas to reduce water use with almonds and other crops. The term to describe these drought mitigating practices is Deficit Irrigation (DI). There are three DI techniques--each with a different approach--that have been used over the past few years. These are: regulated deficit irrigation (RDI), sustainable deficit irrigation (SDI) and partial root drying (PRD) (García-Tejero et al. 2018). The sustainable deficit irrigation (SDI) technique reduces the water applied below the ETc through all the growing season making the crop adapt to these conditions. Regulated deficit irrigation (RDI) on the other hand, reduces the water applied during growth stages where the crop is less sensitive to water scarcity compared to reproductive stage (Alcon and Nortes 2013). Partial root drying (PRD), the third technique, regulates plant response to drying soil by the root-to-shoot relationship, making the crop feel stress; thus, reducing the amount of water uptake.

The next area of focus is plant physiological response to water scarcity conditions, including transpiration. One way in which almond trees decrease transpiration is by closing their stomata. This has a direct impact on water uptake; therefore, a subsequent reduction of growth and photosynthesis is expected.

Espadafor et al. (2017) found that transpiration in almonds is highly sensitive to water deficit. However, there was not a statistical difference between transpiration efficiency during the day, for non-stress water conditions and stress water conditions on 
almonds. Transpiration efficiency on almonds is highly dependent on vapor pressure deficit.

\subsubsection{Deficit Irrigation techniques}

In almond production, the Regulated Deficit Irrigation (RDI) technique is often employed during the kernel-filling period. Mañas and Lopez-Urrea (2014) found that there was not a statistical difference in yields between RDI and SDI methods. The SDI treatment produces $23 \%$ less yield than the fully irrigated treatment. Regulated deficit irrigation produces $33 \%$ less yield than the fully irrigated treatment as well. The water reduction in both of these treatments were above $50 \%$, compared to the fully irrigated treatment. (Mañas and López-Urrea 2014).

Lopez-Lopez et al. (2018) found that there was not a statistical difference between RDI and SDI in almond ET. The ET in both of the treatments decreased by $21 \%$ compared to the fully irrigated treatment. They also reported that in a more severe stress condition, using the RDI method, the ET decreased by $34.4 \%$ compared to the fully irrigated method. This study did not evaluate yield (López-López et al. 2018).

Egea et al. (2010) compared PRD with RDI. The PRD method used three treatment parameters--70\%, 50\% and 30\% respectively--of total ET to irrigate. The RDI method used a parameter of $50 \%$ of total ET. There was no statistical difference between the PRD's $70 \%, 50 \%$ and RDI 50\% treatment parameters, in almond yield. Indeed, the PRD and RDI treatments showed a decrease of approximately $16 \%$ in yield compared with the fully irrigated method. In addition, Egea et al. 2010 reported that partial root drying (PRD) technique with $30 \%$ of total ET resulted in a decrease of $30 \%$ in yield. 
Furthermore, partial root drying requires more manual labor, making it unfeasible for large scale production.

Goldhamer and Salinas (2006) found higher almond yield using the SDI technique compared to RDI. Nevertheless, when RDI was applied during pre-harvesting season, fruit density increased, and there was a reduction of tree canopy. Therefore, this technique could lead to higher tree densities in orchards management. A reduction in tree canopy could reduce the spacing between trees in each row; thus, it can be assumed that yield could potentially be increased.

Notably, Goldhamer and Salinas (2006) used the RDI technique during the postharvesting season, with high water stress conditions (55\% and $70 \%$ of ET) which resulted in lower almond yield compared to RDI in pre-harvesting season and SDI.

Different financial feasibility studies have been done comparing SDI and RDI. These types of studies have been conducted in Spain (Alcon and Nortes 2013; García et al. 2004) and in California's San Joaquin Valley (Goldhamer and Fereres 2017a). Each of these studies propose DI techniques as an alternative to fully irrigated condition. It must be noted, however, that these studies were not made with current climate conditions, or drought conditions.

\section{$\underline{2.4 .3 \text { Conclusion }}$}

Almond production in California represents an important component of the state agricultural economy. Beyond the almond orchard and farm context itself, there is a complex industry that produces large amounts of revenue. 
Since 2011, for environmental and economic reasons, California growers were pressed to adapt agricultural practices due to water scarcity. And drought conditions have indeed made farmers more efficient with the use of water resources.

Further research should focus on decreasing water use in almond production without affecting yield. For better management of physiological stress due to water scarcity, it is essential to identify crop physiological behavior; these include tolerance thresholds and finding the breaking point where yield would be compromised (GarcíaTejero et al. 2018).

Further studies should examine long-term effects of DI methods on almond production prior to implementing their use, to prevent potential irreversible damage to almond orchards when these techniques are used (García-Tejero et al. 2018) as significantly, none of the studies reviewed have had a duration period of longer than five years. Also, none of these studies were conducted with young almond trees. Evaluating the difference in SDI and RDI, the effect in the long-term use on young almond trees will be essential to identifying the best method to use in almond production. 


\section{METHODOLOGY \& PROCEDURES}

\subsection{Study Area}

This study gathered data from farms in Kern County, in California's Central Valley, where agriculture is the primary industry and most lucrative sector of the economy. In 2014 alone, agricultural commodities in the county exceeded more than $\$ 7.5$ billion. Grapes are Kern County's main product, making up 25\% of total agricultural commodity: Kern's second most important crop is almonds, which constitutes $23 \%$ of total agricultural commodities (Almond Board of California 2016).

In 2017, Kern County had the most planted almond acreage in California $(150,000$ acres), representing approximately $18 \%$ of total planted area of California almond production (California Department of Food and Agriculture 2018). In addition, Kern County ranks first among all counties in almond production, with 19\% of California's total almond crop, producing more than 100 million pounds per year (Figure 5) (Almond Board of California 2016). 




Figure 5. Almond producing counties in California (production expressed in million pounds). Excerpted from Almond Board of California 2016.

Kern County is located at the southern end of the San Joaquin Valley. It covers an area of $8,161.42$ square miles. Due to its geographical location, lying between the Coast Range to the west and the Sierra Nevada to the east, Kern County developed a variety of soil orders, discussed below.

The United States Department of Agriculture Natural Resource Conservation Service (USDA-NRCS) divided the survey of Kern County in four zones, depending on cardinal location (NW, NE, SW, and SE) (Figure 6). According to the division made by the USDA-NRCS, fields evaluated in this study were located in the northwestern zone of Kern County where data were gathered during the years 2011, 2013-2015. The total number of analyzed fields were 185 . 




Figure 6. Field sites (east, west and northwest side) analyzed in this study and CIMIS station locations used in this study in the Kern County-northwestern part, CA. Kern County division based on the survey made by the United States Department of Agriculture with the Natural Resource's Conservation Service (USDA-NRCS).

\subsubsection{Climate}

The northwestern zone of Kern County (Figure 7) is located at the southern end of the San Joaquin Valley, covering an area of 2144 squares miles. Located between the Sierra Nevada and the Coast Range, altitudes within the northwestern part vary considerably (180 ft-4332 ft), and this, along with effect of the adjacent mountain ranges, endowed this area with a wide spectrum of climatic conditions and microclimates. The Sierra Nevada to the east stores water in the form of snow during the winter, and then makes this water available during the late spring and early summer. Despite this, the overall climate is considered to be arid to semiarid (USDA-NRCS 1988). 
The wet season is considered to be from October through April. During these months, the average cumulative precipitation ranges from 5-12 inches (during non-drought years) depending on the location within the northwestern zone. Winters are usually mild, foggy and semi-humid. On the other hand, summers are generally warm and dry, with temperatures exceeding $100{ }^{\circ} \mathrm{F}$ during the day. These conditions resemble Mediterranean conditions, which represents optimal climatic conditions for almond production (USDANRCS 1988).

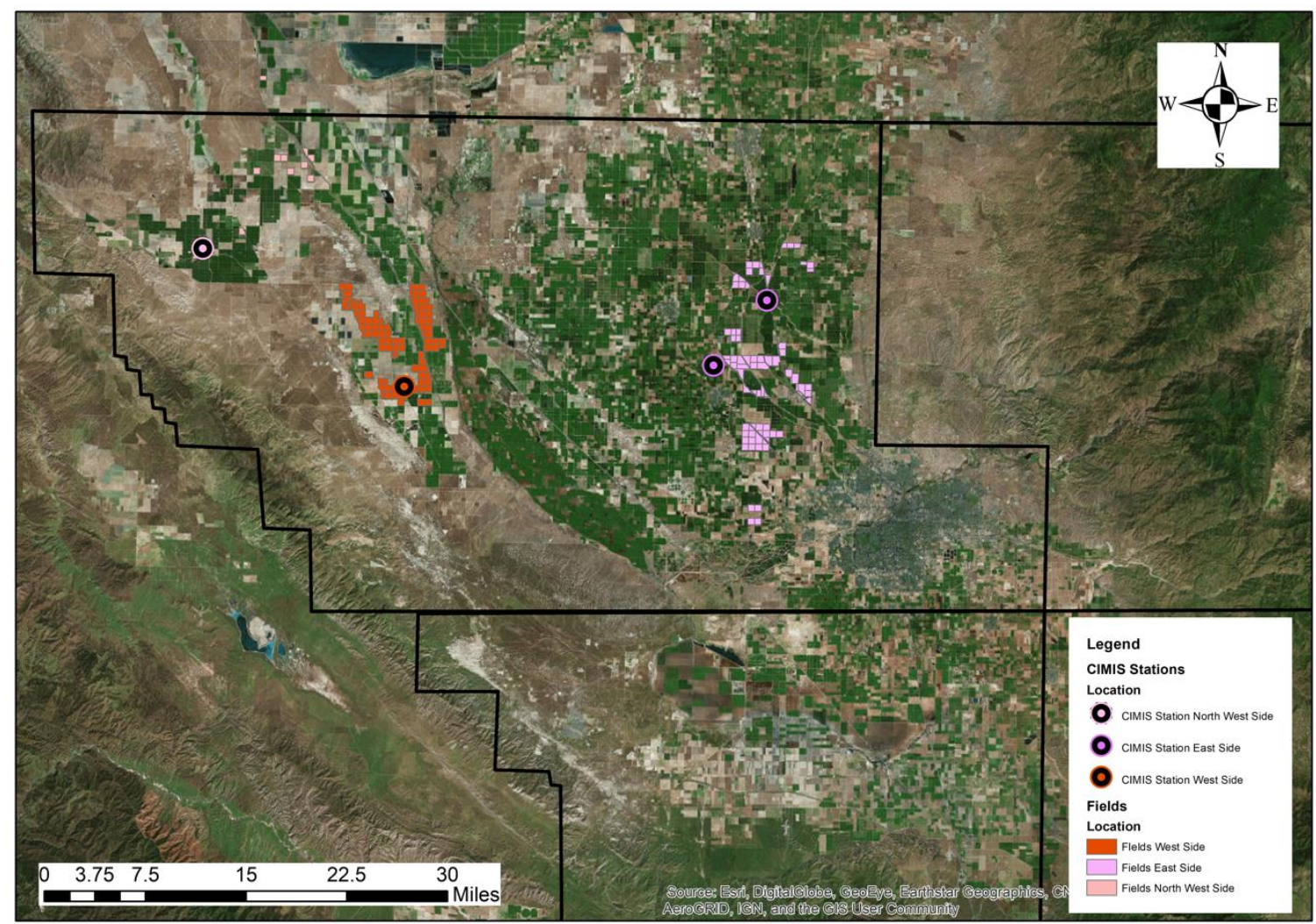

Figure 7. Field sites (east, west and northwest side) analyzed in this study and CIMIS stations location used in this study. Kern County North Western part, CA. Division made by the NRSC-USDA survey.

Because climate conditions were not the same across the 185 (often noncontiguous) fields analyzed during the four years of this study. Within the northwest zone, fields were divided according to their distance from the closest CIMIS station. Thus, there were three 
locations: a northwest, west, and east side-- each location with its own CIMIS station (Table 5). The CIMIS station closest to a given field was used to gather weather data on precipitation and chilling hours.

On the east side, however, data from two CIMIS stations were used, the reason being that CIMIS station Shafter \#5 did not have data for 2012 (Figure 7). Therefore, the CIMIS station Famoso \#138 was used for that year. For the remaining years of the study, on the east side, an average of the precipitation and chilling hours between CIMIS station Shafter \#5 and Famoso \#138 data values were used.

Table 5. CIMIS station names and identification numbers, and number of fields in each location of the study in the Northwestern portion of Kern County, CA.

\begin{tabular}{lccc}
\hline & East Side & West Side & North West Side \\
\hline \multirow{2}{*}{ CIMIS Station } & Shafter \#5 & Belridge \#146 & Blackwells Corner \#54 \\
& Famoso \#138 & & 10 \\
Number Fields & 78 & 97 & \\
\hline
\end{tabular}

\subsubsection{Precipitation}

CIMIS stations employ five different sensors to collect weather data and these data are stored in data loggers to be analyzed. Once analyzed, the data were stored in a database server where it became available over the internet. For collecting precipitation data by the CIMIS stations, a tipping-bucket rain gauge was used. The CIMIS stations measured precipitation data in inches. Cumulative precipitation was obtained from the CIMIS station closest to each field. Cumulative precipitation for this study was gathered during the wet season (October of previous to April of the year evaluated).

Precipitation within the first of the locations of consideration--the east side-changed drastically from 2011 to the period between 2013 and 2015 (Figure 8). Year 
2011 was considered a wet year due to its high precipitation (10.2 inches).

Between 2013 and 2015 precipitation decreased 75\%,81\%, and 61\% respectively.

California experienced drought conditions during in these years (Leslie and Richman 2015).



Figure 8. Precipitation data in inches for the east side location, data gathered from CIMIS Station Shafter \#5 and Famoso \#138, for the months October-April in 2011 and 2013-2015.

Precipitation in the west side--second location of the NW zone studied here--also diverged markedly from 2011 to the period between 2013 and 2015 (Figure 9). Here, as well, year 2011 was considered a wet year due to its high precipitation (9.02 inches). Between 2013 and 2015 precipitation decreased to 79\%, 88\% and 80\%, respectively, constituting drought conditions. Of all areas considered, the west side had the most significant decrease in precipitation from a wet year (2011) to drought years (2013-2015). 




Figure 9. Precipitation data in inches for the west side location, data gathered from CIMIS Station Belridge \#146, for the months October-April in 2011 and 2013-2015.

The third location considered, the north west side of Kern County showed a similar trend from 2011 to the period between 2013 and 2015 (figure 10). Year 2011 was considered a wet year due to its high precipitation (6.54 inches). Between 2013 and 2015 precipitation decreased by $62 \%, 66 \%$ and $66 \%$, respectively, as California experienced drought conditions. The northwest side had the lowest precipitation in a wet year relative to all the other study location (6.54 inches). 


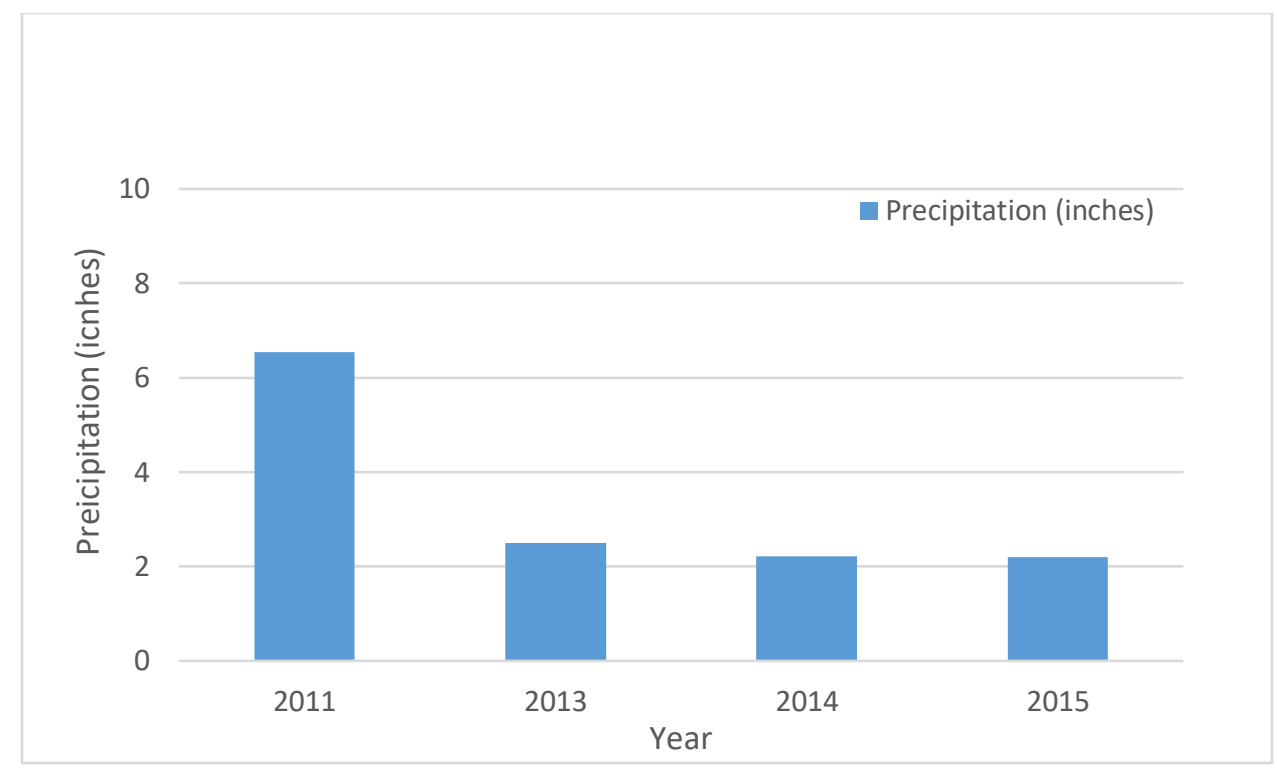

Figure 10. Precipitation data in inches for the northwest side location, data gathered from CIMIS Station Blackwells Corner \#54, for the months October-April in 2011 and 2013-2015.

\subsubsection{Chilling Hours}

Cumulative chilling hours data were provided by the Fruit and Nut Research and Information Center (2018), a service of the University of California Davis, Division of Agriculture and Natural Resources, which gathered this information from CIMIS stations (Figure 7). This service provides the three most common methods used to measure cumulative chilling hours (as described earlier in Chapter 2). Utilized in this study was the cumulative chilling hours below $45^{\circ} \mathrm{F}$ method, which counts the number of hours below $45^{\circ} \mathrm{F}$, considering each hour a chilling unit (CU). In this study, chilling hours data were gathered via this method for the period from November $1^{\text {st }}$ to February $28^{\text {th }}$ only during the years 2011, 2013, 2014 and 2015

The east side location had a cumulative chilling hours mean of $1113 \mathrm{CU}$. Comparing a wet year (2011) to drought condition years (2013-2015) no trend between wet/drought year and number of cumulative chilling hours was observed (Figure 11). 


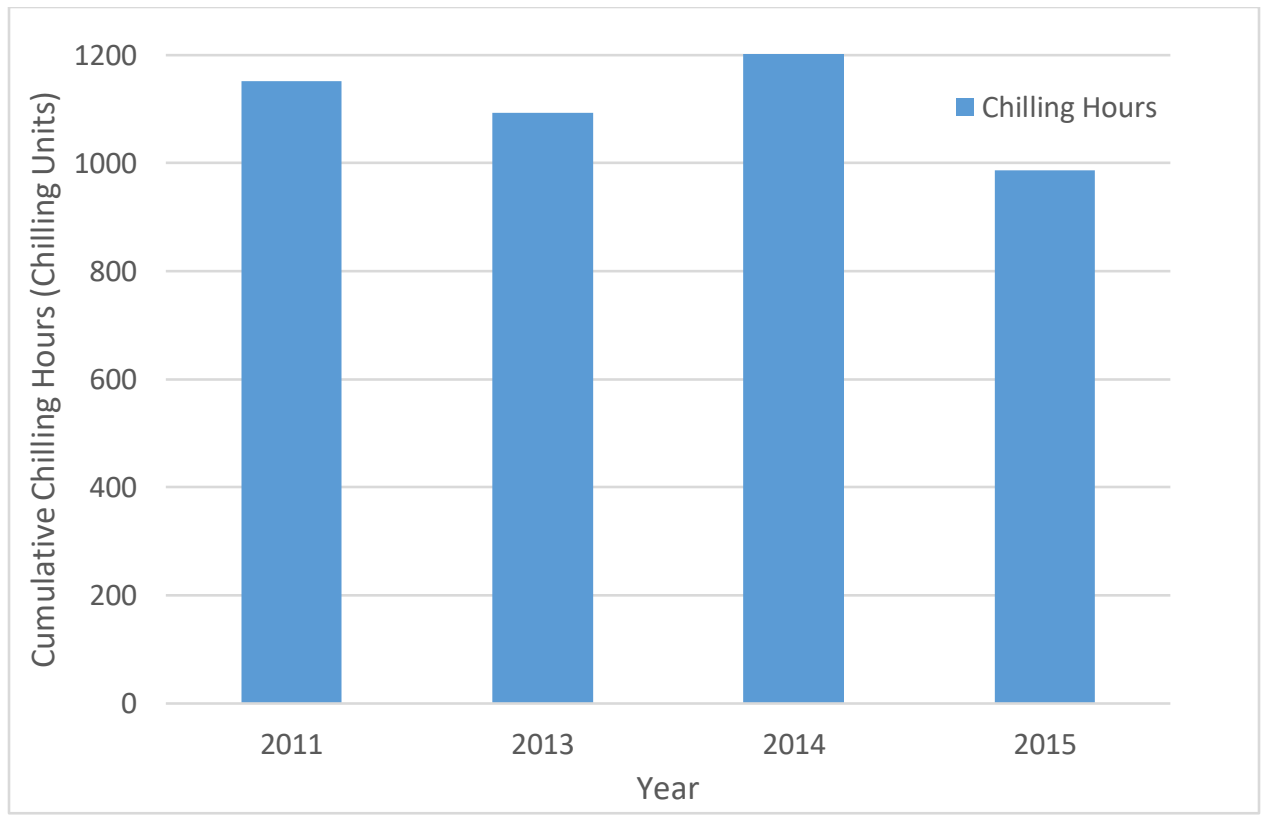

Figure 11. Cumulative chilling hours data in CU for the east side location, data gathered from CIMIS Station Shafter \#5 and Famoso \#138, for the months November-February in 2011 and 2013-2015.

The west side location had a cumulative chilling hours mean of 999 CU.

Comparing a wet year (2011) to drought condition years (2013-2015), no trend between a wet year and number of cumulative chilling hours (Figure 12) was observed. However, there was a considerable decrease in year 2015 (<1000 CU). 


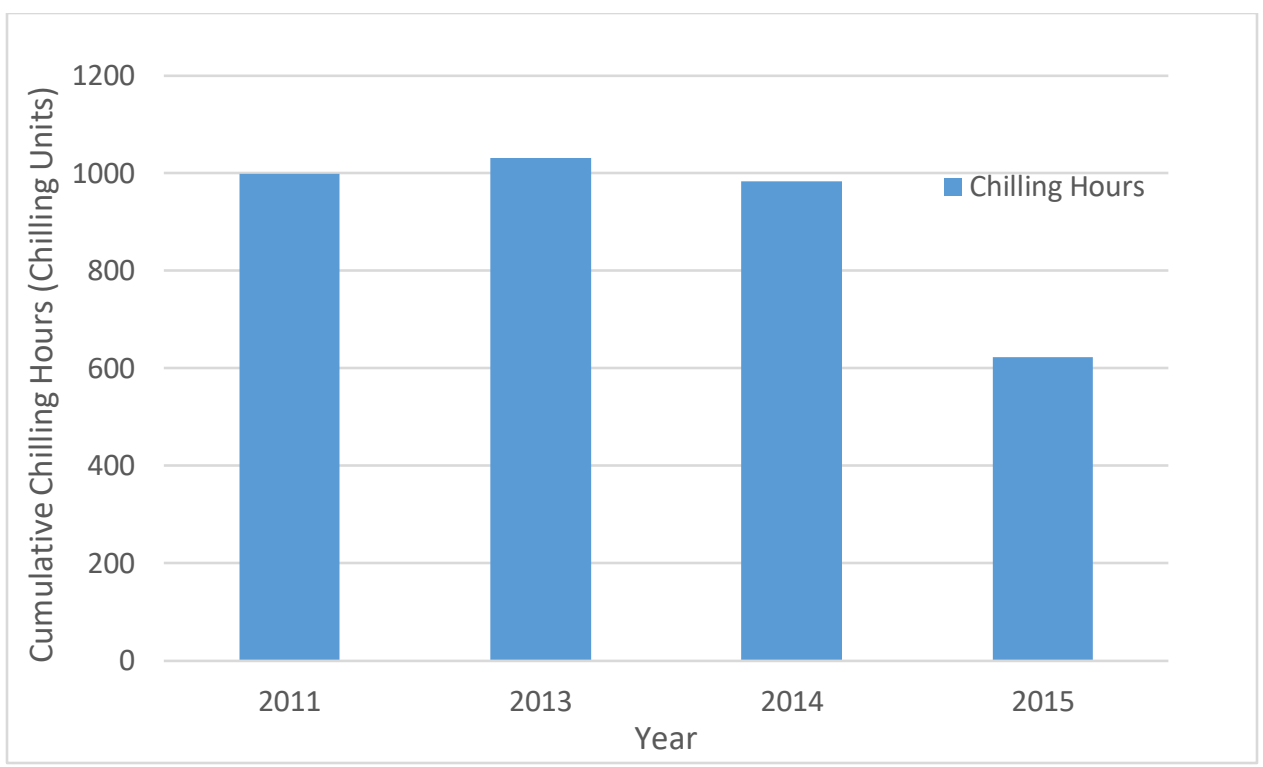

Figure 12 Cumulative chilling hours data in CU for the west side location, data gathered from CIMIS Station Belridge \#146, for the months November-February in 2011 and 2013-2015.

The northwest side location had a cumulative chilling hours mean of $1023 \mathrm{CU}$.

Comparing a wet year (2011) to drought condition years (2013-2015) no trend between these and cumulative chilling hours was observed either (Figure 13). Nevertheless, the years 2014 and 2015 had cumulative chilling hours of less than $1000 \mathrm{CU}$. 


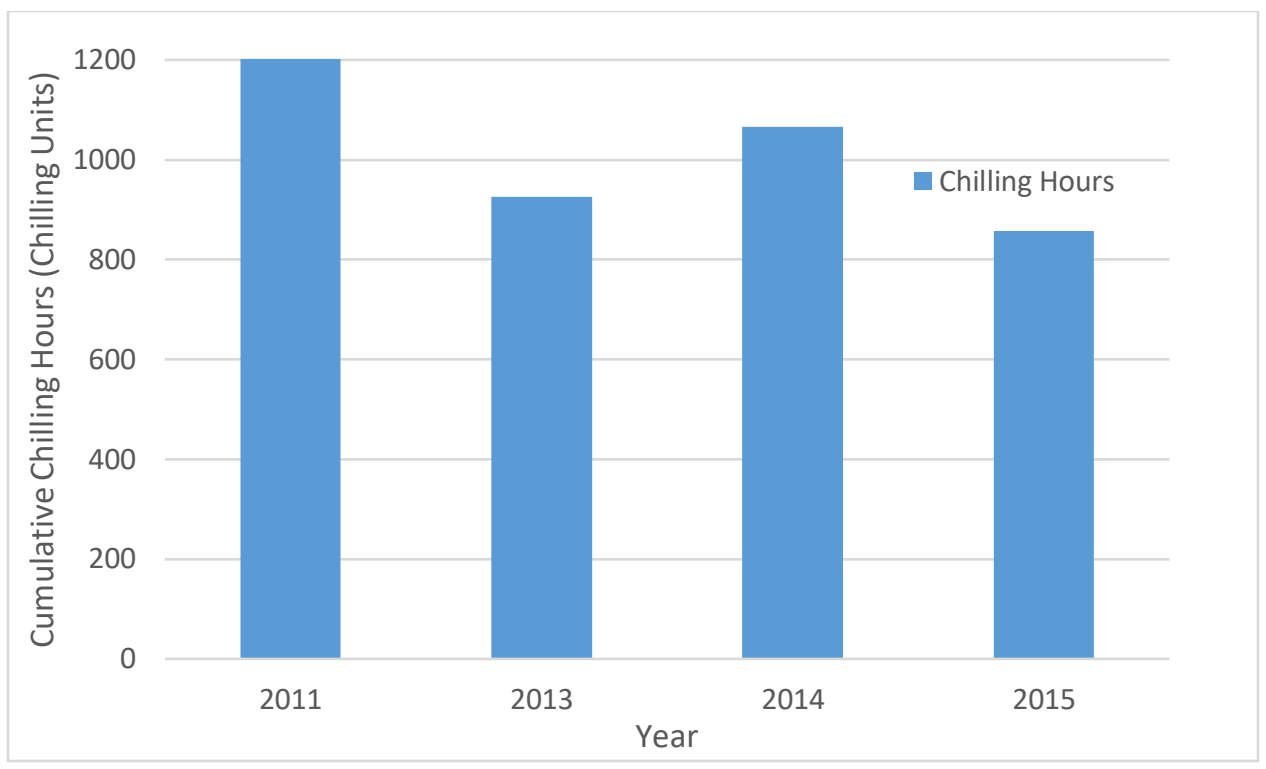

Figure 13. Cumulative chilling hours data in CU for the northwest side location, data gathered from CIMIS Station Blackwells Corner \#54, for the months November-February in 2011 and 2013-2015.

\section{$\underline{\text { 3.1.2 Soils }}$}

The parental material of Kern County soils was alluvium. Depending on the location, the runoff came from different origins (Sierra Nevada Range or Coast Range) forming alluvial fans and plains. The source of alluvial fan and plain materials in the west side came from the run off of the Coast Range. On the other hand, the origin of alluvial fans and plains in the east side subarea came from Sierra Nevada runoff. This led to formation of three of soil orders (Aridisols, Mollisols, and Entisols).

In the both of the east zones (NE, SE) of Kern County, Aridisols, Mollisols, and Entisols were the predominant soil orders found. In the west zone (NW, NE), the predominant soils were Aridisols and Entisols (Figure 14). Meanwhile, in NW zone's alluvial terraces, bordering San Luis Obispo County, the Vertisols type of soil order dominated. 


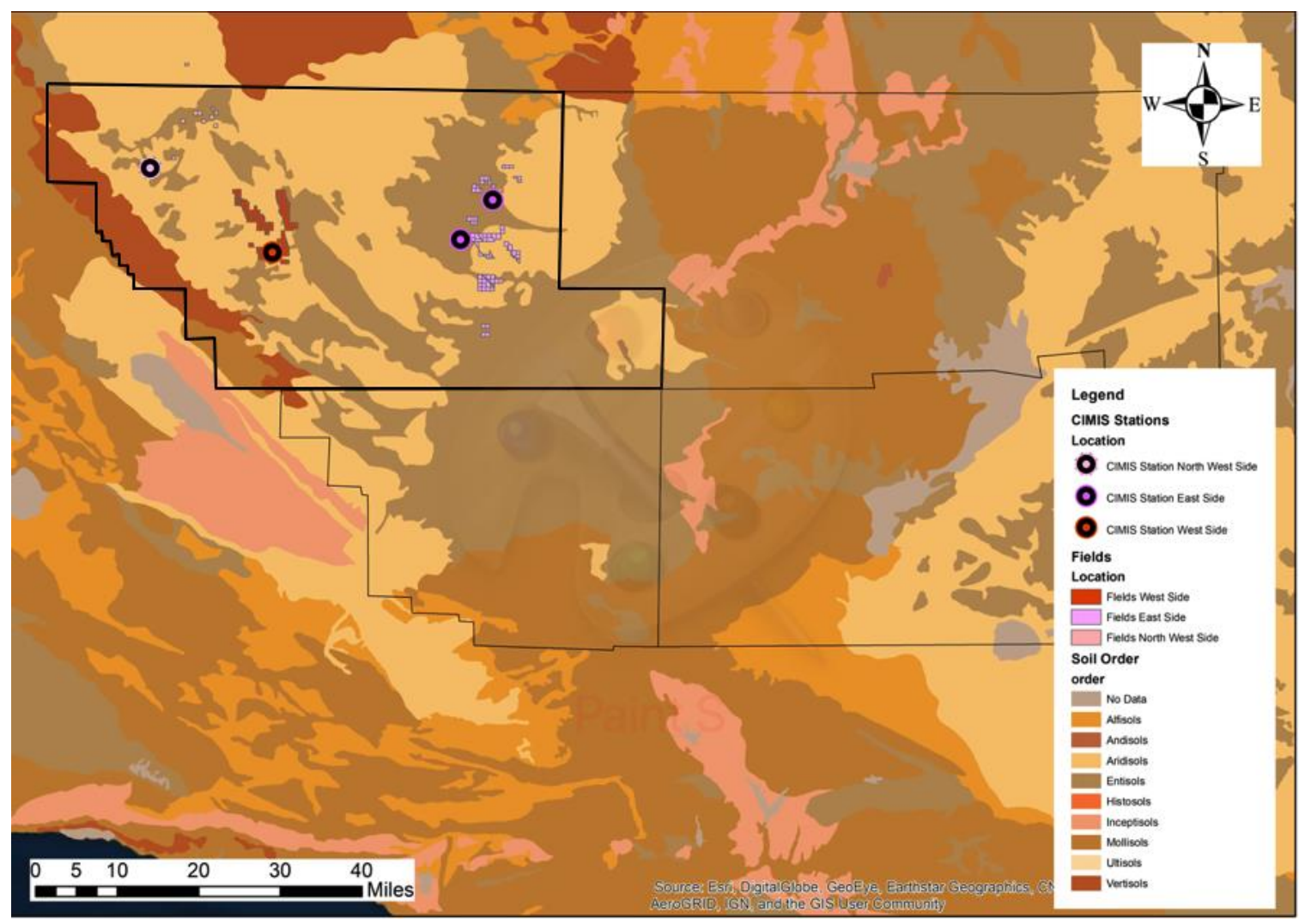

Figure 14. Soil order map for Kern County, CA. Kern County division classified by the USDA-NRCS soil survey. Data excerpted from USDA-NRCS 2018 using ArcGis 10.5.1 (ESRI,2017).

Fields are located in the northwestern part of Kern County where the majority of the soils order were Aridisol and Entisol (Figure 15). 


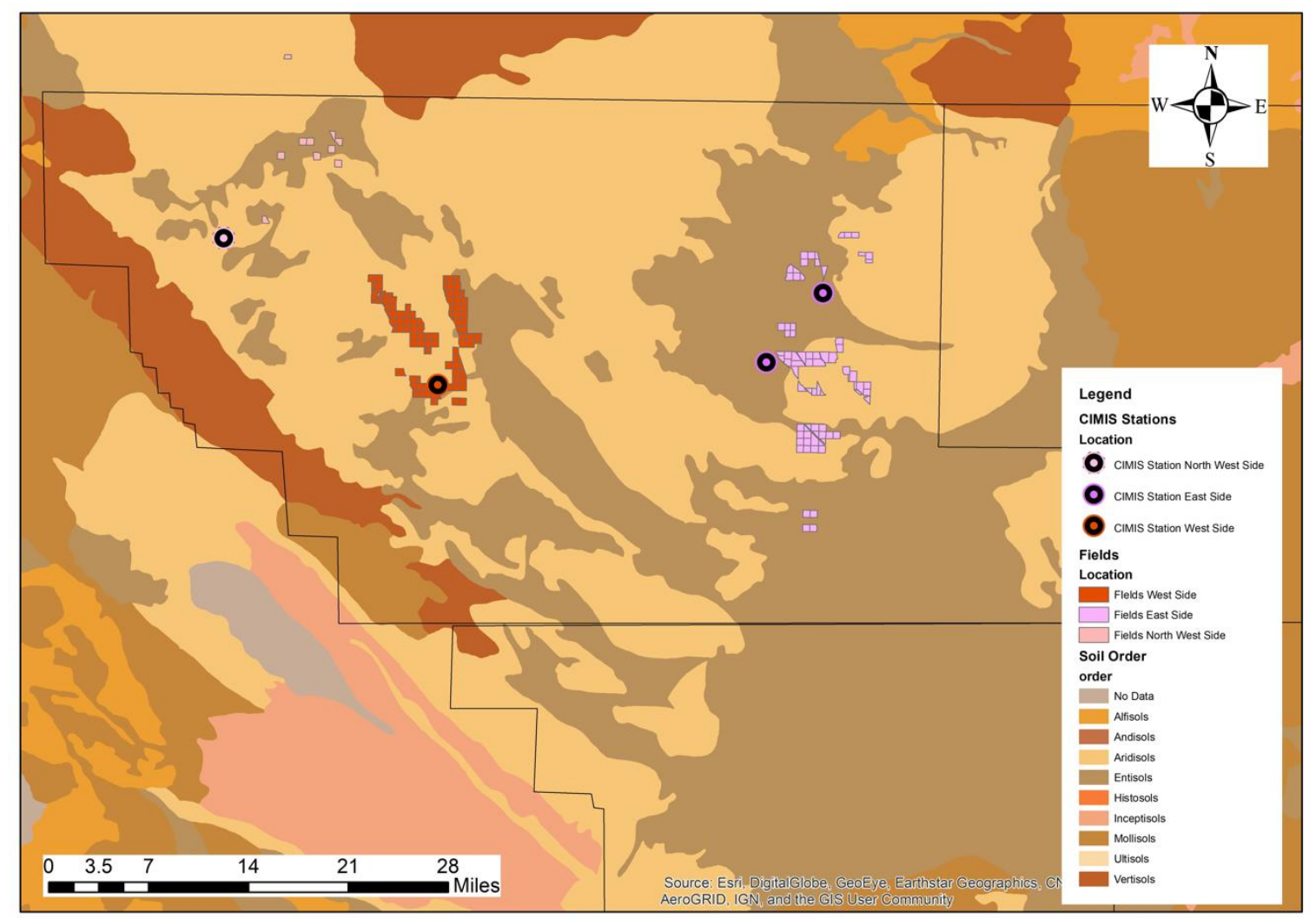

Figure 15. Soil order map for Northwestern part of Kern County, CA. Data excepted from USDA-NRCS 2018 using ArcGis 10.5.1 (ESRI,2017).

In contrast, fields in the east side location of the NW zone contained $44 \%$ Entisol and $56 \%$ Aridisol. However, the west side location, where the majority of the fields in this study were located had mostly Aridisols. The northwest side sub-area fields had more land with Entisols (82\%) than with Aridisols (18\%) (Table 6).

Table 6. Fields locations and soil orders in percentage of the total area of each of the three locations in Kern County North Western part, CA.

\begin{tabular}{lcccr}
\hline \multicolumn{1}{c}{ Location } & Number of & \multicolumn{2}{c}{ Soil Order } & \multirow{2}{*}{ Area (acres) } \\
& Fields & Entisol & Aridisol & \\
\hline East Side & 78 & $44 \%$ & $56 \%$ & 10193.01 \\
West side & 97 & $25 \%$ & $75 \%$ & 12545.32 \\
Northwest Side & 10 & $82 \%$ & $18 \%$ & 1320.22 \\
\hline \multicolumn{7}{c}{} \\
\hline
\end{tabular}


For the purposes of this study, soil data were obtained from the Natural Resources Conservation Service (Soil Survey Geographic Database (SSURGO)). This database contains 130 variables and is divided by geographic sub basins. In studying soil-water relationships, the variable used in this study was available water storage $0-100 \mathrm{~cm}$ (AWS 0-100 cm). Soil depth of 0-100 $\mathrm{cm}$ was examined, due to the fact that most of almond roots are found within this depth. The AWS 0-100 $\mathrm{cm}$ was measured in $\mathrm{cm} / \mathrm{m}$ and has a weighted average (Figure 16).

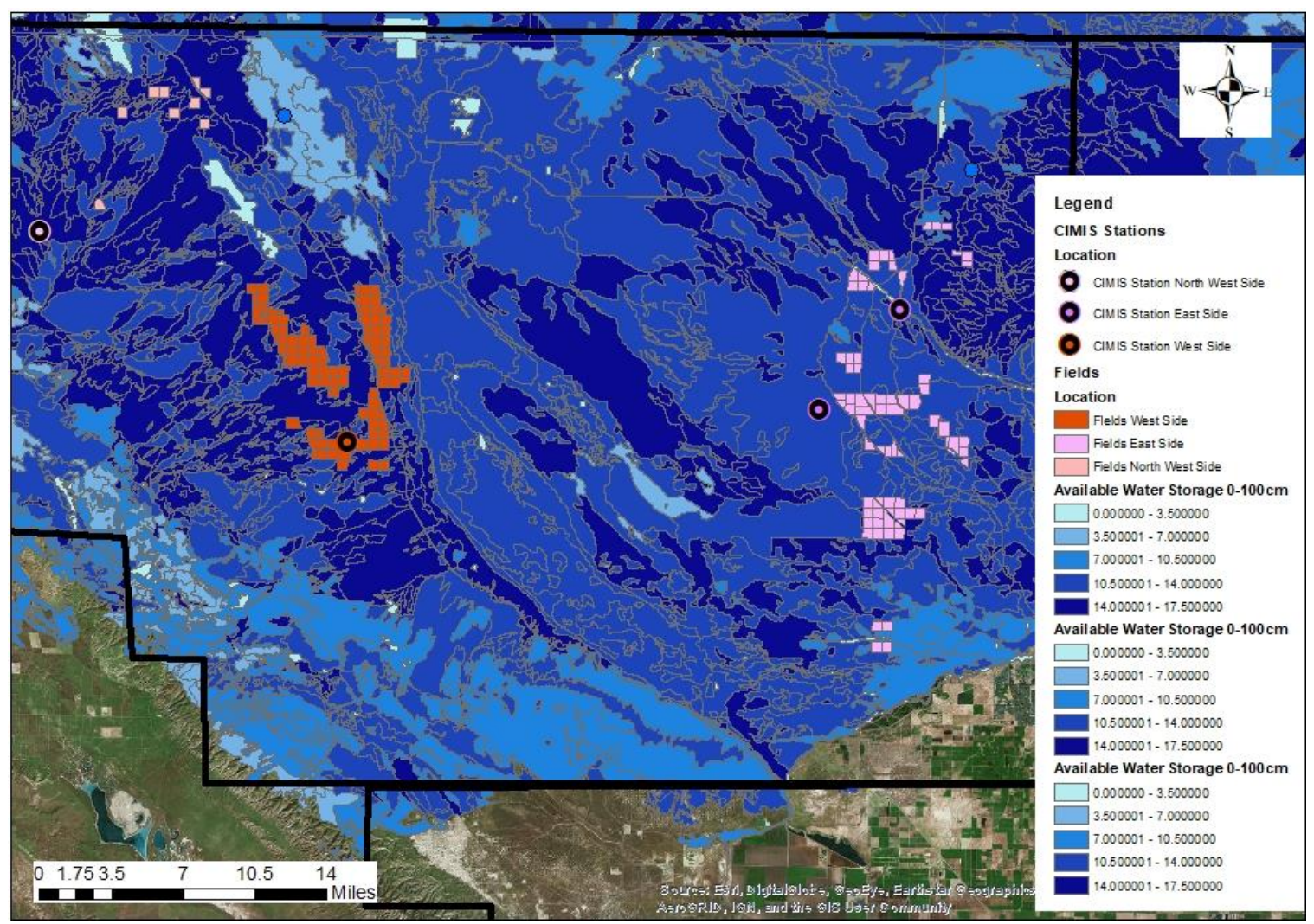

Figure 16. Field sites analyzed (east, west and northwest side) and CIMIS stations used location. In addition, Available water storage for a depth of $100 \mathrm{~cm}$ data in $\mathrm{cm} / \mathrm{m}$, in Northwestern part of Kern County, CA. Data excepted from USDA-NRCS 2018 using ArcGis 10.5.1 (ESRI,2017). 


\subsection{Evapotranspiration (ET)}

Remote sensing of ET in this study was made using ITRC-METRIC (Mapping Evapotranspiration at High Resolution with Internal Calibration) method using the modified version by Irrigation Training and Research Center (ITRC 2017). This method measured the actual ET. For calculating the ET with METRIC, two types of inputs were gathered from actual ground conditions: a thermal image gathered from a satellite, and ground based weather data.

The ITRC modified this method to have more precision with respect to California weather conditions compared to METRIC. The ITRC used high resolution images produced by LandSAT 8's hand ground-based data from CIMIS stations closest to each field.

The ITRC-METRIC used high resolution images in which a pixel covered an area of $30 \mathrm{~m} \times 30 \mathrm{~m}$ to calculate the ET of this area. The number of pixels analyzed varied depending on the size of the field. For each field, ET data of each pixel was used.

LanSAT 8 took an image every 16 days, and in each month, measuring actual ET of each field based on an average of the pixel ET. With these data, a statistical analysis was produced, including average ET, standard deviation, range, and maximum and minimum data of each field. In addition, monthly data from April to October for each of the years of the study was added to calculate annual ET. Annual ET of each field was used for the functional regression models that will be discussed in Data Collection and Analysis (Chapter 3.6). 


\subsection{Coefficient of Variation of Evapotranspiration (CV)}

Each field had its own mean ET, standard deviation ET, minimum ET, maximum ET, and range ET. The ET mean was used for calculating the ET in each month. However, because of the variability of ET data in each field, the study required that the coefficient of variation of ET was calculated monthly (April-October). To calculate coefficient of variation in each month the Equation [4] was used.

$$
C V=\frac{\sigma}{\mu} * 100 \%
$$

Where

$\mathrm{CV}$ : Coefficient of variation expressed in percentage

$\mu$ : Mean of the field

$\sigma:$ Standard deviation of the field

A weighted average was calculated for each of the months used to calculate yearly ET for calculating the coefficient of variation in a year. This was essential because the amount of ET in each month was not the same. For example, the highest ET values were always in July. Equation [5] was used to calculate the CV weighted average. 


$$
\mathrm{CV}_{\mathrm{w}}=\sum\left(\mathrm{CV}_{\mathrm{i}} * \frac{\mathrm{ET} \mathrm{i}}{\mathrm{ET} \mathrm{T}_{\text {total }}}\right)
$$

Where:

$\mathrm{Cv}_{\mathrm{w}}$ : Weighted average for a year of $\mathrm{CV}$

$\mathrm{CV}_{\mathrm{i}}$ : Coefficient of Variation of each month

$\mathrm{ET}_{\mathrm{i}}$ : represent $\mathrm{ET}$ of each month

$\mathrm{ET}_{\text {total }}$ : represent yearly ET

\subsection{Tree Age}

Almonds start producing two years after planting date, and are considered young trees after the second dormancy. Between the second and the fourth dormant period pruning techniques help develop the architecture of an almond tree (Krueger and Freeman 1996). Once the architecture has developed, an almond tree is considered a mature tree. For each of the years in this study (2011 and 2013-2015) the planting date was used to calculate tree age. Fields with trees aged two years or below were not used in the study.

\subsection{Yield}

Yield data were collected in each field. Data considered almond meat or almond kernel, which is almond that has been processed and does not have the hull and the shell. After collecting the data, yield was estimated using Equation [6] 


$$
\text { Yield }=\frac{\text { Total Production }}{\text { Total Area }}
$$

Where:

Yield: Pounds of almond kernel per acre in a year.

Total production: Data in pounds of almond kernel in a year.

Total Area: Data in acres. 


\subsection{Data Collection \& Analysis}

Data were collected, from 185 fields in California's Kern County. Total

production data were gathered from each field for the years 2011, 2013-2015. Then, using yield equation (Equation 6), yield per acre was estimated.

Evapotranspiration of each field was conducted using ITRC-METRIC тм (Mapping of Evapotranspiration with Internal Calibration), with data extracted using Arc GIS 10.5.1 (ESRI, 2017). The Arc GIS tool used was Spatial Analyst tool. The boundary of each field was made with Arc GIS 10.5.1 (ESRI, 2017). After the boundary was made, a raster file containing the ET of Kern County was synchronized (Figure 17).

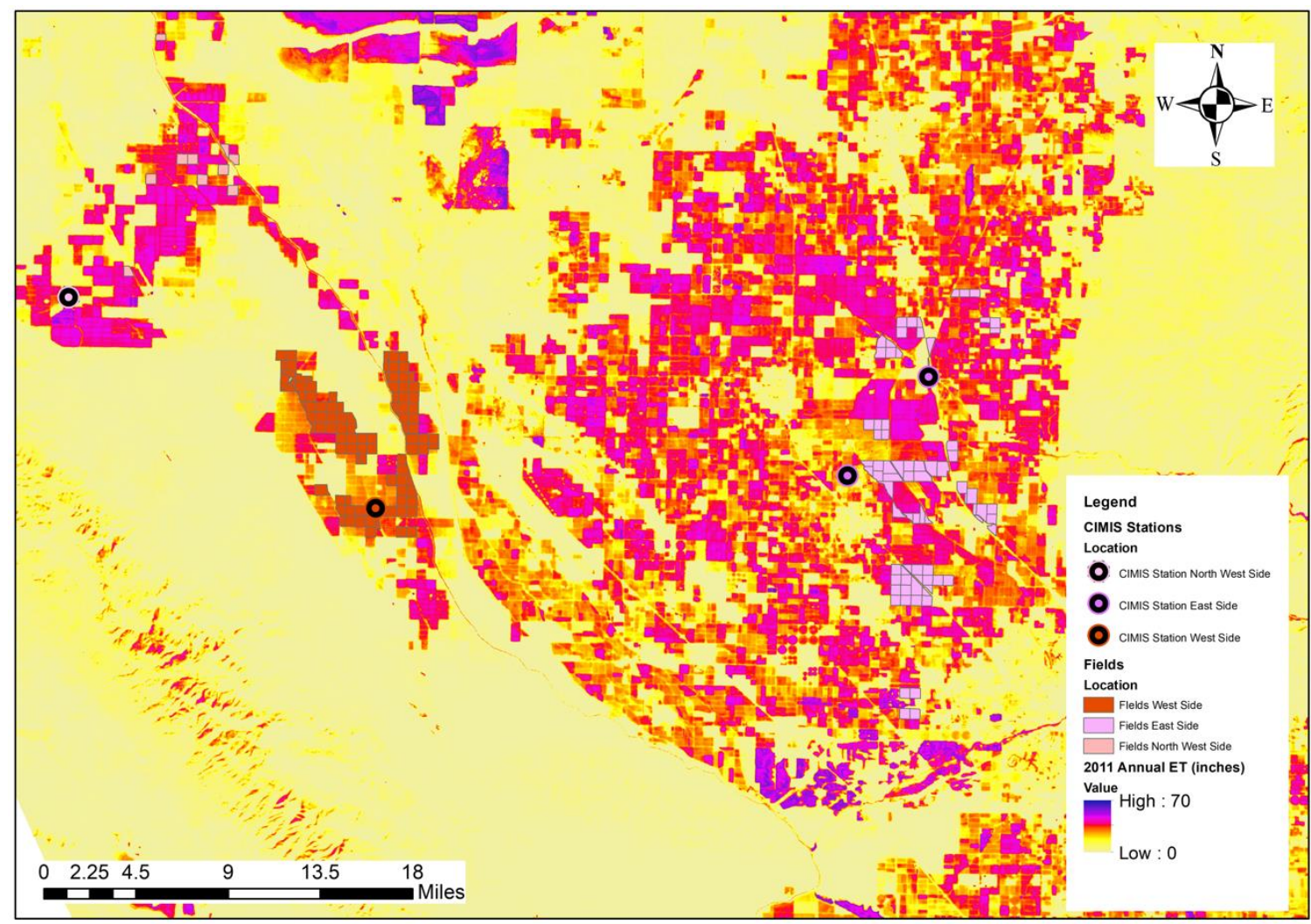

Figure 17. Annual ET measured by ITRC-METRIC (inches) in 2011 for Field sites analyzed (east, west and northwest side) and CIMIS stations used. Data extracted from ITRC-METRIC using Arcgis 10.5.1 (ESRI,2017). 
Evapotranspiration was extracted with a resolution of $30 \mathrm{~m}$ x $30 \mathrm{~m}$, and these data were calculated for each field. Each field had its own identification number. These data were then extracted to MS-Excel, which was used to organize the data (Microsoft, 2015). This process was calculated for each month from April to October during the years 2011 and 2013-2015.

The coefficient of variation $(\mathrm{CV})$ of ET was also calculated monthly using Equation 4 (April to October) for the period of time evaluated. This was accomplished with data extracted from Arc GIS 10.5.1 and then calculating it using MS-Excel (ESRI, 2017; Microsoft, 2015). Afterward, Equations [6] was used to calculate a coefficient of variation per year for each of the 185 fields in each of the 4 years of the study.

To describe and compare the effect of evapotranspiration on almond production in California--particularly during the drought (2013-2015) --three functional regression models were used. Model 1 described the statistical relationship between almond yield and ET, with ET as an explanatory variable and yield as a response variable. This model analyzed 185 field sites during the 4 years of the study having a total of 740 data points.

Model 2 described the statistical relationship between almond yield and ET after adjusting for year, location, cumulative chilling hours and precipitation. The variables that adjusted Model 2 are environmental variables that effected each field depending on its location. These variables also differed depending on the year evaluated. In particular in this study, Model 2 was used to describe year-to-year variations between a wet year (2011) and years with drought conditions (2013-2015).

Model 3 described the statistical relationship between almond yield and evapotranspiration after adjusting for location, tree age, soil available water storage and 
coefficient of variation (CV) of ET. The variables that adjust Model 3 vary in each field except location. Location itself is a categorical variable. Model 3 was used to describe within-year variations during the study's four years; each year of the study was evaluated separately.

A correlation and regression analysis were used for each of the three models and regression function and the correlation coefficient $\mathrm{R}^{2}$ were calculated. A least square mean difference student's t test was utilized to determine difference in mean yield for each year and each location. Statistical software JMP 13.2 Software was employed to run this analysis for the three models and $\mathrm{p}<0.05$ was the threshold to decide if each variable would be included or not in each model (JMP, 2016). 


\section{RESULTS \& DISCUSSION}

\subsection{Model 1}

Model 1 showed no linear association between almond yield per acre (y axis) and evapotranspiration (x axis) (Figure 18) with an $\mathrm{R}^{2}$ of $7.9 \%$. Although the equation for Model 1 would indicate a positive linear association between ET and almond yield, the low $\mathrm{R}^{2}$ showed that the model did not fit the data and; therefore, ET did not explain the variability of almond yield. Previously, Doorenbos and Kassam (1979) described a linear association between yield and evapotranspiration in almonds. However, their model could not often simulate field conditions, because these conditions have inherent variability (Igbadun et al. 2007) and so cannot be considered accurate.



Figure 18. Almond yield as a function of annual evapotranspiration in California's Central Valley (Kern County) for the months April-October in 2011 and 2013-2015 ( $n=185)$. 
The mean square response was 2314.02 pounds of almonds per acre (Table 7). This was the average yield during the 4 years of the study. The low $\mathrm{R}^{2}$ means that ET explains only $7.9 \%$ of the total variation in almond yield; therefore, there was $92.1 \%$ unexplained variability. Also notable, the r coefficient of correlation was 0.28.

Table 7. Model 1 summary of fit of Almond yield as a function of annual evapotranspiration in California's Central Valley (Kern County) for the months April-October in 2011 and 2013-2015 ( $n=185)$.

\begin{tabular}{lr}
\hline Summary of Fit Model 1 & Parameter \\
\hline RSquare & 0.079 \\
RSquare Adj & 0.077 \\
r Coefficient of Correlation & 0.281 \\
Root Mean Square Error & 774.721 \\
Mean of Response & 2314.021 \\
Observations (or Sum Wgts) & 734 \\
\hline
\end{tabular}

Studies on almonds have been done within a range of environments and considering a variety of cultivars. Usually these studies use different deficit irrigation techniques to lower the amount of actual evapotranspiration of the cultivar.

Steduto et al. (2012) in FAO published studies with correlation coefficients ranging from 0.87 to 0.98 ; thus, showing a strong association between evapotranspiration and almond yield. However, the results from Model 1 showed a low correlation coefficient (0.28). Furthermore, Goldhamer and Fereres (2017a) reported a high $\mathrm{R}^{2}$ (98.8\%) compared with the low $\mathrm{R}^{2}(7.9 \%)$ of Model 1. Data of Goldhamer and Fereres (2017a) and previous studies were all done in California, and done before 2012; therefore, they did not assume drought conditions. In addition, the fields were relatively close to each other in their study; thus, sharing similar climatic conditions. 
Doll and Shackel (2015) described that during drought conditions almond trees suffer from stress and yield is reduced. The physiological aspect of the decrease in yield is that during drought conditions, the trees close their stomata to avoid water loss. This closure of the stomata prevents carbon dioxide to enter the leaves. Therefore, photosynthesis is reduced and growth rate is slowed down (Shackel 1996).

In Model 1, the ET regression coefficient was 44.35 (Table 8), indicating that a change in 1 inch in ET will increase the average almond yield by 44.35 pounds per acre. The $\mathrm{p}$ value for ET was less than 0.0001, indicating that evapotranspiration helped explain the variability in almond yield. However, the $\mathrm{R}^{2}$ of the model is close to 0 , showing that the model was inaccurate.

Table 8. Model 1 parameter estimates of Almond yield (lbs/acre) as a function of annual evapotranspiration (inches) in California's Central Valley (Kern County) for the months April-October in 2011 and 2013-2015 (n=185). Alpha level $=0.05$.

\begin{tabular}{lrrrr}
\hline Term & Estimate & Std Error & t Ratio & Prob>|t| \\
\hline Intercept & 702.326 & 205.895 & 3.411 & $0.001^{*}$ \\
Apr-Oct ET (in) & 44.354 & 5.611 & 7.904 & $0.000^{*}$ \\
\hline Abbreviation and symbols: * $=$ P $<0.05$ & & & &
\end{tabular}

It can be suggested that this high unexplained variability in yield $(92.1 \%)$ was due to the differences in climate condition during the years of the study. Data from this study was field data collected from productive almond farms in Kern County during one wet year (2011) and 3 drought years (2013-2015). Drought conditions reduced the amount of water that the orchards received, as well as increasing the ET rate.

Water stress on almond trees can occur under hot and dry conditions even if soil moisture content is high (Shackel 1996). Micke (1996) reported that the optimal temperature for a leaf to photosynthesize is $65-105^{\circ} \mathrm{F}$. During summer in Kern County, daytime temperatures can exceed $105^{\circ} \mathrm{F}$; thus, reducing photosynthesis. 
By introducing "year" as a variable, the unexplained variability of almond yield should decrease, because the effects of drought years and a wet year could be taken into account--and the outcome of the regression model could possibly produce results closer to those reported by Goldhamer and Fereres (2017a) ( $\mathrm{R}^{2}$ 98.8\%). 


\subsection{Model 2: Year to Year Variation}

Year was introduced as an explanatory variable in Model 2. The introduction of year to the model caused the $\mathrm{R}^{2}$ to increase by $50.9 \%$ (Table 9) from $7.9 \%$ (Model 1) to $58.8 \%$. The unexplained almond yield variability decreased from $92.1 \%$ to $41.2 \%$. The later percentage indicated the variable "year" had a positive impact on explaining almond yield variability.

Climate conditions in each of the years of the study were different. Variables such as ET rate, precipitation and chilling hours changed from year to year. It was expected for Model 2 that $\mathrm{R}^{2}$ would increase due to incorporation of these conditions in the model.

Due to the fact of different climate conditions in each of the years of the study, the outcome of average yield was different depending on which year was analyzed.

Table 9. Model 2 summary of fit of Almond yield as a function of annual evapotranspiration after adjusting for year in California's Central Valley (Kern County) for the months April-October in 2011 and 2013-2015 (n=185).

\begin{tabular}{lr}
\hline Summary of Fit of Model 2 & Parameter \\
\hline RSquare & 0.588 \\
RSquare Adj & 0.586 \\
r correlation coeficcient & 0.766 \\
Root Mean Square Error & 518.66 \\
Mean of Response & 2314.02 \\
Observations (or Sum Wgts) & 734 \\
\hline
\end{tabular}

Average almond yield throughout the state of California progressively declined in each of the years of the study (USDA-NASS 2018) (Table 10). It can be suggested that the decrease in yield was due to climatic changes, and in this specific case to drought conditions. Richman and Leslie (2015) described the latest drought period (2011-2015) as 
unique. The wet season (October-March) had $<25$ th percentile of precipitation and $>75$ th percentile in average temperature (with data collected since 1895).

AghaKouchak et al. (2014) reported the extreme daily maximum temperature for 2014: During January, it exceeded the mean by $90 \%$. Therefore, evaporation from the soil increased and soil moisture content was reduced--even though almonds do not use water during this period of time, because they are in a dormant stage. In addition, this increase in maximum daily temperature can shorten the dormant period; therefore, chilling requirements would not be satisfied (Luedeling et al. 2012). This would consequently lengthen and delay flower formation and would produce problems such as bud drop and fruit set (Erez 2000). Table 10 shows average almond yield (lbs/acre) for the years

Table 10. Average almond yield (lbs/acre) for the years 2011, 2013-2015 in all the state of California. (Adapted from USDA/NASS, Pacific Regional Office 2018).

\begin{tabular}{rr}
\hline Year & Mean yield (lbs/acre) \\
\hline 2011 & 2540.00 \\
2013 & 2360.00 \\
2014 & 2150.00 \\
2015 & 2070.00 \\
\hline
\end{tabular}

Comparing yield data from this study (Table 11) to the average yield for the entire state of California (Table 10), the trends were similar showing a yield decrease through the years of the study.

The highest average almond yield was in 2011 (3229.09 lbs/acre) and the lowest was in 2015 (1786.78 lbs/acre) (Table 11). During drought years (2013-2015), yield was progressively reduced compared to a wet year (2011). Between 2011 and 2013, average almond yield significantly decreased (approximately 1000 lbs/acre) (Table 11). 
Goldhamer and Smith (1995) found lower average yield in a drought condition year in mature orchards in Fresno County (1476 lbs/acre) compare to our study in Kern County. Irrigation scheduling was based in ET with drip irrigation. However, in the same study in a normal year, the average yield was $2437 \mathrm{lbs} / \mathrm{acre}$. Therefore, the maximum relative yield was lower than our study (3229.09 lbs/acre to 2437lbs/acre).

Girona (2006) found an average yield of $1566 \mathrm{lbs} / \mathrm{acre}$. His study was made in a mature almond orchard in Spain. The irrigation system was micro sprinkler and irrigation scheduling was based on ET. The yield found by Girona was lower compared to our study during drought condition year (1786lbs/acre-2397 lbs/acre). Both Goldhamer and Smith (1995) and Girona (2006) studies were develop during the early 90's (Goldhamer and Smith from 1989 to 1991; Girona from 1990-1993).

On the other hand, Sanden et al. (2012) found an average yield of $4000 \mathrm{lbs} / \mathrm{acre}$ in Kern County. Their study was made in Kern County during the years 2008-2011. These years are considered non-drought conditions year. Comparing Sanden et al. (2012) yield to our yield in a wet year (2011), it can be observed that their average yield was higher (4000 lbs/acre to $3229.09 \mathrm{lbs} / \mathrm{acre})$.

Table 11. Average almond yield (lbs/acre) for the years 2011, 2013-2015 in California's Central Valley (Kern County) $(n=185)$. Alpha level $=0.05$.

\begin{tabular}{|c|c|c|}
\hline Level & Letter report* & Mean Yield (lbs/acre) \\
\hline 2011 & $\mathrm{~A}$ & 3229.0931 \\
\hline 2013 & B & 2397.1735 \\
\hline 2014 & $\mathrm{C}$ & 1833.0381 \\
\hline 2015 & $\mathrm{C}$ & 1786.7800 \\
\hline
\end{tabular}

*Different letter explains statistical difference.

The parameter estimates for Model 2 showed which of the variables in the model contributed to explaining the variability of almond yield (Table 12). Except for year 
2013, which had a $\mathrm{p}$ value of 0.092 , all the other variables were below $p<0.05$ and; therefore, helped explain the variability of almond yield.

The variable year 2013 did not have an effect on average yield showed in Model 1. In other words, there was no statistical difference between average yield of year 2013 to the average yield of Model 1 (Table 7).

Model 2 suggested that additional variables, such as precipitation, location and chilling hours would help explain almond yield variability.

Table 12. Model 2 parameter estimates of fit of almond yield (lbs/acre) as a function of annual evapotranspiration (inches) after adjusting for year in California's Central Valley (Kern County) for the months April-October in 2011 and 2013-2015 (n=185). Alpha level=0.05.

\begin{tabular}{lrrrr}
\hline Term & Estimate & Std Error & t Ratio & Prob>|t| \\
\hline Intercept & 718.58 & 148.79 & 4.83 & $<0.0001^{*}$ \\
Apr-Oct ET (in) & 43.83 & 4.06 & 10.79 & $<0.0001^{*}$ \\
Year[2011] & 911.61 & 33.07 & 27.56 & $<0.0001^{*}$ \\
Year[2013] & 56.18 & 33.30 & 1.69 & 0.0920 \\
Year[2014] & -577.69 & 34.43 & -16.77 & $<0.0001^{*}$ \\
\hline Abbreviation and symbols: * $=\mathrm{P}<0.05$ & & & &
\end{tabular}

\section{$\underline{4.2 .1 \text { Location }}$}

Fields were classified according to their location in Kern County and the distance to the closest CIMIS station. In Figure 19, a trend regarding almond yield can be observed for each location during the years of the study. Comparing the trend for each location to overall average almond yield in Table 12 led to considering the introduction of additional explanatory variables to decrease unexplained variability of almond yield in Model 2, so that variable "Year 2013" would also fall below $\mathrm{p}<0.05$. 


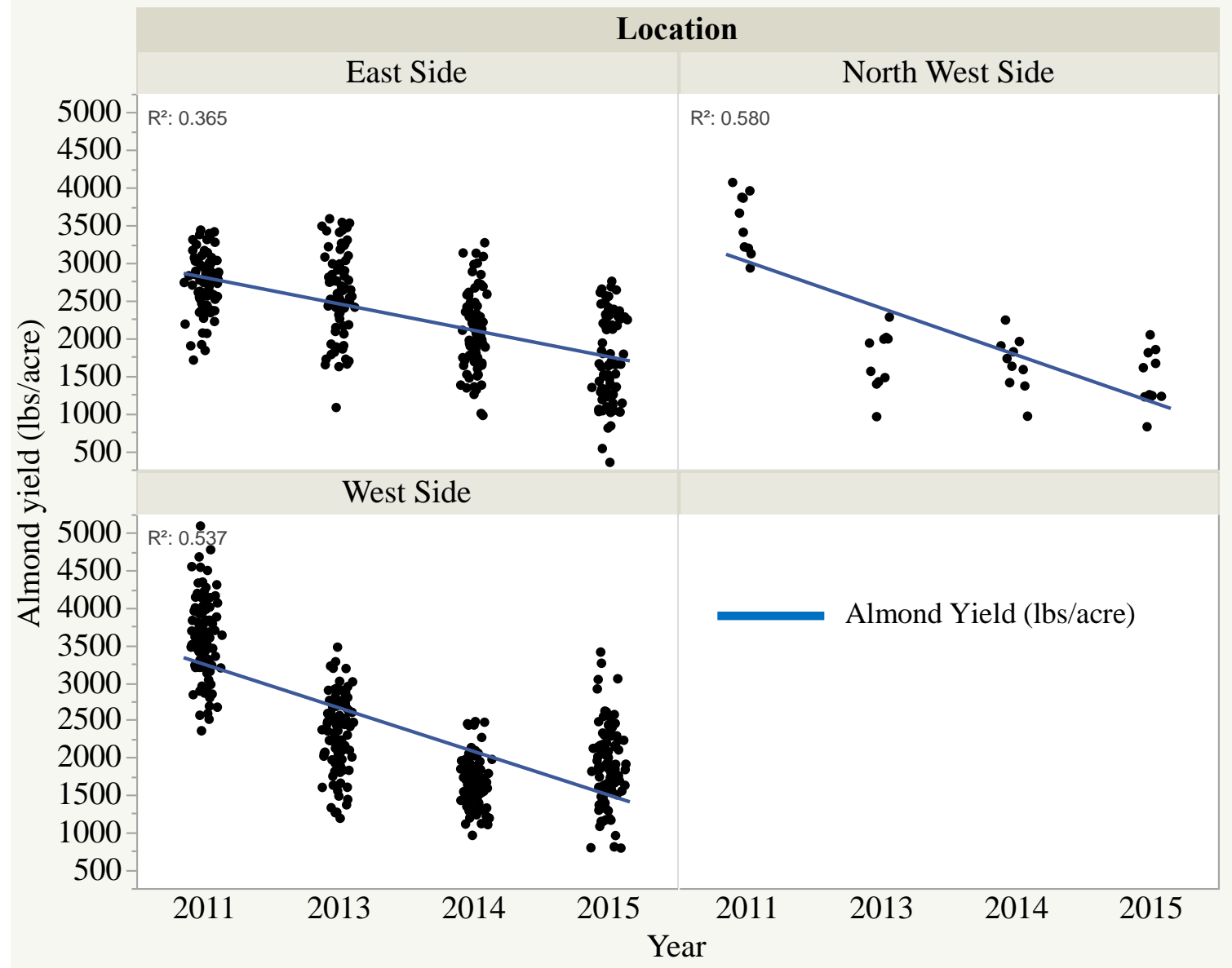

Figure 19. Almond yield (lbs/acre) as a function of year and geographic area in California's Central Valley (Kern County) for the years 2011, 2013-2015(n=185).

\subsubsection{East Side}

Average almond yield did not have a significant difference between years 2011 and 2013 (Table 13). Clearly, these results did not support the theory regarding lower yields during drought conditions. However, there was a significant decrease in yield between 2011 and 2013 compared to 2014. Year 2015 had the lowest average yield (1709.46 lbs/acre) (Table 13).

The decrease in precipitation between 2011 and 2013 was $75 \%$ for the east side (Figure 8). However, there was no statistical difference between average yield during these same years. Cumulative chilling hours (CU), did not have an abrupt change 
(decrease in 5\% from 2011 to 2013) (Figure 12). Additional explanatory variables for the east side were needed to support the theory of lower yield during drought conditions year.

Table 13. Average almond yield (lbs/acre) for the years 2011, 2013-2015 in east side location of Kern County, CA (n=97). Alpha level $=0.05$.

\begin{tabular}{|c|c|c|c|c|}
\hline Level & \multicolumn{2}{|r|}{ Letter report* } & & $\begin{array}{r}\text { Mean Yield } \\
\text { (lbs/Acre) }\end{array}$ \\
\hline & 2011 & A & & 2716.4257 \\
\hline & 2013 & A & & 2596.4294 \\
\hline & 2014 & B & & 2080.3368 \\
\hline & 2015 & & $\mathrm{C}$ & 1709.4676 \\
\hline
\end{tabular}

*Different letter explains statistical difference

\subsubsection{West Side}

There was significant difference observed in average almond yield during each of the 4 years of the study in the west side location (Table 14). The highest yield was in 2011 with an average yield of $3610 \mathrm{lbs} / \mathrm{acre}$; the lowest average yield was in 2014 with $1657 \mathrm{lbs} /$ acre. There was also a considerable difference between the highest and lowest average yield (approximately 2000 lbs/acre). Also, there was a significant difference in average yield between 2011 and 2013 of approximately 1300 lbs/acre.

The trend in the west side led us to suggest that the decrease in almond yield was due to drought conditions (Table 14). The low precipitation during 2013-2015 (compared to 2011) could have led to poor soil moisture content (Figure 9) --reduction in precipitation during 2011 to 2013 was almost 80\%. Notably, the lowest average yield year (2014) matched the lowest precipitation (1.06 inches) during the years of the study (2014). 
Table 14. Average almond yield (lbs/acre) for the years 2011, 2013-2015 in west side location of Kern County, CA $(n=78)$. Alpha level $=0.05$.



*Different letter explains statistical difference

\subsubsection{North West Side}

There was a significant difference in average almond yield between a wet year (2011) and drought years (2013-2015) on the northwest side of Kern County (Table 15). There was no statistical difference between average almond yield during drought condition years (2013-2015). The difference in average yield between the wet year and drought condition years was approximately $2100 \mathrm{lbs} / \mathrm{acre}$.

Northwest side precipitation for year 2011 was the lowest when it was compared to west and east side fields (Figure 11). However, this location's average almond yield during 2011 was not the lowest one of the three. There are marked similarities between the precipitation trend and average almond yield trend for the northwest side: During drought conditions years (2013-2015) the average yield did not have a statistical difference. The precipitation in the same period also did not change (i.e., was less that $4 \%)$. 
Table 15. Average almond yield (lbs/acre) for the years 2011, 2013-2015 in north west side location of Kern County, CA $(n=10)$ Alpha level $=0.05$.

\begin{tabular}{rlrr}
\hline Level & Letter report* & & $\begin{array}{r}\text { Mean Yield } \\
\text { (lbs/acre) }\end{array}$ \\
\hline 2011 & A & & 3527.1441 \\
2013 & & B & 1695.123 \\
2014 & B & 1653.601 \\
2015 & B & 1466.9721 \\
\hline
\end{tabular}

*Different letter explains statistical difference

\subsubsection{Chilling hours and Precipitation}

Cumulative chilling hours and precipitation differed in each of the three locations

(Figures 8-13). After introducing chilling hours and precipitation as explanatory variables into Model 2, the $\mathrm{R}^{2}$ increased from $58.8 \%$ to $62.6 \%$ (Table 16), thus reducing the unexplained almond yield variability.

Table 16. Summary of fit estimates of Almond yield as a function of annual evapotranspiration after adjusting for year, location, precipitation and chilling hours in California's Central Valley (Kern County) for the months April-October in 2011 and 2013-2015 $(n=185)$.

\begin{tabular}{lr}
\hline Summary of Fit Model 2 & Parameter \\
\hline RSquare & 0.626 \\
RSquare Adj & 0.622 \\
Root Mean Square Error & 496.12 \\
Mean of Response & 2314.02 \\
Observations (or Sum Wgts) & 734 \\
\hline
\end{tabular}

After introducing precipitation, chilling hours and location into Model 2, the parameter estimates showed that each of these new variables helped explain the yield variability (Table 17). The p value for 2013, without additional climatic variables (precipitation and chilling hours) and locations, was 0.092. However, with the additional variables the $\mathrm{p}$ value was $<0.05$. 
The $37.4 \%$ unexplained yield variability in Model 2 suggests that additional factors were affecting the variability of the almond yield. These factors could be environmental or due to agricultural practices. It was assumed that year 2011 was a wet year because of the high precipitation before April (Figures 8-10), and that the years 2013 to 2015 were drought years due to low precipitation (Figures 8-10). The parameter estimates of Model 2 cannot be compared to other studies due to its high unexplained variability $\left(\mathrm{R}^{2}=62.4 \%\right)$.

Table 17. Parameter estimates for Model 2 of almond yield (lbs/acre) as a function of annual evapotranspiration (inches) after adjusting for year, location, precipitation (inches) and chilling hours (CU) in California's Central Valley (Kern County) for the months April-October in 2011 and 2013-2015 (n=185). Alpha level $=0.05$.

\begin{tabular}{llllc}
\hline Term & Estimate & Std Error & t Ratio & Prob>|t| \\
\hline Intercept & 499.816 & 371.72 & 1.34 & 0.1792 \\
Apr-Oct ET (in) & 49.478 & 4.165 & 11.88 & $<0.0001^{*}$ \\
Cumulative Chilling Hours & 0.853 & 0.311 & 2.74 & $0.0063^{*}$ \\
Precipitation & -257.299 & 43.781 & -5.88 & $<0.0001^{*}$ \\
Location[East Side] & 311.883 & 55.902 & 5.58 & $<0.0001^{*}$ \\
Location[North West Side] & -445.347 & 59.099 & -7.54 & $<0.0001^{*}$ \\
Location[West Side] & 133.464 & 47.318 & 2.82 & $0.0049^{*}$ \\
Year[2011] & 2244.209 & 237.14 & 9.46 & $<0.0001^{*}$ \\
Year[2013] & -439.939 & 86.606 & -5.08 & $<0.0001^{*}$ \\
Year[2014] & -1301.933 & 120.47 & -10.81 & $<0.0001^{*}$ \\
Year[2015] & -502.337 & 85.134 & -5.90 & $<0.0001^{*}$ \\
\hline Abbreviation and symbols: * $=\mathrm{P}<0.05$ & & & &
\end{tabular}

Focusing on precipitation, it can be suggested that the decrease in average yield was because of this variable. Esparza et al. (2001) found that precipitation or irrigation after harvesting and before blooming (October- March) had an impact on yield. During approximately the same period, Griffin and Anchukaitis (2014) found that due to drought conditions, soil moisture in California was below average for the years 2012-2014 (November-April). 
Vegetative growth developed from dormant meristems usually begins in late February or early March; this process is completed when full leaf expansion is achieved. This physiological growth process is essential because shoots and leaves are required for fruit position and as a carbohydrate reserve for future yields (Doll 2017). During this vegetative growth process almond trees begin using water that was stored in the soil, and during the winter usually the almond trees grow stress free due to adequate soil moisture conditions. If the soil does not have the optimal soil moisture content, vegetative growth will be negatively impacted; thus, a reduction of yield would be expected (Rafael Socias i Company and Gradziel 2017).

Precipitation during the months in which the cultivar is dormant helps increase the soil moisture content until field capacity, but also reduces salinity levels due to salt leaching. If precipitation does not fill the soil to the point of saturation, salt leaching due to deep percolation is not achieved. Doll (2014) recommended leaching salts during the dormant season or when the ET of almond trees is low.

During the study, a vast majority of the fields analyzed were made up of Aridisol soils. This soil order is often characterized as saline soil (Dregne 1976). With the reduction of precipitation, and with less water available due to drought conditions, salt accumulation would be expected.

The amount of cumulative (winter) chilling hours did not show a high variability during the years of the study. Indeed, drought conditions did not affect the number of cumulative chilling hours, even though during these years, the mean daily temperature during the winter was high (Richman and Leslie 2015). 
Egea et al. (2003) reported different chilling requirements for different almond cultivars. The variability reported by Egea et al. (2003) ranged from 266-966 CU for the 10 cultivars analyzed.

Comparing chilling units measured during the years of this study (2011 and 20132015) to those reported by Egea et al. (2003), chilling requirements were fulfilled in all three (east, west and northwest) locations. Ostensibly, per results of Egea et al. (2003), cumulative chilling hours could be excluded from Model 2. However, cumulative chilling hours helped explain the variability in the model with a $\mathrm{p}<0.05$ (Table 17). 


\subsection{Model 3: Within-Year Variation}

Model 3 described the variations in almond yield between fields--within the same year, for each of the years of the study. The association between yield per acre and evapotranspiration is shown in Figure 20 for each of the years of the study. The $R^{2}$ in each year was low compared to different studies reported by Goldhamer et al. (2012) ( $\mathrm{R}^{2}$ $93.2 \%$ to $98.9 \%)$.

The highest $\mathrm{R}^{2}$ in this study was in 2015 , with an $\mathrm{R}^{2}$ of $26.5 \%$. The high variability could be attributed to the different location of each field, different soil available water storage and/or coefficient of variation of ET. In summary, additional predictor variables were needed to help explain almond yield variability. 


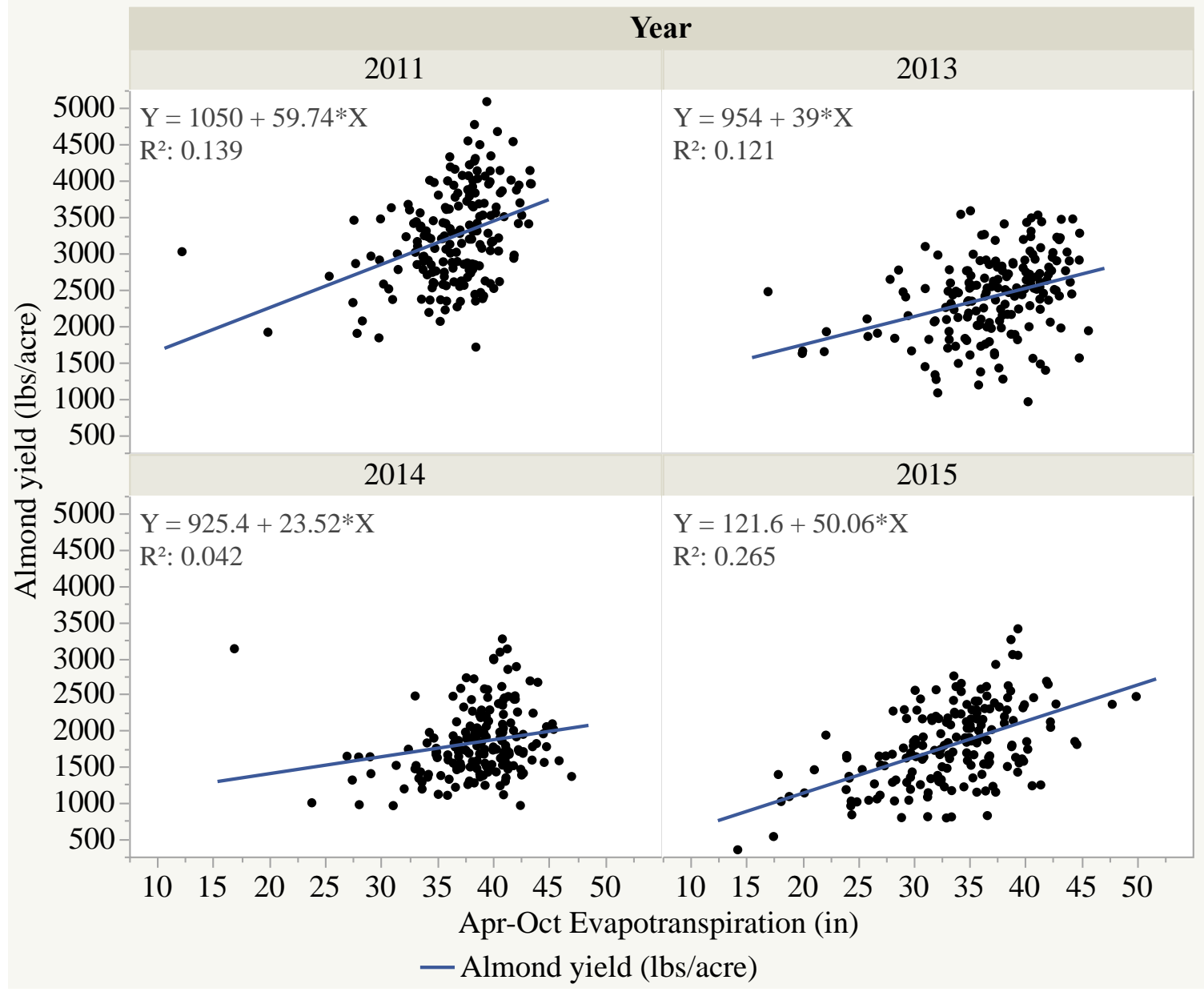

Figure 20. Almond yield as a function of annual evapotranspiration and year in California's Central Valley (Kern County) for the months April-October in 2011 and 2013-2015 (n=185).

\subsubsection{Explanatory Variables}

Chilling hours and precipitation were not included as explanatory variables in

Model 3. This was done because fields in the same location would have had the same precipitation and chilling hours. It was assumed that introducing location in Model 3 would help reduce the unexplained variability of almond yield. 


\subsubsection{Tree age}

Figure 21 shows the association between almond yield and tree age within the years 2011, 2013-2015. The $\mathrm{R}^{2}$ in each year showed the association between almond yield and tree age. These results led to introducing tree age as a variable into Model 3 for the purpose of reducing the unexplained variability in almond yield.

In 2011, all of the almond trees evaluated in the study were above 8 years of age (Figure 21). Because the same fields were evaluated during the study's subsequent years, all trees considered in the study were adults ( $>4$ years) and had full canopy cover. Therefore, evapotranspiration and yield were not affected by trees that had not reached the mature stage. 


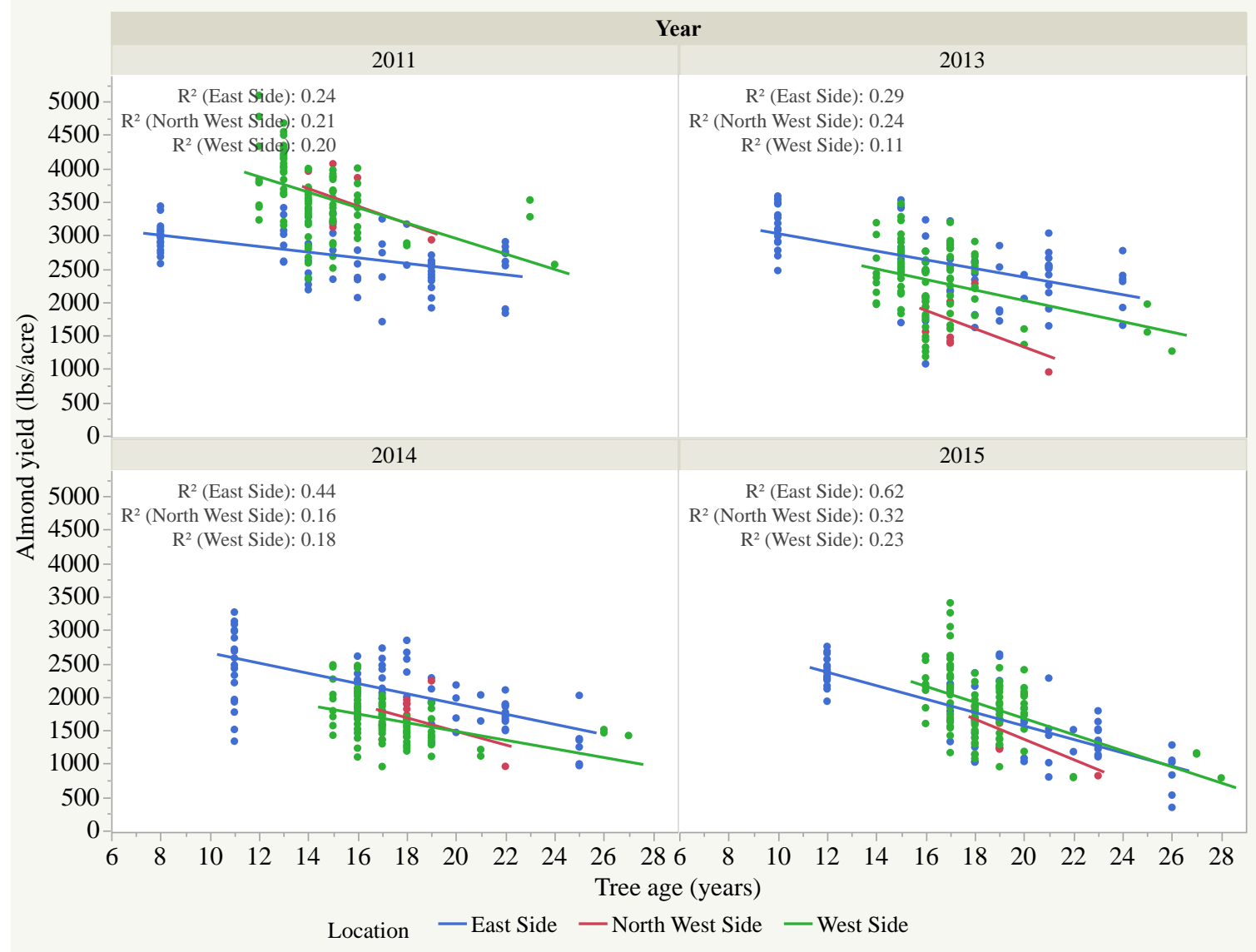

Figure 21. Almond yield as a function of tree age and year in three locations of Kern County, CA for the years 2011 and 2013-2015 $(n=185)$.

Krueger and Freeman (1996) stated that almond trees reach maturity stage after between 10 and 15 years of growth, depending on the cultivar. By the time trees reach this stage, they become less vigorous and yield is reduced. Pruning techniques to invigorate trees are recommended. Usually these practices are done when the trees are 9 to 10 years old.

On the other hand, Micke et al. (1991) reported that pruning techniques will not improve vigor or yield, and other management practices should be considered if an orchard's yield is decreasing. Krueger and Yeager (1998) concluded that yield will not decrease due to the lack of fruitwood renewal or pruning practices. And Arquero and 
Jarvis-Shean (2017) describe pruning as an important practice for other reasons, but not to maintain yield. Thus, although pruning techniques are a practice commonly used on almond farms, it was beyond the scope of this study to evaluate the effect of pruning techniques in yield. From studies cited above, it can be suggested; however, that the negative association between tree age and yield could be due to tree maturity and not due to management practices.

Figure 22 show the association between evapotranspiration and tree age. In each location, ET and tree age did not show any type of association $\left(\mathrm{R}^{2}<10 \%\right)$.

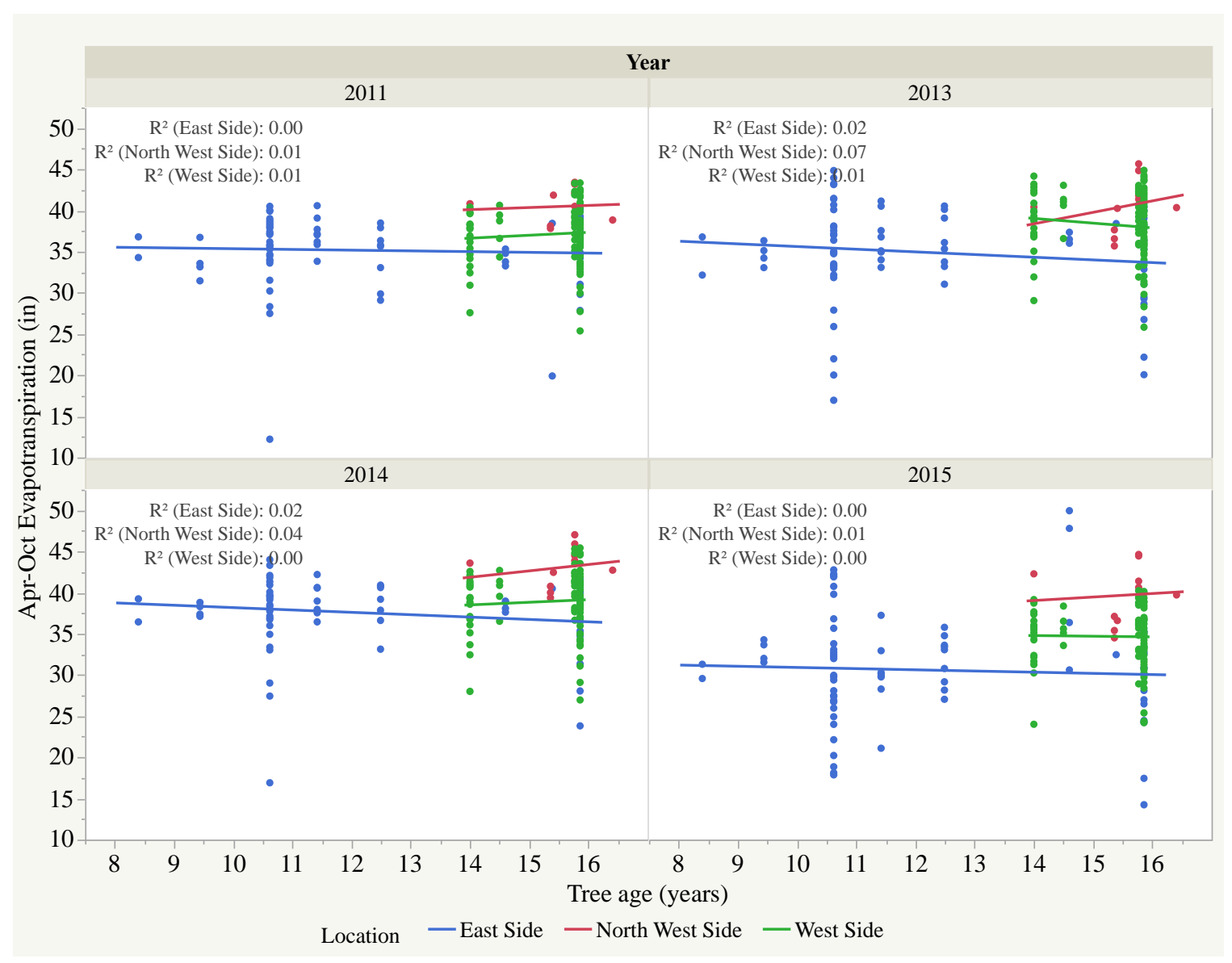

Figure 22. Evapotranspiration as a function of tree age and year in three locations of Kern County, CA for the years 2011 and 2013-2015 $(n=185)$. 
Arquero and Jarvis-Shean (2017) define a mature tree as a tree that has completely established its architecture or has full canopy. This usually happens after the third or fourth dormant season. Therefore, evapotranspiration was not affected by the age of the trees in the study because the youngest tree was 8 years old (in year 2011).

Allen and Pereira (2009) found that the amount of canopy cover influenced the evapotranspiration. They define that when full canopy cover has been reached, the rate of phenological growth depends on plant genotype than on weather conditions; therefore, photosynthesis rate and evapotranspiration rate will be similar. Given Allen's results, in the Kern county study, the lack of association between evapotranspiration and tree age was expected.

\subsubsection{Soil Available Water Storage (AWS)}

Soil available water storage was evaluated as an explanatory variable to help explain the variability of almond yield in Model 3. The association between almond yield and soil AWS had a markedly low $\mathrm{R}^{2}$ for each year, leading to the conclusion that soil AWS would not reduce the unexplained variability of almond yield. Soil AWS did not change during the years the study was conducted--thus, it was a fixed value for every year of the study.

As stated in the literature review, almond roots can reach to a depth of 3 meters (Alonso 2017). However, 75\% or more of the roots are found in the upper 0.7-1.0 meters (Catlin 1996). Goldhamer (1996) reported an allowable depletion of water (AD) of 30$40 \%$ in shallow clayed soils under hot and windy conditions as the maximum allowable depletion before almond yield would be affected. In mild weather, with a deep-rooted crop and sandy soil could tolerate 70-80\% AD before yield was affected. In California, 
farmers usually use a maximum allowable depletion (MAD) of $50 \%$ as a parameter for irrigation scheduling (Goldhamer 1996).

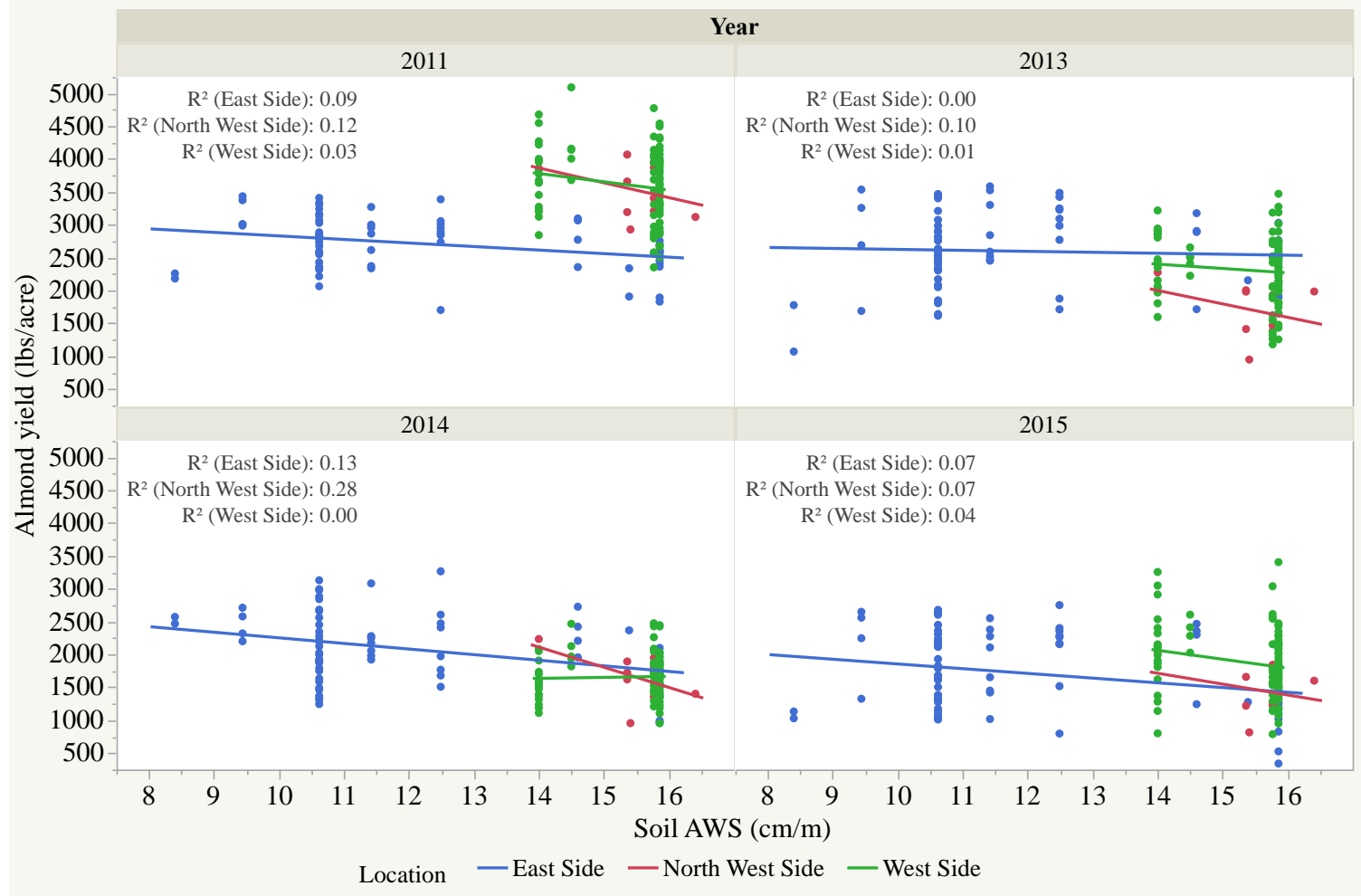

Figure 23. Almond yield as a function of soil available water storage and year in three locations of Kern County, CA for the years 2011 and 2013-2015 (n=185).

Considering the AWS and MAD, the smallest soil AWS within the entire evaluated field was $(8.4 \mathrm{~cm} / \mathrm{m}$ or $3.3 \mathrm{inch} / 3 \mathrm{ft})$, and with the smallest MAD (30\%) reported in Chapter 2, the available water would be $1 \mathrm{inch} / \mathrm{ft}$. Even in this scenario, the soil moisture depletion would give farmers high flexibility during irrigation scheduling: depending on the climate conditions. For example, the maximum ET for a day could range from 0.25 inches to 0.3 inches. It can be assumed this high flexibility is the reason why no association between soil AWS and yield was observed. 
Evapotranspiration and soil AWS were modeled for the years 2011, 2013-2015, with no association observed between these variables. The $\mathrm{R}^{2}$ in each year and location was $<10 \%$ (Figure 24).

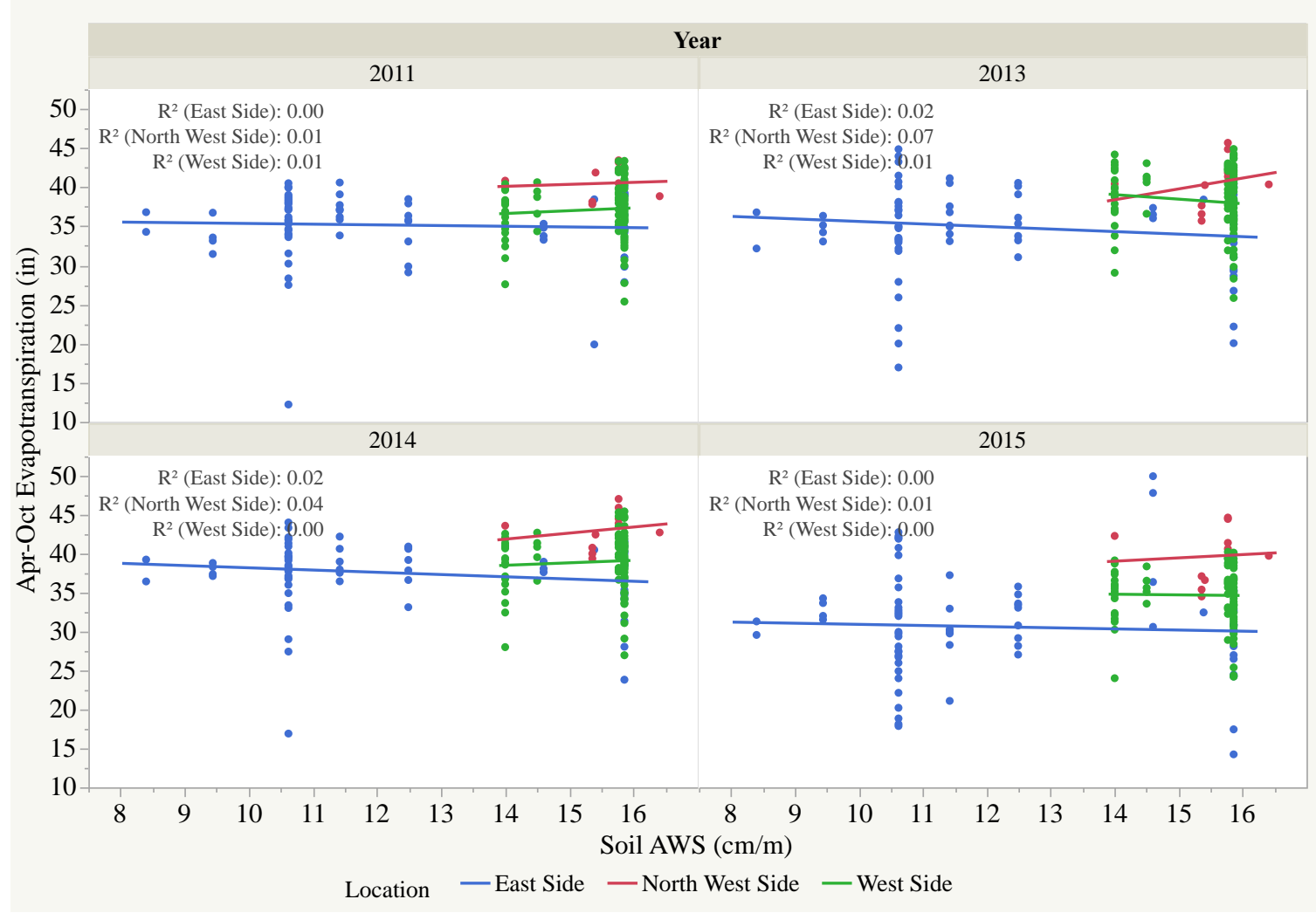

Figure 24. Evapotranspiration as a function of soil available water storage and year in three locations of Kern County, CA for the years 2011 and 2013-2015 ( $n=185)$.

During drought conditions, positive association between evapotranspiration and soil AWS was expected to have. High soil AWS stores more water in winter--usually a time of higher precipitation-- which can be used in subsequent months; therefore, reducing water stress on almonds trees.

Most likely, in this study low precipitation during drought conditions years (20132015) caused soil moisture content to be low. Compounding this scenario, as Richman and Leslie (2015) described, the $>75$ th percentile in average winter temperature (since 
1895) led to high water loss due to evaporation from the soil, potentially promoting water stress and salt built up (Doll 2014).

In 2015, despite 3 years of drought conditions, there was no association between evapotranspiration and soil AWS: it is possible that this is because farmers usually irrigate until the soil reaches field capacity--the highest amount of plant available water--. After the first irrigation, farmers irrigate according the needs of the orchard (Schulbach and Schwankl 1996).

Soil AWS was excluded from Model 3 due to low $\mathrm{R}^{2}$, and the lack of evidence just discussed. In Appendix B, Model 3 did include soil AWS during each year of the study for the purpose of showing that $\mathrm{R}^{2}$ increased for each year was negligible. $\left(\mathrm{R}^{2}\right.$ adjusted: difference $<2 \%$ ).

\subsubsection{Coefficient of Variation (CV) of Evapotranspiration}

There was a low association between yield and CV of ET in each of the years of the study, 2011, and 2013-2015 (Figure 25). The $\mathrm{R}^{2}$ values were relatively low $(<10 \%)$ for the years 2011, 2013 and 2014. In 2015 the $\mathrm{R}^{2}$ was highest compared to the other years; however, still less than $20 \%$. 


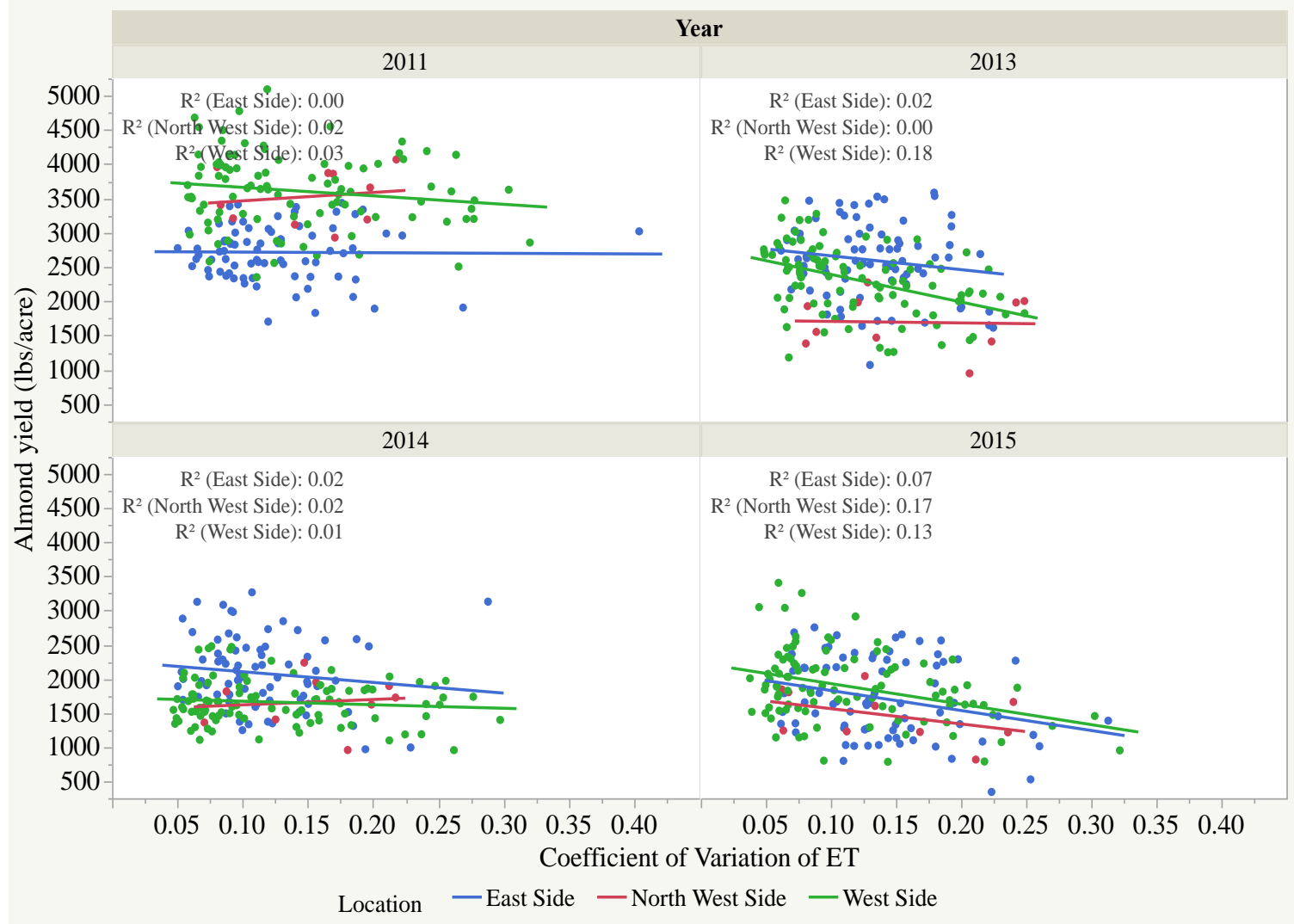

Figure 25. Almond yield as a function of coefficient of variation of evapotranspiration and year in three locations of Kern County, CA for the years 2011 and 2013-2015 ( $n=185)$.

Howes and Gaudi (2012) found that irrigation uniformity had a significant effect on ET uniformity. Therefore, it can be assumed that CV of ET is a way of measuring irrigation uniformity in a field.

It is possible that higher CV of ET values from this study's Kern county sites were due to poor distribution uniformity (DU) of the applied water. On the other hand, it is possible that lower $\mathrm{CV}$ of ET values were due to high DU of the applied water. However, other environmental and agronomic factors such as soil type, pruning techniques, tree age, diseases and fertilization could also be responsible for reducing ET uniformity. 
Fields observed during the study were in actual income-producing almond orchards that make up a key part of the local economy, rather than experimental sites with controlled conditions. These farms cannot afford to utilize poor agronomic practices that could reduce yield. Thus, it can be assumed that each field had adequate management practices reducing the possibility of low ET uniformity.

In 2008, using the same variables, Montazar and Sadeghi (2008) found a positive association between DU of the applied water and yield in their study on alfalfa. Their study used sprinkler irrigation as the irrigation system. In another study, Santos (1996) found a positive association between distribution uniformity of the applied water and tomato yield watered with drip irrigation.

According to the previous studies noted above, (Howes and Gaudi 2012; Montazar and Sadeghi 2008), it can be assumed that the CV of ET and DU have a strong association and; therefore, a discernible impact on yield.

In this study in Kern County, it was expected to find a negative association between yield and CV of ET. There was, however, no association between yield and CV of ET in the three locations. This led to the decision not to introduce this variable into Model 3 (Figure 26).

In addition, an association between ET and CV of ET was expected. Using the same approach as before, where CV of ET and DU are related, a high $\mathrm{R}^{2}$ was expected. The west side $\mathrm{R}^{2}$ was relatively constant each year of the study (53\%-59\%). There was, however, a variation in the $\mathrm{R}^{2}$ in the east and northwest side locations. 


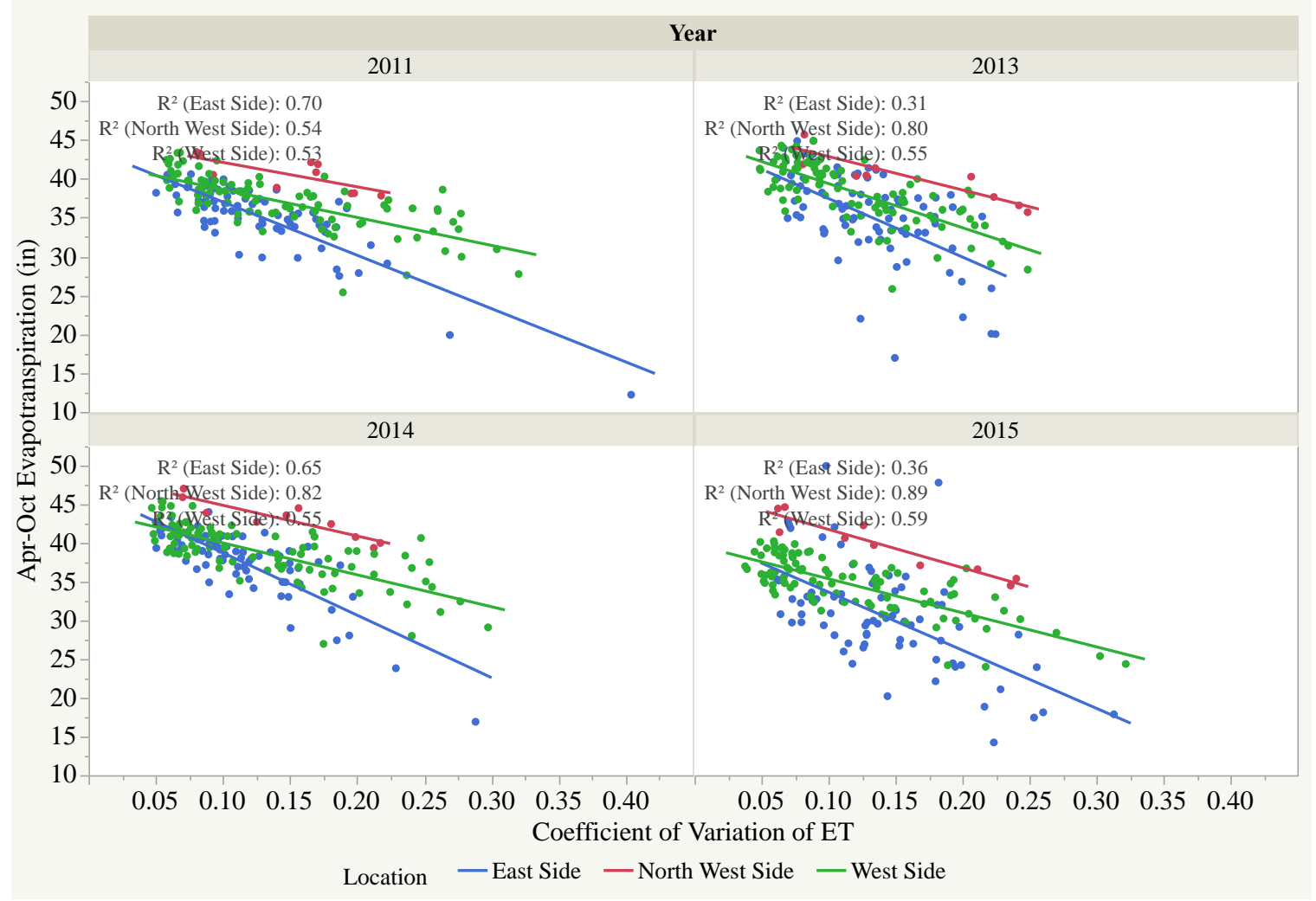

Figure 26. Evapotranspiration as a function of coefficient of variation of evapotranspiration and year in three locations of Kern County, CA for the years 2011 and 2013-2015 (n=185).

Jimenez and Ortega (2010) found that high DU was related to high ET. This study was done on onions with a sprinkler type irrigation system. Howes and Gaudi (2012) found that DU had an influence of 55\% of ET non-uniformity, and emphasized that irrigation non-uniformity lead to lower soil moisture content and negatively affected the potential evapotranspiration.

In the study in Kern County, it was expected that CV of ET would reduce the unexplained variability in the model. However, after introducing CV of ET in Model 3, the $\mathrm{R}^{2}$ adjusted did not significantly increase $(<2 \%)$. Furthermore, it was expected that $\mathrm{CV}$ of ET would be an indicator of DU of water applied, and hence explain the variability of yield. However, $\mathrm{R}^{2}$ values did not show this. 
Clearly, software or data processing could be another factor affecting CV of evapotranspiration. The resolution in LandSAT (30 m x $30 \mathrm{~m}$ ) could be a factor affecting ET variability; if, for example, resolution were higher, it would lead to lower CV of ET. Appendix B shows the summary of fit when CV of ET was introduced to Model 3 in each of the years of the study.

\section{$\underline{4.3 .2 \text { Year } 2011}$}

Model 3 for year 2011, showed the $\mathrm{R}^{2}$ increased from $13.9 \%$ to $60.4 \%$ when tree age and location were introduced as explanatory variables. Year 2011 had the highest $\mathrm{R}^{2}$ and the highest mean response of yield compared to the rest of the years of the study (Table 18). In addition 2011, was considered a wet year, due to high precipitation in each of the locations of the study.

López-López et al. (2018) found an $\mathrm{R}^{2}$ of $78 \%$, for almond yield as a function of evapotranspiration. They use is a logarithmic model, compared to the simple linear model made in this study. During their experiment, the precipitation was approximately $30 \%$ of total ET. However, the year with maximum yield was the year with the lowest precipitation (16\% of total ET) as well. Their $\mathrm{R}^{2}$ was not that distant from the ones found in this study ( $\mathrm{R}^{2}$ of $60.4 \%$ ). However, in Model 3, additional variables caused an increase in the $\mathrm{R}^{2}$. 
Table 18. Model 3 summary of fit for year 2011 of almond yield as a function of annual evapotranspiration in California's Central Valley after adjusting for tree year and location (Kern County) for the months April-October in 2011 ( $n=185$ ).

\begin{tabular}{lr}
\hline Summary Fit model for year 2011 & Parameter \\
\hline RSquare & 0.604 \\
RSquare Adj & 0.595 \\
Root Mean Square Error & 410.786 \\
Mean of Response & 3229.093 \\
Observations (or Sum Wgts) & 185 \\
\hline
\end{tabular}

Table 19 showcases which specific variable helped explain the variability of the model. With the exception of the northwest side location, which has a p value of 0.0767 , all the other variables helped explain the model $(\mathrm{p}<0.05)$, and; therefore, helped explain the variability of almond yield. It should be noted that the northwest side had the lowest precipitation in 2011 compared to the east and west side locations (Figures 8-10). Based on these data, it could be possible that below average precipitation in a wet year could be the reason for the high $\mathrm{p}$ value $(\mathrm{p}>0.05)$.

According to Esparza et al. (2001), high precipitation has a positive impact on almond yield. However, in our study in Kern County, the regression coefficient for the east side was negative: this translated to lower yield on the east side as compared to west and northwest locations (Table 19). Thus, it could not be suggested that precipitation was the reason for having the lowest yields in the east side in 2011. 
Table 19. Model 3 parameter estimates for year 2011 of almond yield (lbs/acre) as a function of annual evapotranspiration (inches) in California's Central Valley after adjusting for tree year and location (Kern County) for the months April-October in $2011(n=185)$. Alpha level $=0.05$.

\begin{tabular}{lllll}
\hline Term & Estimate & Std Error & t Ratio & Prob>|t| \\
\hline Intercept & 2735.900 & 322.588 & 8.48 & $<.0001^{*}$ \\
2011 Apr-Oct ET (in) & 38.757 & 8.014 & 4.84 & $<.0001^{*}$ \\
2011 Tree Age & -61.538 & 9.097 & -6.76 & $<.0001^{*}$ \\
Location[East Side] & -479.004 & 58.345 & -8.21 & $<.0001^{*}$ \\
Location[North West Side] & 163.931 & 92.067 & 1.78 & 0.0767 \\
Location[West Side] & 315.073 & 54.025 & 5.83 & $<.0001^{*}$ \\
\hline
\end{tabular}

In this study, the regression coefficient for tree age was found to be negative. It was expected that tree age had a negative coefficient regression for the reasons previously described (5.3.1.1 Tree age). The study's youngest tree in year 2011 was 8 years of age, and the average of tree age was 14.5 years. According to Kreuger and Freeman (1996), tree yield would be expected to decrease after 15 years of growth.

The year 2011 had the highest precipitation among the years covered by this study in Kern county: Rainfall that year was also greater than the historical average, and so it was considered a wet year. In addition, 2011 had the highest $\mathrm{R}^{2}(60.4 \%)$ compared to the rest of the years. However, in this same year, there was $39.6 \%$ unexplained almond yield variability. This could possibly be reduced if additional variables were added to Model 3 .

The result found for 2011 in Kern county were compared with other studies. Goldhamer and Fereres (2017) found a relationship between almond yield and water applied. The $\mathrm{R}^{2}$ in their study was $(97.9 \%)$, which was much higher than in our study in Kern County. However, the model proposed by them was a third order polynomial expression. Also, they found a high year-to-year variation in average yield $(<2600$ lbs/acre to $4000 \mathrm{lbs} / \mathrm{acre}$ ); however, they concluded that this variation was due to another 
factor they analyzed--fruit load--which was beyond the scope of the study in Kern County.

In another study, Sanden et al. (2012) did not find a relationship between almond yield and ET in their California Central Valley study. The yearly ET ranged from 49 to 62 inches, which was data found by measuring soil moisture depletion. Their study was carried out during non-drought conditions (2008-2011)

The 2011 had the highest yield--and maximum relative yield--of all years considered in this study. It can be suggested that the almond orchards did not experience stress due to drought conditions in 2011 , due to the fact that precipitation during the period of October through March (Figures 8-10) was high that year, compared to the years 2013-2015.

\section{$\underline{4.3 .3 \text { Year } 2013}$}

Model 3 for 2013 reported an $\mathrm{R}^{2}$ of $49.7 \%$ (Table 20). The $\mathrm{R}^{2}$ increased from $12.1 \%$ to $49.7 \%$ when tree age and location were introduced to Model 3. Year 2013 had the lowest $\mathrm{R}^{2}$ compared to each of the years of the study. Still, while it's average yield was below that of 2011, it was higher than that of 2014 or 2015.

It should be considered that 2013 was a drought condition year due to its low precipitation in each location of the study (Figures 8-10). 
Table 20. Model 3 summary of fit for year 2013 of almond yield as a function of annual evapotranspiration in California's Central Valley after adjusting for tree year and location (Kern County) for the months April-October in 2013 ( $n=183$ ).

\begin{tabular}{lr}
\hline Summary of fit year 2013 & Parameter \\
\hline RSquare & 0.497 \\
RSquare Adj & 0.486 \\
Root Mean Square Error & 399.709 \\
Mean of Response & 2397.173 \\
Observations (or Sum Wgts) & 183 \\
\hline
\end{tabular}

Table 21 showcases the impact of each variable in the model. $\mathrm{P}$ values below 0.05 showed if the given explanatory variables explained almond yield variability. However, the overall Model 3 for 2013 had a low R R $\left.^{2} 49 \%\right)$. Thus, the data did not fit the model.

In 2013 , the west side had a p value of 0.176 ; hence, location did not explain almond yield variability in Model 3. The west side also had the lowest precipitation--but not lowest almond yield, compared to the other locations in this study (Figures 8-10). Therefore, it could not be suggested that precipitation had an effect on almond yield variability in the west side.

Lobell et al. (2007) found an $\mathrm{R}^{2}$ of $80 \%$ for a model in which January precipitation and almond yield were the variables in California. In that study, historical data from 1980-2003 were used. However, these were not drought condition years--in contrast with year 2013. Therefore, it could not be suggested, in the study in Kern County, that precipitation was the major factor affecting the unexplained variability of almond yield in the west side.

USDA-NASS (2013) forecasted a decrease in almond yield due to cold temperature during the winter of 2013. However, the cumulative chilling hours were quite similar for each of the locations (ranged from 925-1093 CU) (Figure 11-13). Thus, 
it was not possible that cumulative chilling hours explained the difference in average almond yield between east and northwest sides.

Table 21. Model 3 parameter estimates for year 2013 of almond yield (lbs/acre) as a function of annual evapotranspiration (inches) in California's Central Valley after adjusting for tree year and location (Kern County) for the months April-October in 2013 ( $n=183)$ Alpha level $=0.05$.

\begin{tabular}{lllll}
\hline Term & Estimate & Std Error & t Ratio & Prob $>|\mathbf{t}|$ \\
\hline Intercept & 1043.679 & 329.903 & 3.16 & $0.0018^{*}$ \\
2013 Tree Age & -49.887 & 9.291 & -5.37 & $<.0001^{*}$ \\
2013 Apr-Oct ET (in) & 52.548 & 6.607 & 7.95 & $<.0001^{*}$ \\
Location[East Side] & 540.400 & 57.342 & 9.42 & $<.0001^{*}$ \\
Location[North West Side] & -611.626 & 88.794 & -6.89 & $<.0001^{*}$ \\
Location[West Side] & 71.226 & 52.510 & 1.36 & 0.1767 \\
\hline
\end{tabular}

Abbreviation and symbols: $*=\mathrm{P}<0.05$

In 2013, the northwest side had the highest evapotranspiration compared to each of the other locations (east and west side). It is possible that high evapotranspiration and low precipitation led to salt accumulation in the soil; therefore, a negative impact on almond yield would be expected. Nightingale et al. (1991) found an increase from 4.74 $\mathrm{dS} / \mathrm{m}$ to $5.7 \mathrm{dS} / \mathrm{m}$ in soil salinity when only $50 \%$ of the ET requirement was applied in an almond orchard after four years. The irrigation water in Nightingale et al. (1991) study was $1.5 \mathrm{dS} / \mathrm{m}$. This study was made in California's San Joaquin Valley.

Doll (2014) stated that salt accumulation becomes more severe during drought conditions in the Central Valley, because farmers usually use more groundwater that contains a higher salinity compared to surface water during drought years (Doll 2014). Moreover, Mass and Hoffman (1977) reported a decrease in yield when the salinity in the root zone was beyond $1.5 \mathrm{dS} / \mathrm{m}$.

In 2013, the east side had the highest regression coefficient for ET among the three locations. In addition, year 2013 had the highest precipitation, and the lowest 
evapotranspiration. It is possible that the amount of salt accumulation in the east side was lower than the other two locations (west side and northwest side) due to the latter two factors, which may explain the highest regression coefficient for ET.

\subsubsection{Year 2014}

Model 3 for 2014 showed $\mathrm{R}^{2}$ increased from $4 \%$ to $53.8 \%$ when tree age and location were introduced as explanatory variables to adjust evapotranspiration to explain almond yield variability (Table 22). Also, there was $46.2 \%$ unexplained variation of almond yield in this model. The average almond yield for 2014 was lower than in 2011 and 2013 (mean response $1833 \mathrm{lbs} / \mathrm{acre}$ ).

According to Griffin and Anchukaitis (2014), the drought conditions that occurred between 2012 and 2014--below-average soil moisture, low precipitation and high daily temperature during the cold season--were not uncommon. Nevertheless, they stated that this drought was the most severe in the last 1200 years.

To this end, Griffin and Anchukaitis (2014) stated further that 2014 had the lowest accumulated soil moisture during the period of time of 2012-2014. Meanwhile, AghaKouchak et al. (2014)reported that in all of California, 2014 had the highest mean temperature during November-April of the last 118 years--with, for example, a daily temperature increase of 59\% during a January heatwave in the Central Valley town of Bakersfield. 
Table 22. Model 3 summary of fit for year 2014 of almond yield as a function of annual evapotranspiration in California's Central Valley after adjusting for tree year and location (Kern County) for the months April-October in 2014 ( $n=183$ ).

\begin{tabular}{lr}
\hline Summary of fit year 2014 & Parameter \\
\hline RSquare & 0.538 \\
RSquare Adj & 0.527 \\
Root Mean Square Error & 320.233 \\
Mean of Response & 1833.038 \\
Observations (or Sum Wgts) & 183 \\
\hline
\end{tabular}

Table 23 showcases the impact of each explanatory variable in Model 3. P values below 0.05 showed that each predictor variable helped explain the almond yield variability of Model 3. All of the variables had $p<0.05$ and; therefore, helped reduce the unexplained variability in almond yield in Model 3.

Table 23. Model 3 parameter estimates for year 2014 of almond yield (lbs/acre) as a function of annual evapotranspiration (inches) in California's Central Valley after adjusting for tree year and location (Kern County) for the months April-October in 2014 ( $n=183)$. Alpha level $=0.05$.

\begin{tabular}{lllll}
\hline Term & Estimate & Std Error & t Ratio & Prob $>|\mathbf{t}|$ \\
\hline Intercept & 1850.196 & 295.392 & 6.26 & $<.0001^{*}$ \\
2014 Apr-Oct ET (in) & 29.536 & 6.170 & 4.79 & $<.0001^{*}$ \\
2014 Tree Age & -69.483 & 7.267 & -9.56 & $<.0001^{*}$ \\
Location[East Side] & 337.571 & 45.355 & 7.44 & $<.0001^{*}$ \\
Location[North West Side] & -195.750 & 72.463 & -2.70 & $0.0076^{*}$ \\
Location[West Side] & -141.821 & 42.491 & -3.34 & $0.0010^{*}$ \\
\hline
\end{tabular}

Abbreviation and symbols: $*=\mathrm{P}<0.05$

The regression coefficient for ET was 29.56: this was the lowest regression coefficient during the years of the study (Table 23). The precipitation in 2014 was the lowest, among all years studied, in each location. Therefore, it is possible that a low regression coefficient is a symptom of water stress.

Torrecillas et al. (1996) and Dejong (1996) defined stomatal closure as beneficial in water stress conditions because it prevents water loss from almond trees. However, 
they stated, stomatal closure also reduces the photosynthesis rate because $\mathrm{CO}_{2}$ uptake is reduced. Therefore, it can be concluded that the relationship between growth development and yield is affected.

In the present study in Kern County, the east side had the highest regression coefficient in 2014 and also the lowest average ET compared to other locations (west and northwest sides). It can be suggested that low salt accumulation due to lower evapotranspiration was the reason for a high regression coefficient for the east side. This result resembles the result found in 2013 for the east side.

A decrease in the regression coefficient for tree age as trees grew older was expected. And indeed, tree age had a lower regression coefficient in 2014 compared to 2013. As previously stated (Figures 8-10), 2014 had the most severe drought conditions (lowest precipitation among years analyzed). And as asserted in a related report by Shackel (1996), stress conditions were detrimental to mature almond orchards because mature trees must have sufficient growth development to maintain active fruiting wood.

\subsubsection{Year 2015}

Model 3 for 2015 reported an increase in $\mathrm{R}^{2}$ from $26.5 \%$ to $53.2 \%$ when tree age and location were introduced as explanatory variables that adjusted ET to explain almond yield variability (Table 24). The 2015 average yield was the lowest (mean response $1786.78 \mathrm{lbs} / \mathrm{acre}$ ) among all the years in this study, most likely because precipitation was below average. Thus, 2015 was considered a drought conditions year.

After analyzing the last drought (2011 -2015) in California, Richman and Leslie (2015) concluded that drought conditions can no longer be defined solely by a lack of precipitation: rather, warm temperatures during the cold season must also be considered. 
These higher temperatures cause greater evaporation rates during the cool season, which enhances drought conditions.

Table 24. Model 3 summary of fit for year 2015 of almond yield as a function of annual evapotranspiration in California's Central Valley after adjusting for tree year and location (Kern County) for the months April-October in 2015 ( $n=183$ ).

\begin{tabular}{lr}
\hline Summary of fit 2015 & Parameter \\
\hline RSquare & 0.532 \\
RSquare Adj & 0.522 \\
Root Mean Square Error & 379.296 \\
Mean of Response & 1786.780 \\
Observations (or Sum Wgts) & 183 \\
\hline
\end{tabular}

Table 25 showcases the impact of each variable in Model 3 for 2015. P values below 0.05 means that a given variable did help explain almond yield variability (Table 25). Each explanatory variable used in Model 3 helped explicate almond yield variability. Ultimately, $46.8 \%$ of unexplained variability of almond yield in Model 3 remained for year 2015 .

Comparing the regression coefficient for tree age for each of the years of the study, 2015 had the highest value. In addition, the average tree age for that year was 18.5 years. Therefore, it is possible that mature trees, as well as stress due to drought conditions mentioned above, both had a detrimental effect on almond yield.

In 2015, following 3 years of drought conditions, the lowest average yield in this study was reported. This finding had to be tempered; however, by the research of Spinelli et al. (2016), which showed that after long period of water stress, almond trees promote leaf senescence which lead to leaf-area reduction and thereby avoided a total stomatal closure in order to maintain a constant photosynthesis rate. 
Table 25. Model 3 summary of fit for year 2015 of almond yield (lbs/acre) as a function of annual evapotranspiration (inches) in California's Central Valley after adjusting for tree year and location (Kern County) for the months AprilOctober in $2015(n=183)$. Alpha $=0.05$.

\begin{tabular}{lllll}
\hline Term & Estimate & Std Error & t Ratio & Prob>|t| \\
\hline Intercept & 1889.961 & 346.028 & 5.46 & $<.0001^{*}$ \\
2015 Tree Age & -79.185 & 9.635 & -8.22 & $<.0001^{*}$ \\
2015 Apr-Oct ET (in) & 36.482 & 6.283 & 5.81 & $<.0001^{*}$ \\
Location[East Side] & 169.382 & 58.345 & 2.90 & $0.0042^{*}$ \\
Location[North West Side] & -342.005 & 88.463 & -3.87 & $0.0002^{*}$ \\
Location[West Side] & 172.623 & 49.960 & 3.46 & $0.0007^{*}$ \\
\hline
\end{tabular}

Abbreviation and symbols: $*=\mathrm{P}<0.05$

In Model 3 for 2015 the northwest side had a negative regression coefficient. This location also had the highest evapotranspiration in each of the years of the study. It is possible that high ET and drought conditions could have led to salt accumulation in the soil (Doll 2014). Due to the lack of precipitation and increased water prices during drought condition, it is also possible that farmers did not use water for leaching salts.

It can be suggested that during drought conditions, the Model 3 had a worse fit (2011 showed $\mathrm{R}^{2}>60 \%$; 2013-2015 showed $\mathrm{R}^{2}<54 \%$ ). This means that it had more unexplained variability of almond yield during drought years. It can be suggested that the unexplained variability of almond yield could be due to agricultural practices or to low photosynthesis rate due to a stomatal closure caused by water stress. 


\section{SUMMARY AND CONCLUSION}

\subsection{Contributions of your work to the field}

Three functional regression models were used to evaluate and then describe the effect of evapotranspiration on almond yield during a wet year (2011) and drought condition years (2013-2015). Model 1 described the relationship between evapotranspiration and almond yield. Model 2 described year-to-year variation in which the parameters--location, precipitation and chilling hours--were used to adjust the effect of ET on almond yield. Model 3 described within-the-year variation in which the variables--tree year, soil available water storage, and coefficient of evapotranspiration-were used to adjust the effect of evapotranspiration on almonds yield.

Model 1 showed a high unexplained variability on almond yield $\left(\mathrm{R}^{2}=7.9 \%\right)$. It can be suggested that this high unexplained variability was due to different environmental conditions among the four different years of the study. It was defined 2011 as a wet year, and 2013-2015 as drought years. The equation proposed by Model 1; however, did not fit the data; therefore, the regression coefficients were not considered accurate.

Model 2 described the year-to-year variation in almond yield. In this study there were also two types of years considered: a wet year and year with drought conditions. The effect of drought conditions on yield was observed. Almond yield decreased from 2011 to 2015; however, these variables--location, precipitation and chilling hours-- could only explain $62.4 \%$ of yield variability. Therefore, it cannot be suggested that the evaluated variables could be the exclusive reason for this decrease.

Model 3 results showed that the $\mathrm{R}^{2}(60.4 \%)$ in the year 2011 was higher than in the years (2013-2015) with drought conditions $\left(\mathrm{R}^{2}<54 \%\right)$--i.e., the predictor variables of 
the model fit better in a wet year compared to a year with drought conditions. Coefficient of variation of evapotranspiration and soil available water storage were analyzed separately, as potential variables to be used in Model 3. However, ultimately, they were not introduced into Model 3 due to the low increase in $\mathrm{R}^{2}$ in each year $(<2 \%)$.

Because the $\mathrm{R}^{2}$ value in each model was relatively low $\left(\mathrm{R}^{2} \leq 63 \%\right)$, the data suggested that some additional factors could help further explain the almond yield variability. Excluding environmental factors (such as close proximity of fields to each other), it is possible that additional variables--for example, agronomic practices such as fertilization plans, pest management or orchard management--could be the reason for this high unexplained variability. However, a multi-field evaluation using data from a largescale almond-producing farm is needed to accurately describe the effect of these factors. 


\subsection{Limitation/Strengths and weakness of your work}

The most important limitation of this study was that it was not an experiment. Therefore, the results of the study represented field observations but in the long term any conclusion can be made. Nevertheless, this research did describe the effect of drought on almond production in Kern County during the years of the study.

Another weakness was that the models used in the study did not predict or

describe the relationship between almond yield and evapotranspiration due to low $\mathrm{R}^{2}$ $(<60 \%)$. This led to a high unexplained yield variability. Because of this high unexplained variability, recommendations to farmers about how to avoid a decrease in yield cannot yet be made.

An important strength of the study came after adjusting Model 3, for the variables of tree age and location, to improve the description of yield variation. After doing so, it could be suggested that between fields, the high variability in yield means that some of the fields studied were under better management practices than others. That is to say that fields with the evapotranspiration value could have either a low or a high yield depending on means of cultivation. An important output of this study was that fields can be identified, then observed for which practices help to produce a greater yield. Perhaps most significantly, Model 3 results showed that there is room for improvement in almond yield even under existing drought conditions. 


\subsection{Future Work}

This study focusing on almond production in the California Central Valley opened essential unanswered questions about drought conditions and their effect on yield. Answers to these questions require further research not only on the past climate conditions but on current ones as well.

To begin with, during the years of this study, the unexplained yield variability was very high, so much research remains to be done to explain that variability, in order to reduce it. To this end, considering additional variables to Model 3 would be important. In particular, the type of irrigation system used in almond orchards is one variable that could affect not only yield, but also evapotranspiration. Using irrigation systems as a variable could lead to reducing the unexplained variability of almond yield.

It is also important to conduct further research for the years subsequent to those in this study, to observe any within-year variations in yield, and if Model 2 results for these subsequent years still show the same amount of unexplained variation (37.6\%) as in this study. Further research should also analyze data from year 2016--still considered a drought year, and 2017, which was not. It would be important to observe if almond yield improved during these years, or followed the same trend--a decrease--observed during the drought years of 2014 and 2015.

Finally, this study was carried out in Kern County. It is recommended that further studies be conducted in different locations in the Central Valley, to observe if almond yield data from those areas resembles data from the same years in this study. 


\section{BIBLIOGRAPHY}

AghaKouchak, Amir, Linyin Cheng, Omid Mazdiyasni, and Alireza Farahmand. 2014. "Global Warming and Changes in Risk of Concurrent Climate Extremes: Insights from the 2014 California Drought.” Geophysical Research Letters 41 (24). WileyBlackwell: 8847-52. https://doi.org/10.1002/2014GL062308.

Alcon, Francisco, Gregorio Egea, and Pedro A. Nortes. 2013. "Financial Feasibility of Implementing Regulated and Sustained Deficit Irrigation in Almond Orchards." Irrigation Science 31 (5). Springer Berlin Heidelberg: 931-41. https://doi.org/10.1007/s00271-012-0369-6.

Allen, R. G., and L.S. Pereira. 2011. "Evapotranspiration Information Reporting: I. Factors Governing Measurement Accuracy.” Agricultural Water Management 98 (6): 899-920. https://doi.org/10.1016/j.agwat.2010.12.015.

Allen, R.G., and L.S. Pereira. 2009. "Estimating Crop Coefficients from Fraction of Ground Cover and Height." Irrigation Science 28 (1). Springer-Verlag: 17-34. https://doi.org/10.1007/s00271-009-0182-z.

Allen, Richard G. 2011. "Skin Layer Evaporation to Account for Small Precipitation Events-An Enhancement to the FAO-56 Evaporation Model." Agricultural Water Management 99 (1). Elsevier: 8-18. https://doi.org/10.1016/J.AGWAT.2011.08.008.

Allen, Richard G., Masahiro Tasumi, Anthony Morse, Ricardo Trezza, James L. Wright, Wim Bastiaanssen, William Kramber, Ignacio Lorite, and Clarence W. Robison. 2007. "Satellite-Based Energy Balance for Mapping Evapotranspiration with Internalized Calibration (METRIC)—Applications.” Journal of Irrigation and Drainage Engineering 133 (4): 395-406. https://doi.org/10.1061/(ASCE)0733- 
9437(2007)133:4(395).

Allen, Richard G., Masahiro Tasumi, and Ricardo Trezza. 2007. "Satellite-Based Energy Balance for Mapping Evapotranspiration with Internalized Calibration (METRIC)— Model." Journal of Irrigation and Drainage Engineering 133 (4): 380-94. https://doi.org/10.1061/(ASCE)0733-9437(2007)133:4(380).

Allen, Richard G, Luis S Pereira, Dirk Raes, and Martin Smith. 1998. Crop Evapotranspiration. Irrigation and Drainage. Vol. 300. Rome. https://doi.org/10.1016/j.eja.2010.12.001.

Allen, Richard, Luis Pereira, Dirk Raes, and Martin Smith. 1998. Crop Evapotranspiration: Guidelines for Computing Crop Water Requirements. Food and Agriculture Organization of the United Nations.

Allen, Richard, Luis Pereira, Martin Smith, Dirk Raes, and James Wright. 2005. "FAO56 Dual Crop Coefficient Method for Estimating Evaporation from Soil and Application Extensions.” Journal of Irrigation and Drainage Engineering 131 (1): 2-13. https://doi.org/10.1061/(ASCE)0733-9437(2005)131:1(2).

Almond Board of California. 2015. "Almond Almanc 2015."

http://newsroom.almonds.com/sites/default/files/pdf_file/2015\%20Almond\%20Almanac \%20Annual\%20Report.pdf

Almond Board of California. 2016. "Almond Almanc 2016.” Modesto. http://www.almonds.com/sites/default/files/2016_almond_almanac.pdf.

Alonso, J.M., J.M. Ansón, M.T. Espiau, and R. Socias i Company. 2005. "Determination of Endodormancy Break in Almond Flower Buds by a Correlation Model Using the Average Temperature of Different Day Intervals and Its Application to the 
Estimation of Chill and Heat Requirements and Blooming Date." Journal of the American Society for Horticultural Science 130 (3). [American Society for Horticultural Science]: 308-18.

http://journal.ashspublications.org/content/130/3/308.abstract.

Alonso, José. 2017. "Enviromental Requirements." In Almonds Botany Production and Uses, 254-78.

Alston, Julian M., Hoy F. Carman, Jason E. Christian, Jeffrey H. Dorfman, Juan-Ramon Murua, and Richard J. Sexton. 1997. "Optimal Reserve and Export Policies for the California Almond Industry: Theory, Econometrics, and Simulations." Monographs. University of California, Davis, Giannini Foundation. https://ideas.repec.org/b/ags/dgiamo/11937.html.

Anderson, J.L., E.A. Richardson, and C.D. Kesner. 1986. "Validation Of Chill Unit And Flower Bud Phenology Models For ‘Montmorency' Sour Cherry.” Acta Horticulturae, no. 184 (May): 71-78. https://doi.org/10.17660/ActaHortic.1986.184.7.

Arquero, Octavio. 2013. Manual Del Almendro. Edited by Pesca y Desarrollo. Junta de Andalucia Consejeria de Agricultura. 1st ed. Sevilla. http://www.juntadeandalucia.es/servicios/publicaciones/detalle/77668.html. Arquero, Octavio, and Katherine Jarvis-Shean. 2017. "Orchard Management.” In Almonds Botany Production and Uses, 240-53.

Barrett, J.W.Hugh, and Gaylord V. Skogerboe. 1980. "Crop Production Functions and the Allocation and Use of Irrigation Water.” Agricultural Water Management 3 (1): $53-$ 64. https://doi.org/10.1016/0378-3774(80)90015-3. 
Bastiaanssen, W.G.M. 2000. "SEBAL-Based Sensible and Latent Heat Fluxes in the Irrigated Gediz Basin, Turkey.” Journal of Hydrology 229 (1-2). Elsevier: 87-100. https://doi.org/10.1016/S0022-1694(99)00202-4.

Bastiaanssen, W G M, and M G Bos. 1999. "Irrigation Performance Indicators Based on Remotely Sensed Data: A Review of Literature.” Irrigation and Drainage Systems 13: $291-311$. https://link.springer.com/content/pdf/10.1023\%2FA\%3A1006355315251.pdf.

Burt, Charles M., Daniel J. Howes, and Andrew Mutziger. "Evaporation estimates for irrigated agriculture in California." In 2001 Irrigation Association Conference: San Antonio, TX. 2001.

Byrne, David H., and Terry Bacon. 1992. "Chilling Accumulation: Its Importance and Estimation." The Texas Horticulturist 18 (8): 8-9. https://aggiehorticulture.tamu.edu/stonefruit/chillacc.html.

California Department of Food and Agriculture, California Agricultural Production Statistics 2018. https://www.cdfa.ca.gov/statistics/

Campos, Isidro, Jose González-Piqueras, Arnaud Carrara, Julio Villodre, and Alfonso Calera. 2016. "Estimation of Total Available Water in the Soil Layer by Integrating Actual Evapotranspiration Data in a Remote Sensing-Driven Soil Water Balance.” Journal of Hydrology 534 (March). Elsevier: 427-39.

https://doi.org/10.1016/J.JHYDROL.2016.01.023.

Campoy, J.A., D. Ruiz, and J. Egea. 2011. "Dormancy in Temperate Fruit Trees in a Global Warming Context: A Review.” Scientia Horticulturae 130 (2). Elsevier: 357-72. https://doi.org/10.1016/J.SCIENTA.2011.07.011. 
Catlin, Peter. 1996. "Root System and Root Physiology." In Almond Production Manual, $107-12$.

Chavez, Jose L, Prasanna H Gowda, and Terry A Howell. 2007. "Evapotranspiration Mapping Using METRIC TM for a Region with Highly Advective Conditions.” In Evapotranspiration Mapping Using METRICTM for a Region with Highly Advective Conditions, 12. Minneapolis: ASABE. https://naldc.nal.usda.gov/download/2342/PDF.

Cody, Betsy A, Peter Folger, and C Brougher. 2015. "California Drought: Hydrological and Regulatory Water Supply Issues." CRS Report for Congress.

Connell, Joseph, Steven Sibbet, John Labavitch, and Mark Freeman. 1996. "Preparing for Harvesting." In Almond Production Manual, 254-59.

Doll, David. 2009. “The Seasonal Patterns of Almond Production.” University of California Cooperative Extension. 2009. http://thealmonddoctor.com/2009/06/22/the-seasonal-patterns-of-almondproduction/.

-2014 "Soil Salinity and Leaching for almonds" University of California Cooperative Extension. 2014.

http://thealmonddoctor.com/2014/11/14/soil-salinity-leaching-almonds/

—. 2017a. "Almond Water Requirements." In Almonds Botany Production and Uses, 279-90.

_. 2017b. "Yellow Trees from Being Too Wet - The Almond Doctor." University of California Cooperative Extensive. 2017. http://thealmonddoctor.com/2017/04/10/yellow-trees-from-being-too-wet/. 
Doll, David, and Kenneth Shackel. 2015. "Drought Management for California Almonds Impacts of Stress on Almond Growth and Yield.” ANR Publication 8515. http://anrcatalog.ucanr.edu.

Doorenbos, J, and A H Kassam. 1979. "Yield Response to Water.” Irrigation and Drainage Paper 33: 257.

Dorfman, Jeffrey, Melody Dorfman, and D Heien. 1988. California Agriculture. California Agriculture. Vol. 42. [California Agricultural Experiment Station]. http://calag.ucanr.edu/archive/?article=ca.v042n05p27.

Dregne, H. E. (Harold E.). 1976. "Characteristics of Arid-Region Soils.” In Soils of Arid Regions, 37-50. Lubbock: Elsevier Scientific Pub. Co.

Egea, Gregorio, Pedro A. Nortes, María M. González-Real, Alain Baille, and Rafael Domingo. 2010. “Agronomic Response and Water Productivity of Almond Trees under Contrasted Deficit Irrigation Regimes.” Agricultural Water Management 97 (1). Elsevier: 171-81. https://doi.org/10.1016/J.AGWAT.2009.09.006.

Egea, José, Encarnación Ortega, Pedro Martínez-Gómez, and Federico Dicenta. 2003. "Chilling and Heat Requirements of Almond Cultivars for Flowering." Environmental and Experimental Botany 50 (1). Elsevier: 79-85. https://doi.org/10.1016/S0098-8472(03)00002-9.

Erez, Amnon. 2000. "Bud Dormancy; Phenomenon, Problems and Solutions in the Tropics and Subtropics." In Temperate Fruit Crops in Warm Climates, 17-48. Dordrecht: Springer Netherlands. https://doi.org/10.1007/978-94-017-3215-4_2. Espadafor, Mónica, Francisco Orgaz, Luca Testi, Ignacio Jesús Lorite, Victoria González-Dugo, and Elías Fereres. 2017. "Responses of Transpiration and 
Transpiration Efficiency of Almond Trees to Moderate Water Deficits.” https://doi.org/10.1016/j.scienta.2017.06.028.

Espadafor, M, F Orgaz, L Testi, I J Lorite, O García-Tejera, F J Villalobos, and E

Fereres. 2018. "Almond Tree Response to a Change in Wetted Soil Volume under Drip Irrigation.” https://doi.org/10.1016/j.agwat.2018.01.026.

Esparza, G, T M DeJong, S A Weinbaum, and I Klein. 2001. "Effects of Irrigation Deprivation during the Harvest Period on Yield Determinants in Mature Almond Trees.” Tree Physiology 21 (14): 1073-79.

http://www.ncbi.nlm.nih.gov/pubmed/11560821.

ESRI 2017. ArcGIS Desktop: Release 10.5.1. Redlands, CA: Environmental Systems Research Institute.

Food and Agriculture Organizacion 2015. FAO STATS . Almond production. Accessed 03/04/2018. http://www.fao.org/faostat/en/\#data/QC

Fuentealba, Maria P., Jing Zhang, Kevin Kenworthy, John Erickson, Jason Kruse, and Laurie Trenholm. 2016. "Transpiration Responses of Warm-Season Turfgrass in Relation to Progressive Soil Drying." Scientia Horticulturae 198 (January). Elsevier: 249-53. https://doi.org/10.1016/J.SCIENTA.2015.11.042.

Franco, J.A, J.M Abrisqueta, A Hernansáez, and F Moreno. 2000. "Water Balance in a Young Almond Orchard under Drip Irrigation with Water of Low Quality.” Agricultural Water Management 43 (1). Elsevier: 75-98. https://doi.org/10.1016/S0378-3774(99)00049-9.

Fulton, Allan, William Wildman, Eugene Begg, and Gordon Huntington. 1996. "The Evaluation and Modification of Physical Soil Problems. " In Almond Production 
Manual, 20-28.

García-Tejero, I F, A Hernández, V M Rodríguez, J R Ponce, V Ramos, J L Muriel, and V H Durán-Zuazo. 2015. "Estimating Almond Crop Coefficients and Physiological Response to Water Stress in Semiarid Environments (SW Spain).” J. Agr. Sci. Tech 17: $1255-66$. http://ir.jkuat.ac.ke:8080/bitstream/handle/123456789/3863/JAST_Volume 17_Issue 5_Pages 1255-1266.pdf?sequence=1\&isAllowed=y.

García-Tejero, Iván F., Alfonso Moriana, Carmen R. Rodríguez Pleguezuelo, Víctor H. Durán Zuazo, and Gregorio Egea. 2018. "Sustainable Deficit-Irrigation Management in Almonds ( Prunus Dulcis L.).” In Water Scarcity and Sustainable Agriculture in Semiarid Environment, 271-98. Elsevier. https://doi.org/10.1016/B978-0-12813164-0.00012-0.

Girona, Joan. 2006. "La Respuesta Del Cultivo Del Almendro Al Riego.” Vida Rural, no. 234. Eumedia: 12-16.

Goldhamer, D, and T Smith. 1995. "Single-Season Drought Irrigation Strategies Influence Almond Production." California Agriculture 49 (1). University of California, Agriculture and Natural Resources: 19-22.

Goldhamer, David A. 1996. "Irrigation Scheduling." In Almond Production Manual, $171-78$.

Goldhamer, David A., and Elias Fereres. 2017a. "Establishing an Almond Water Production Function for California Using Long-Term Yield Response to Variable Irrigation.” Irrigation Science 35 (3). Springer Berlin Heidelberg: 169-79. https://doi.org/10.1007/s00271-016-0528-2. 
Goldhamer, David A, and Elias Fereres. 2017b. "Establishing an Almond Water Production Function for California Using Long-term Yield Response to Variable Irrigation.” Irrigation Science 35: 169-79. https://doi.org/10.1007/s00271-0160528-2.

Goldhamer, David A., Mario Viveros, and Mario Salinas. 2006. "Regulated Deficit Irrigation in Almonds: Effects of Variations in Applied Water and Stress Timing on Yield and Yield Components.” Irrigation Science 24 (2): 101-14. https://doi.org/10.1007/s00271-005-0014-8.

Gradziel, Thomas. 2017. "History of Cultivation." In Almonds Botany Production and Uses, 43-69.

Gradziel, Thomas, Robert Curtis, and Rafael Socias i Company. 2017. Production and Growing Seasons. Edited by T. (Thomas) Gradziel and R. (Rafael) Socias i Company. Almonds Botany Production and Uses. Boston.

Gradziel, Thomas, and Dale Kester. 1996. “Genetics Improvements.” In Almond Production Manual, 70-75.

Griffin, Daniel, and Kevin J. Anchukaitis. 2014. "How Unusual Is the 2012-2014 California Drought?” Geophysical Research Letters 41 (24). Wiley-Blackwell: 9017-23. https://doi.org/10.1002/2014GL062433@10.1002/(ISSN)19448007.CALDROUGHT1

Howes, Daniel J, Lucas Hoffmann, and Franklin Gaudi. 2012. “Comparison of Field Level and Regional Actual ETc Values Developed from Remote Sensing and Dual Crop Coefficient Procedure.” San Luis Obispo. http://www.itrc.org/papers/pdf/etc.pdf. 
Irrigation Training and Research Center (ITRC) 2017. " Does High Evapotranspiration Lead to Highest Yields in Pistachios and Almonds?" 55th Annual California Irrigation Institute Meeting. Sacramento, CA

Igbadun, Henry E., Andrew K.P.R. Tarimo, Baanda A. Salim, and Henry F. Mahoo. 2007. "Evaluation of Selected Crop Water Production Functions for an Irrigated Maize Crop.” Agricultural Water Management 94 (1-3). Elsevier: 1-10. https://doi.org/10.1016/J.AGWAT.2007.07.006.

Jiménez, M., De Juan, J.A., Tarjuelo, J.M. and Ortega, J.F., 2010. Effect of irrigation uniformity on evapotranspiration and onion yield. The Journal of Agricultural Science, 148(2), pp.139-157.

Kato, Yoichiro, Akihiko Kamoshita, and Junko Yamagishi. 2008. "Preflowering Abortion Reduces Spikelet Number in Upland Rice ( L.) under Water Stress.” Crop Science 48 (6). Crop Science Society of America: 2389. https://doi.org/10.2135/cropsci2007.11.0627.

Kester, Dale, George Martin, and John Labavitch. 1996. "Growth and Development.” In Almond Production Manual, 3364:90-98.

Kester, Dale, and Norman Ross. 1996. "History." In Almond Production Manual, 1-3. Krueger, William, Joseph Connell, and Mark Freeman. 1996. "Prunning Bearing Trees." In Almond Production Manual, 125-31.

Kool, D., N. Agam, N. Lazarovitch, J.L. Heitman, T.J. Sauer, and A. Ben-Gal. 2014. “A Review of Approaches for Evapotranspiration Partitioning." Agricultural and Forest Meteorology 184 (January). Elsevier: 56-70. https://doi.org/10.1016/J.AGRFORMET.2013.09.003. 
Laio, F., A. Porporato, L. Ridolfi, and I. Rodriguez-Iturbe. 2001. "Plants in WaterControlled Ecosystems: Active Role in Hydrologic Processes and Response to Water Stress: II. Probabilistic Soil Moisture Dynamics.” Advances in Water Resources 24 (7). Elsevier: 707-23. https://doi.org/10.1016/S0309-1708(01)000057.

Lang, G. A., J. D. Early, G. C. Martin, and R. L. Darnell. 1987. "Endo-, Para-, and Ecodormancy: Physiological Terminology and Classification for Dormancy Research." HortScience 22 (3): 371-77. https://eurekamag.com/research/001/585/001585177.php.

López-López, Manuel, Mónica Espadafor, Luca Testi, Ignacio Jesús Lorite, Francisco Orgaz, and Elías Fereres. 2018. "Water Use of Irrigated Almond Trees When Subjected to Water Deficits.” Agricultural Water Management 195 (January). Elsevier: 84-93. https://doi.org/10.1016/J.AGWAT.2017.10.001.

Luedeling, Eike. 2012. "Climate Change Impacts on Winter Chill for Temperate Fruit and Nut Production: A Review." Scientia Horticulturae 144 (September). Elsevier: 218-29. https://doi.org/10.1016/J.SCIENTA.2012.07.011.

Luedeling, Eike, Minghua Zhang, Volker Luedeling, and Evan H. Girvetz. 2009. "Sensitivity of Winter Chill Models for Fruit and Nut Trees to Climatic Changes Expected in California's Central Valley." Agriculture, Ecosystems \& Environment 133 (1-2). Elsevier: 23-31. https://doi.org/10.1016/J.AGEE.2009.04.016. Mañas, F., P. López-Fuster, and R. López-Urrea. 2014. “EFFECTS OF DIFFERENT REGULATED AND SUSTAINED DEFICIT IRRIGATION STRATEGIES IN ALMOND PRODUCTION.” Acta Horticulturae, no. 1028 (March): 391-94. 
https://doi.org/10.17660/ActaHortic.2014.1028.64.

Mass, V. E., and G. J. Hoffman. 1977. Crop Salt Tolerance - Current Assessment. Journal of the Irrigation and Drainage Division, American Society of Civil Engineers.

http://swrcb2.swrcb.ca.gov/waterrights/water_issues/programs/bay_delta/sds_srjf/sd s/hist_exhibits/1977bdh_p2ex1.pdf.

Micke, Warren C. Almond production manual. Vol. 3364. UCANR Publications, 1996.

Micke, Warren, Mark Freeman, Bob Beede, Lonnie Hendricks, and Jim Yeager. 1991 "COMPARISON OF PRUNING TECHNIQUES TO INVIGORATE LOW-VIGOR ALMOND TREES." HortScience 27, no. 6: 619-619.

Montazar, A., and M. Sadeghi. 2008. "Effects of Applied Water and Sprinkler Irrigation Uniformity on Alfalfa Growth and Hay Yield." Agricultural Water Management 95 (11). Elsevier: 1279-87. https://ideas.repec.org/a/eee/agiwat/v95y2008i11p12791287.html.

Nightingale, H I, G J Hoffman, D E Rolston, and J W Biggar. 1991. “Trickle Irrigation Rates and Soil Salinity Distribution in an Almond (Prunus Amygdalus) Orchard." Agricultural Water Management 19: 271-83. https://ac.elscdn.com/037837749190046L/1-s2.0-037837749190046L-main.pdf?_tid=031 ae77ef3d3-4a04-aa3edc14c633bb21\&acdnat=1527992881_a32328a366089fefbbddd778e9eb6817.

Ottman, Y., and D.H. Byrne. 1988. "HortScience : A Publication of the American Society for Horticultural Science." HortScience : A Publication of the American Society for Horticultural Science. The Society. http://agris.fao.org/agris- 
search/search.do?recordID=US19890015561.

Palacio-Bielsa, Ana, Mariano Cambra, Carmen Martinez, Antonio Olmos, Vicente Pallas, Maria Lopez, James Adaskaveg, et al. 2017. “Almond Diseases.” In Almonds Botany Production and Uses, 321-74.

Phogat, V., T. Pitt, J.W. Cox, J. Šimůnek, and M.A. Skewes. 2018. "Soil Water and Salinity Dynamics under Sprinkler Irrigated Almond Exposed to a Varied Salinity Stress at Different Growth Stages." Agricultural Water Management 201 (March). Elsevier: 70-82. https://doi.org/10.1016/J.AGWAT.2018.01.018.

Prudencio, A.S., P. Martínez-Gómez, and F. Dicenta. 2018. "Evaluation of Breaking Dormancy, Flowering and Productivity of Extra-Late and Ultra-Late Flowering Almond Cultivars during Cold and Warm Seasons in South-East of Spain.” Scientia Horticulturae 235 (May). Elsevier: 39-46.

https://doi.org/10.1016/J.SCIENTA.2018.02.073.

Ramírez, L., K.X. Sagredo, and G.H. Reginato. 2010. "PREDICTION MODELS FOR CHILLING AND HEAT REQUIREMENTS TO ESTIMATE FULL BLOOM OF ALMOND CULTIVARS IN THE CENTRAL VALLEY OF CHILE.” Acta Horticulturae, no. 872 (August): 107-12. https://doi.org/10.17660/ActaHortic.2010.872.12.

Rana, G, and N Katerji. 2000. "Measurement and Estimation of Actual Evapotranspiration in the Field under Mediterranean Climate: A Review.” European Journal of Agronomy 13 (2-3). Elsevier: 125-53. https://doi.org/10.1016/S11610301(00)00070-8.

Ravina, Israela, and Joshua Magier. 1984. "Hydraulic Conductivity and Water Retention 
of Clay Soils Containing Coarse Fragments." Soil Science Society of America Journal 48 (4): 736. https://doi.org/10.2136/sssaj1984.03615995004800040008x.

Richman, Michael B., and Lance M. Leslie. 2015. "Uniqueness and Causes of the California Drought." Procedia Computer Science 61. Elsevier Masson SAS: 428 35. https://doi.org/10.1016/j.procs.2015.09.181.

Robin, Abcarian. 2015. “Almonds, the Demons of Drought? Frustrated Growers Tell Another Story.” Los Angeles Times, April 16, 2015.

Sadras, V.O., and S.P. Milroy. 1996. "Soil-Water Thresholds for the Responses of Leaf Expansion and Gas Exchange: A Review." Field Crops Research 47 (2-3). Elsevier: 253-66. https://doi.org/10.1016/0378-4290(96)00014-7.

Sanden, B. L., A. E. Fulton, D. S. Munk, S. Ewert, C. Little, F. Anderson, J. H. Connell, M. Rivera, M. N. Orang, and R. L. Snyder. 2012. “California's Effort to Improve Almond Orchard Crop Coefficients.” EGU General Assembly 2012, Held 22-27 April, 2012 in Vienna, Austria., p.7043 14: 7043.

http://adsabs.harvard.edu/abs/2012EGUGA..14.7043S.

Schulbach, Herb, and Lawrence Schwank1. 1996. "Measuring Soil Moisture.” In Almond Production Manual, 167-70.

Shackel, Kenneth. 1996. "Physiological Aspects of Water Use." In Almond Production Manual, 113-16.

Socias i Company, Rafael, and Thomas Gradziel. 2017. Almonds: Botany, Production and Uses. Edited by R. Socias i Company and T. M. Gradziel. Wallingford: CABI. https://doi.org/10.1079/9781780643540.0000.

Steduto, Pasquale, Theodore Hsiao, Elias Fereres, and Dirk Raes. 2012. Crop Yield 
Response to Water. Rome: FOOD AND AGRICULTURE ORGANIZATION OF THE UNITED NATIONS Rome, 2012.

http://www.fao.org/docrep/016/i2800e/i2800e.pdf.

Sumner, Daniel A, William A Matthews, Josué Medellín-Azuara, and Adrienne Bradley. 2015. "The Economic Impacts of the California Almond Industry A Report Prepared for the Almond Board of California."

Torrecillas, A., J.J. Alarcón, R. Domingo, J. Planes, and M.J. Sánchez-Blanco. 1996. "Strategies for Drought Resistance in Leaves of Two Almond Cultivars." Plant Science 118 (2). Elsevier: 135-43. https://doi.org/10.1016/0168-9452(96)04434-2

United States Department of Agriculture, National Agricultural Statistics Service 2013. Objective Measurement Report :https://www.nass.usda.gov/Statistics_by_State/California/Publications/Specialty_a nd_Other_Releases/Almond/Acreage/201205almac.pdf

United States Department of Agriculture, National Agricultural Statistics Service 2018. 2018 California Almond Forecast.

https://www.nass.usda.gov/Statistics_by_State/California/Publications/Specialty_an d_Other_Releases/Almond/Forecast/201805almpd.pdf

United States Department of Agriculture, National Resource and Conservation Service 1988. Chang, Kan Kim. "Soil survey of Kern County, California, northwestern part."

United States Department of Agriculture, National Resource and Conservation Service 2018. Soil Survey Staff, Natural Resources Conservation Service, United States Department of Agriculture. Soil Survey Geographic (SSURGO) Database for Kern 
County.

United States Department of Agriculture, Economic Research Service 2016. Data Files: U.S. and State-Level Farm Income and Wealth Statistics https://data.ers.usda.gov/reports.aspx?ID=49642

Zrig, A., H. Ben Mohamed, T. Tounekti, H. Khemira, M. Serrano, D. Valero, and A.M. Vadel. 2016. "Effect of Rootstock on Salinity Tolerance of Sweet Almond (Cv. Mazzetto).” South African Journal of Botany 102 (January). Elsevier: 50-59. https://doi.org/10.1016/J.SAJB.2015.09.001. 


\section{APPENDICES}

\section{A. Definition}

AWS: Available water storage

$\mathrm{CV}$ : Coefficient of Variation

ET: Evapotranspiration

ETc: Crop evapotranspiration

ETo: Evapotranspiration of reference crop

ITRC: Irrigation Training and Research Center

Kc: Crop coefficient

Ks: is an adjustment for transpiration reduction, based on limited root zone moisture

Ke: is an adjustment for increased evaporation from the wet soil or plant surface

Kcb: is the basal crop coefficient (no stress, dry soil surface)

METRIC: Mapping of Evapotranspiration with Internal Calibration

SEBAL: Surface Energy Balance Algorithm for Land 


\section{B. Within year statistics}

Year 2011

\begin{tabular}{|c|c|c|c|c|}
\hline \multicolumn{4}{|c|}{ Summary of Fit } & \\
\hline \multicolumn{3}{|c|}{$\begin{array}{l}\text { RSquare } \\
\text { RSquare Adj } \\
\text { Root Mean Square Error } \\
\text { Mean of Response } \\
\text { Observations (or Sum Wgts) }\end{array}$} & $\begin{array}{r}0.6182 \\
0.605258 \\
406.1401 \\
3231.566 \\
184\end{array}$ & \\
\hline \multicolumn{5}{|c|}{ Analysis of Variance } \\
\hline Source & DF & $\begin{array}{l}\text { Sum of } \\
\text { Squares }\end{array}$ & s Mean Square & F Ratio \\
\hline Model & 6 & 47273546 & 7878924 & 47.7656 \\
\hline Error & 177 & 29196108 & 164950 & Prob $>$ F \\
\hline C. Total & 183 & 76469654 & & $<.0001 *$ \\
\hline
\end{tabular}

\section{Parameter Estimates}

$\begin{array}{lrrrr}\text { Term } & \text { Estimate } & \text { Std Error } & \mathbf{t} \text { Ratio } & \text { Prob }>|\mathbf{t}| \\ \text { Intercept } & 1997.1433 & 602.3756 & 3.32 & 0.0011^{*} \\ \text { 2011 Apr-Oct ET (in) } & 59.528078 & 12.00832 & 4.96 & <.0001^{*} \\ \text { CV WEIGHTED AVERAGE } & 1703.1782 & 736.6609 & 2.31 & 0.0219^{*} \\ \text { 2011 Tree Years } & -57.62213 & 9.524181 & -6.05 & <.0001^{*} \\ \text { Location[East Side] } & -460.1597 & 79.17841 & -5.81 & <.0001^{*} \\ \text { Location[North West Side] } & 110.91669 & 99.91096 & 1.11 & 0.2684 \\ \text { Soil AWHC } & -23.66163 & 20.1395 & -1.17 & 0.2416\end{array}$

\section{Effect Tests}

\begin{tabular}{|c|c|c|c|c|c|}
\hline Source & Nparm & DF & $\begin{array}{l}\text { Sum of } \\
\text { Squares }\end{array}$ & F Ratio & Prob $>F$ \\
\hline 2011 Apr-Oct ET (in) & 1 & 1 & 4053509 & 24.5742 & $<.0001^{*}$ \\
\hline CV WEIGHTED AVERAGE & 1 & 1 & 881732 & 5.3455 & $0.0219^{*}$ \\
\hline 2011 Tree Years & 1 & 1 & 6037748 & 36.6036 & $<.0001^{*}$ \\
\hline Location & 2 & 2 & 12082769 & 36.6256 & $<.0001^{*}$ \\
\hline Soil AWHC & 1 & 1 & 227690 & 1.3804 & 0.2416 \\
\hline
\end{tabular}

\section{Expanded Estimates}

Nominal factors expanded to all levels

$\begin{array}{lrrrr}\text { Term } & \text { Estimate } & \text { Std Error } & \text { t Ratio } & \text { Prob }>|\mathbf{t}| \\ \text { Intercept } & 1997.1433 & 602.3756 & 3.32 & 0.0011^{*} \\ \text { 2011 Apr-Oct ET (in) } & 59.528078 & 12.00832 & 4.96 & <.0001^{*} \\ \text { CV WEIGHTED AVERAGE } & 1703.1782 & 736.6609 & 2.31 & 0.0219^{*} \\ \text { 2011 Tree Years } & -57.62213 & 9.524181 & -6.05 & <.0001^{*} \\ \text { Location[East Side] } & -460.1597 & 79.17841 & -5.81 & <.0001^{*} \\ \text { Location[North West Side] } & 110.91669 & 99.91096 & 1.11 & 0.2684 \\ \text { Location[West Side] } & 349.24297 & 57.80426 & 6.04 & <.0001^{*} \\ \text { Soil AWHC } & -23.66163 & 20.1395 & -1.17 & 0.2416\end{array}$


Year 2013

\section{Summary of Fit}

$\begin{array}{lr}\text { RSquare } & 0.503465 \\ \text { RSquare Adj } & 0.486538 \\ \text { Root Mean Square Error } & 399.3996 \\ \text { Mean of Response } & 2397.173 \\ \text { Observations (or Sum Wgts) } & 183\end{array}$

\begin{tabular}{|l|r|r|r|r|}
\hline \multicolumn{5}{|l|}{ Analysis of Variance } \\
\hline Source & DF & $\begin{array}{r}\text { Sum of } \\
\text { Squares }\end{array}$ & Mean Square & F Ratio \\
\hline Model & 6 & 28467402 & 4744567 & 29.7428 \\
Error & 176 & 28075528 & 159520 & Prob > F \\
C. Total & 182 & 56542930 & & $<.0001^{*}$
\end{tabular}

\section{Parameter Estimates}

Term
Intercept
2013 Tree Years
2013 Apr-Oct ET (in)
CV WEIGHTED AVERAGE 2013
Soil AWHC
Location[East Side]
Location[North West Side]

$\begin{array}{rrrl}\text { Estimate } & \text { Std Error } & \mathbf{t} \text { Ratio } & \text { Prob }>|\mathbf{t}| \\ 478.29551 & 561.2573 & 0.85 & 0.3953 \\ -52.64135 & 9.787473 & -5.38 & <.0001^{*} \\ 56.140277 & 8.763161 & 6.41 & <.0001^{*} \\ 448.56982 & 809.7061 & 0.55 & 0.5803 \\ 28.969316 & 20.13518 & 1.44 & 0.1520 \\ 617.11793 & 76.74048 & 8.04 & <.0001^{*} \\ -662.7319 & 97.577 & -6.79 & <.0001^{*}\end{array}$

\section{Effect Tests}

\begin{tabular}{|c|c|c|c|c|c|}
\hline Source & Nparm & DF & $\begin{array}{r}\text { Sum of } \\
\text { Squares }\end{array}$ & F Ratio & Prob $>$ F \\
\hline ree Year & 1 & 1 & 4614537 & 28.9276 & $<.0001^{*}$ \\
\hline r-Oct ET (in) & 1 & 1 & 654 & 41.0419 & $<.0001^{*}$ \\
\hline CV WEIGHTED AVERAGE 2013 & 1 & 1 & 48958 & 0.3069 & 0.5803 \\
\hline oil AWHC & 1 & 1 & 330203 & 2.0700 & 0.1520 \\
\hline ocation & 2 & 2 & 10363015 & 32.4819 & $<.0001^{*}$ \\
\hline
\end{tabular}

\section{Expanded Estimates}

Nominal factors expanded to all levels

\begin{tabular}{l|rrrc} 
Term & Estimate & Std Error & t Ratio & Prob $>|t|$ \\
Intercept & 478.29551 & 561.2573 & 0.85 & 0.3953 \\
2013 Tree Years & -52.64135 & 9.787473 & -5.38 & $<.0001^{*}$ \\
2013 Apr-Oct ET (in) & 56.140277 & 8.763161 & 6.41 & $<.0001^{*}$ \\
CV WEIGHTED AVERAGE 2013 & 448.56982 & 809.7061 & 0.55 & 0.5803 \\
Soil AWHC & 28.969316 & 20.13518 & 1.44 & 0.1520 \\
Location[East Side] & 617.11793 & 76.74048 & 8.04 & $<.0001^{*}$ \\
Location[North West Side] & -662.7319 & 97.577 & -6.79 & $<.0001^{*}$ \\
Location[West Side] & 45.613991 & 57.99638 & 0.79 & 0.4326
\end{tabular}


Year 2014

\section{Summary of Fit}

RSquare

0.561104

RSquare Adj

0.546142

Root Mean Square Error

313.85

Mean of Response

1833.038

Observations (or Sum Wgts)

183

\begin{tabular}{|l|r|r|r|r|}
\multicolumn{5}{|c|}{ Analysis of Variance } \\
Source & DF & $\begin{array}{r}\text { Sum of } \\
\text { Squares }\end{array}$ & Mean Square & F Ratio \\
\hline Model & 6 & 22163519 & 3693920 & 37.5010 \\
\hline Error & 176 & 17336318 & 98502 & Prob $>$ F \\
C. Total & 182 & 39499837 & & $<.0001^{*}$
\end{tabular}

\section{Parameter Estimates}

\section{Term}

Intercept

CV WEIGHTED AVERAGE 2014

2014 Apr-Oct ET (in)

2014 Tree Years

Location[East Side]

Location[North West Side]

Soil AWHC

$\begin{array}{rrrl}\text { Estimate } & \text { Std Error } & \text { t Ratio } & \text { Prob }>|\mathbf{t}| \\ 1212.9829 & 515.1181 & 2.35 & 0.0196^{*} \\ 1588.1984 & 620.447 & 2.56 & 0.0113^{*} \\ 46.689288 & 9.143442 & 5.11 & <.0001^{*} \\ -62.42458 & 7.555077 & -8.26 & <.0001^{*} \\ 341.76309 & 62.21252 & 5.49 & <.0001^{*} \\ -251.0023 & 80.6815 & -3.11 & 0.0022^{*} \\ -26.29217 & 15.77973 & -1.67 & 0.0975\end{array}$

\section{Effect Tests}

\begin{tabular}{l|rrrrr|} 
Source & Nparm & DF & $\begin{array}{r}\text { Sum of } \\
\text { Squares }\end{array}$ & F Ratio & Prob > F \\
CV WEIGHTED AVERAGE 2014 & 1 & 1 & 645422.8 & 6.5524 & $0.0113^{*}$ \\
2014 Apr-Oct ET (in) & 1 & 1 & 2568379.7 & 26.0744 & $<.0001^{*}$ \\
2014 Tree Years & 1 & 1 & 6724773.1 & 68.2706 & $<.0001^{*}$ \\
Location & 2 & 2 & 3586176.5 & 18.2036 & $<.0001^{*}$ \\
Soil AWHC & 1 & 1 & 273462.5 & 2.7762 & 0.0975
\end{tabular}

\section{Expanded Estimates}

Nominal factors expanded to all levels

Term

Intercept

CV WEIGHTED AVERAGE 2014

2014 Apr-Oct ET (in)

2014 Tree Years

Location[East Side]

Location[North West Side]

Location[West Side]

Soil AWHC

$\begin{array}{rrrr}\text { Estimate } & \text { Std Error } & \text { t Ratio } & \text { Prob }>\mid \text { t| } \\ 1212.9829 & 515.1181 & 2.35 & 0.0196^{*} \\ 1588.1984 & 620.447 & 2.56 & 0.0113^{*} \\ 46.689288 & 9.143442 & 5.11 & <.0001^{*} \\ -62.42458 & 7.555077 & -8.26 & <.0001^{*} \\ 341.76309 & 62.21252 & 5.49 & <.0001^{*} \\ -251.0023 & 80.6815 & -3.11 & 0.0022^{*} \\ -90.76075 & 45.93036 & -1.98 & 0.0497^{*} \\ -26.29217 & 15.77973 & -1.67 & 0.0975\end{array}$


Year 2015

\section{Summary of Fit}

\begin{tabular}{|c|c|c|c|c|}
\hline \multirow{2}{*}{\multicolumn{3}{|c|}{\begin{tabular}{l|} 
RSquare \\
RSquare Adj \\
Root Mean Square Error \\
Mean of Response \\
Observations (or Sum Wgts) \\
Analysis of Variance \\
\end{tabular}}} & \multicolumn{2}{|l|}{$\begin{array}{r}.546777 \\
.531326 \\
375.4388 \\
1786.78 \\
183\end{array}$} \\
\hline & & & & \\
\hline Source & DF & $\begin{array}{l}\text { Sum of } \\
\text { Squares }\end{array}$ & Mean Square & F Ratio \\
\hline Model & 6 & 29928792 & 4988132 & 35.3883 \\
\hline Error & 176 & 24807956 & 140954 & Prob $>$ F \\
\hline C. Total & 182 & 54736748 & & $<.0001^{\star}$ \\
\hline
\end{tabular}

\begin{tabular}{lrrrrr}
\hline Parameter Estimates & & & & \\
Term & Estimate & Std Error & t Ratio & Prob $>|\mathbf{t}|$ \\
Intercept & 2810.2925 & 524.9773 & 5.35 & $<.0001^{*}$ \\
2015 Tree Years & -80.39427 & 10.60848 & -7.58 & $<.0001^{*}$ \\
CV WEIGHTED AVERAGE 2015 & -1145.705 & 649.7425 & -1.76 & 0.0796 \\
Soil AWHC & -29.39189 & 18.99111 & -1.55 & 0.1235 \\
Location[East Side] & 70.923246 & 72.66433 & 0.98 & 0.3304 \\
Location[North West Side] & -251.8069 & 95.97738 & -2.62 & $0.0095^{*}$ \\
2015 Apr-Oct ET (in) & 27.185563 & 8.609431 & 3.16 & $0.0019^{*}$
\end{tabular}

\section{Effect Tests}

\begin{tabular}{l|r|rrrr|} 
& Nparm & DF & $\begin{array}{r}\text { Sum of } \\
\text { Squares }\end{array}$ & F Ratio & Prob > F \\
2015 Tree Years & 1 & 1 & 8095099.2 & 57.4307 & $<.0001^{*}$ \\
CV WEIGHTED AVERAGE 2015 & 1 & 1 & 438269.9 & 3.1093 & 0.0796 \\
Soil AWHC & 1 & 1 & 337623.7 & 2.3953 & 0.1235 \\
Location & 2 & 2 & 1534817.9 & 5.4444 & $0.0051^{*}$ \\
2015 Apr-Oct ET (in) & 1 & 1 & 1405419.9 & 9.9707 & $0.0019^{*}$
\end{tabular}

\section{Expanded Estimates}

\begin{tabular}{l|r|rrr|}
\begin{tabular}{l|r} 
Vominal factors expanded to all levels \\
Term
\end{tabular} & Estimate & Std Error & t Ratio & Prob $>|\mathbf{t}|$ \\
\hline Intercept & 2810.2925 & 524.9773 & 5.35 & $<.0001^{*}$ \\
\hline 2015 Tree Years & -80.39427 & 10.60848 & -7.58 & $<.0001^{*}$ \\
CV WEIGHTED AVERAGE 2015 & -1145.705 & 649.7425 & -1.76 & 0.0796 \\
Soil AWHC & -29.39189 & 18.99111 & -1.55 & 0.1235 \\
Location[East Side] & 70.923246 & 72.66433 & 0.98 & 0.3304 \\
\hline Location[North West Side] & -251.8069 & 95.97738 & -2.62 & $0.0095^{*}$ \\
Location[West Side] & 180.88363 & 55.94919 & 3.23 & $0.0015^{*}$ \\
2015 Apr-Oct ET (in) & 27.185563 & 8.609431 & 3.16 & $0.0019^{*}$
\end{tabular}




\section{Residuals plots for year to year variation}

Year 2011

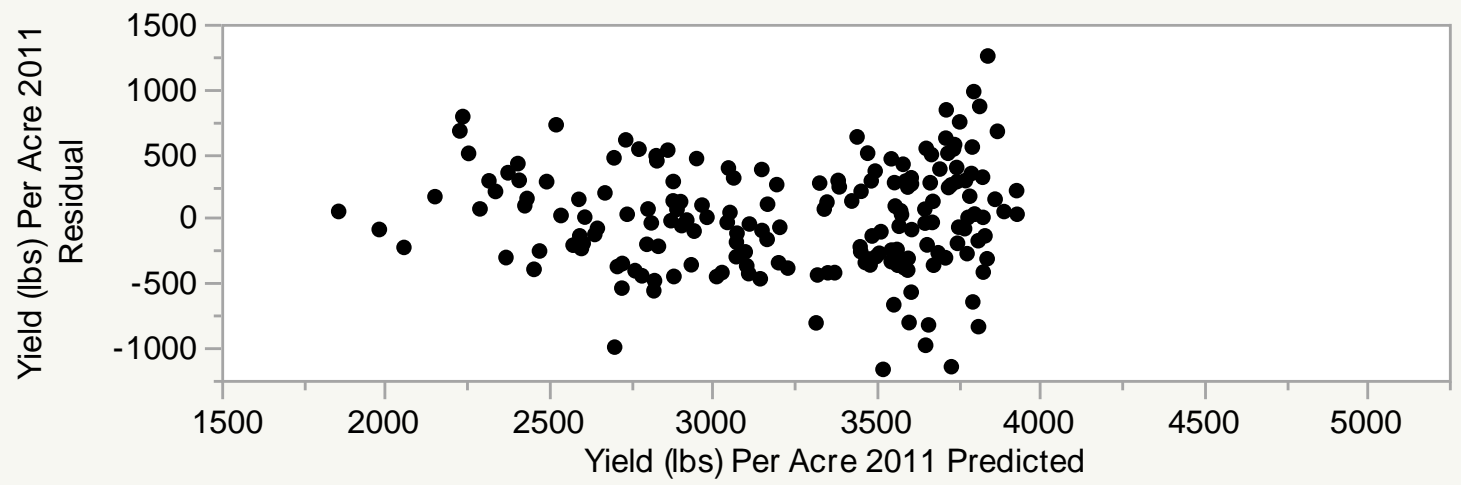

Year 2013

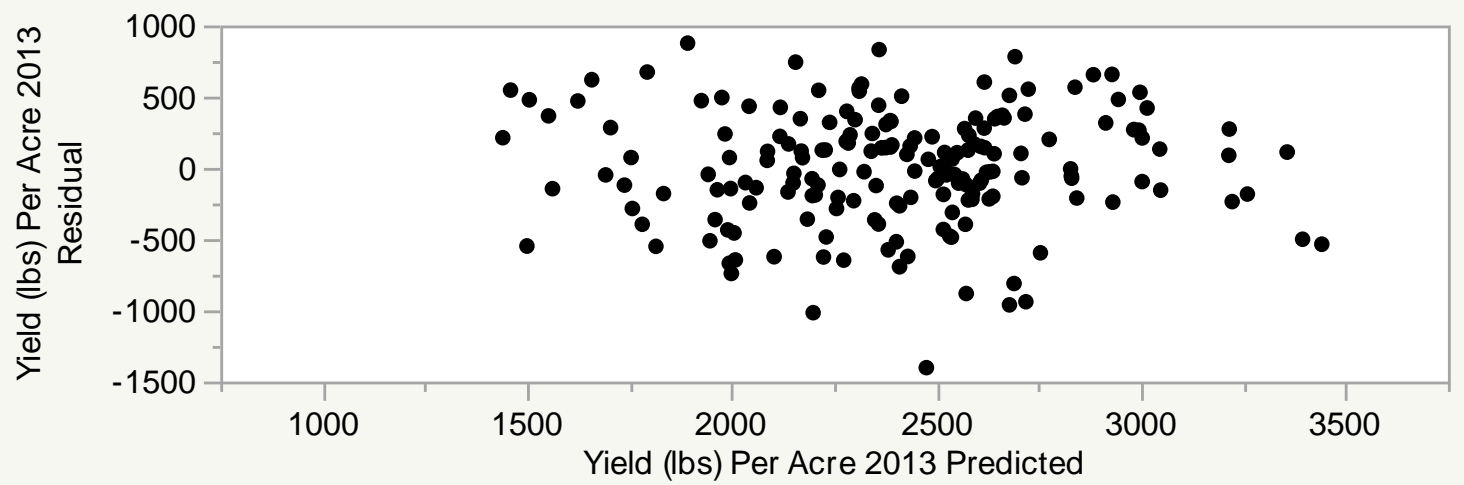

Year 2014

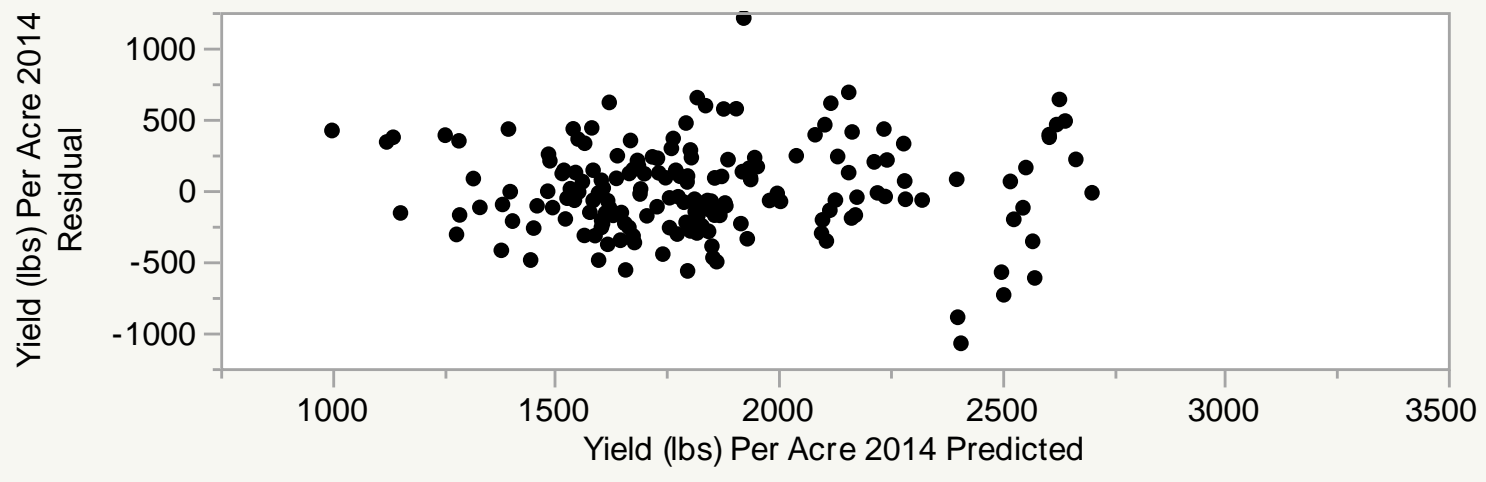


Year 2015



